Portland State University

PDXScholar

1988

\title{
A Study of Successful Management Teams in Oregon Public School Systems
}

James R. Carnes

Portland State University

Follow this and additional works at: https://pdxscholar.library.pdx.edu/open_access_etds Let us know how access to this document benefits you.

\section{Recommended Citation}

Carnes, James R., "A Study of Successful Management Teams in Oregon Public School Systems" (1988). Dissertations and Theses. Paper 1231.

https://doi.org/10.15760/etd.1230

This Dissertation is brought to you for free and open access. It has been accepted for inclusion in Dissertations and Theses by an authorized administrator of PDXScholar. Please contact us if we can make this document more accessible: pdxscholar@pdx.edu. 


\title{
A STUDY OF SUCCESSFUL MANAGEMENT TEAMS
}

IN OREGON PUBLIC SCHOOL SYSTEMS

\author{
by \\ JAMES R. CARNES
}

A dissertation submitted in partial fulfillment of the requirements for the degree of

\author{
DOCTOR OF EDUCATION \\ in \\ EDUCATIONAL LEADERSHIP: \\ ADMINISTRATION AND SUPERVISION
}

Portland State University

(C) 1988 
TO THE OFFICE OF GRADUATE STUDIES:

The members of the Committee approve the dissertation of James $\mathrm{R}$. Carnes presented May 10, 1988.

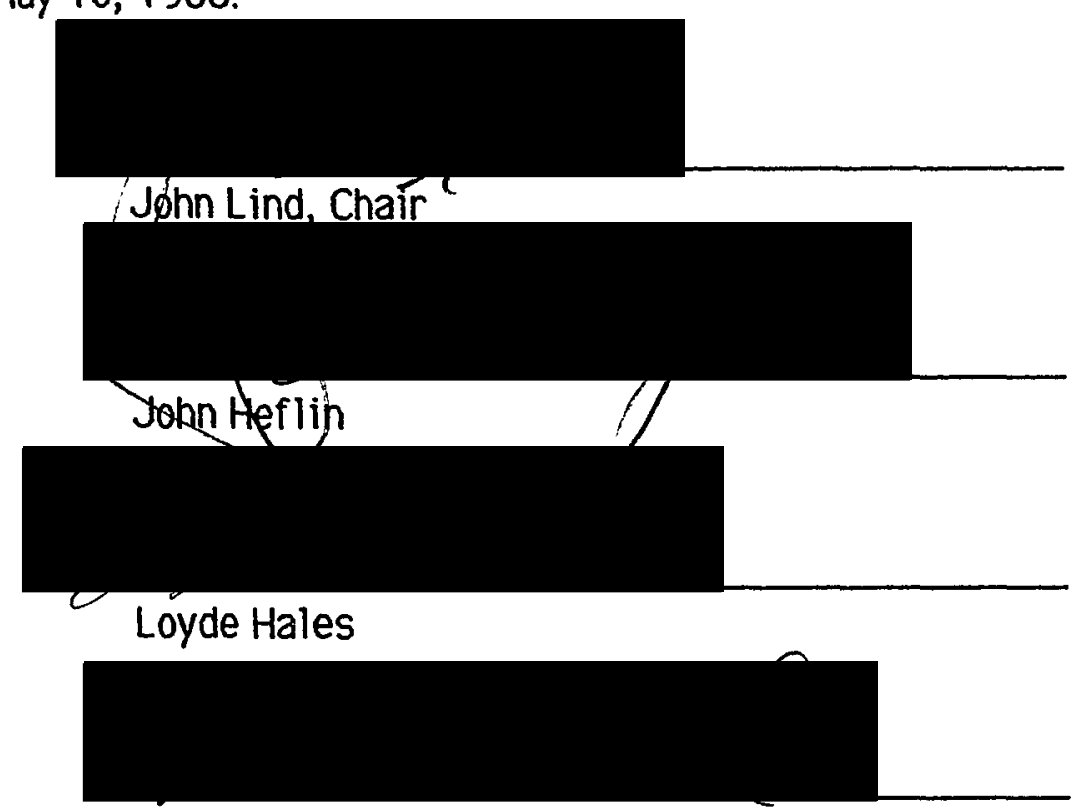

$$
\text { Michael Carl }
$$

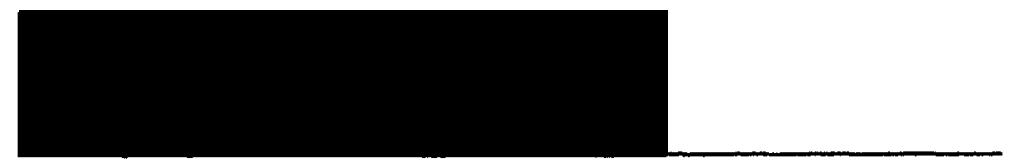

Roderic Diman

\section{APPROVED:}

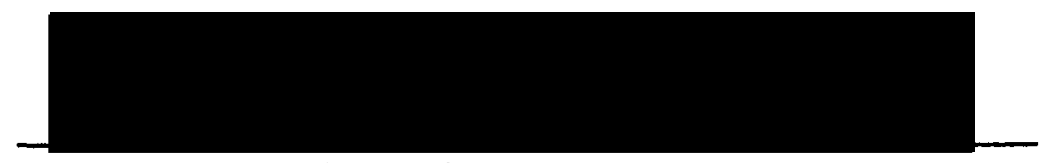

Robert Everhart, Dean of the School of Education

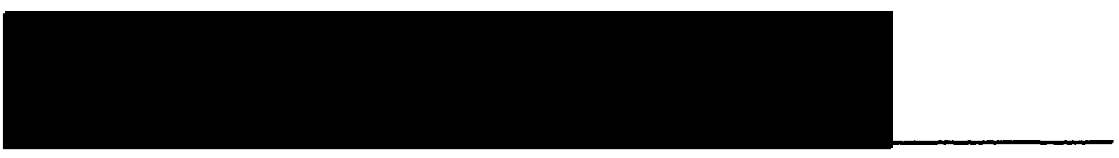

Bernard Ross, Dean of Graduate Studies and Research 


\section{ACKNOWLEDGEMENTS}

\section{Dissertation Committee}

Without the cooperation and support of the dissertation committee, this study would not have been possible. This writer thanks:

- Dr. John Lind, Chair (School of Education)

- Dr. John Heflin (School of Education)

- Dr. Loyde Hales (School of Education)

- Dr. Michael Carl (School of Education)

- Dr. Roderic Diman (Office of Academic Affairs)

\section{Case Studies}

This writer appreciates the cooperation received from the staffs of the school systems in which the case studies were conducted. A special thanks is expressed to the superintendents of those districts.

- Eagle Point School District 9; Mr. Steve Miller, Superintendent - Lincoln Counity School District; Dr. John Erickson, Superintendent

- Lake Oswego School District 7J; Mr. Bill Korach, Superintendent

\section{Eamily}

For the unself ish sacrifices and unending support provided for this writer during the doctoral program and dissertation, a very special thankyou is offered, with love, to my wife and sons.

- Carole

- Jeff

- Chad 
TABLE OF CONTENTS

PAGE

ACKNOWLEDGEMENTS................................................................................... ii

LIST OF TABLES...................................................................................................... viii

CHAPTER

I INTRODUCTION TO THE STUDY....................................................

The Development of the Management

Team Concept................................................................

Def inition of Management Team...................................... 3

Management Team Involvement with

Policies and Regulations...................................... 8

Purpose of the Study.......................................................... 10

II REVIEW OF RELATED LITERATURE............................................ 13

The Rationale for Management Teams........................... 14

Organizational Suitability............................................... 20

Tight-loose Coupling

Membership of Management Teams

Responsibilities of Team Members

Teamwork

Summary...............................................................................

III METHODS AND PROCEDURES....................................................... 34

Case Studies............................................................................. 35

Study Questions

Propositions

Units of Analysis

Linking Data to Propositions

Criteria for Interpreting Findings 
Validity and Reliability.

39

Construct Validity

Internal Validity

External Validity

Rellability

Procedures.

40

Selecting the Cases

Sources of Evidence

Experience and Role of the Investigator

Conducting the Study

IV PRESENTATION AND ANALYSIS OF FINDINGS........................... 46

Case Study: Eagle Point School District 9.

Why Was the Team Management Concept Implemented?

How Has the Team Management Team Evolved?

How Is the Management Team Organized?

How Does the Management Team Operate?

How Are Management Team Members

Involved in Developing, Recom-

mending, Implementing, and

Monitoring School District

Policies and Administrative

Regulations?

What Are the Most Important Characteristics or Elements Found as

Part of Successful Management

Teams Which Are Essential to the

School District's Management

Team Being "Successful"?

Case Study: Lincoln County School District

Why Was the Team Management

Concept Implemented?

How Has the Team Management

Team Evolved?

How Is the Management Team Organized? 
How Does the Management Team Operate?

How Are Management Team Members Involved in Developing, Recommending, Implementing, and Monitoring School District Policies and Administrative Regulations?

What Are the Most Important Characteristics or Elements Found as Part of Successful Management Teams Which Are Essential to the School District's Management Team Being "Successful"?

Case Study: Lake Oswego School District 7J.............

Why Was the Team Management Concept Implemented?

How Has the Team Management Team Evolved?

How Is the Management Team Organized? How Does the Management Team Operate? How Are Management Team Members Involved in Developing, Recommending, Implementing, and Monitoring School District Policies and Administrative Regulations?

What Are the Most Important Characteristics or Elements Found as Part of Successful Management Teams Which Are Essential to the School District's Management Team Being "Successful"?

Why Was the Team Management Concept Implemented?

How Has the Team Management Team Evolved?

How is the Management Team Organized? 
How Does the Management Team Operate?

How Are Management Team Members

Involved in Developing, Recom-

mending, Implementing, and

Monitoring School District

Policies and Administrative

Regulations?

What Are the Most Important Charac-

teristics or Elements Found as

Part of Successful Management

Teams Which Are Essential to the

School District's Management

Team Being "Successful"?

$\checkmark \quad$ CONCLUSIONS AND RECOMMENDATIONS...................................... 102

Conclusions........................................................................... 103

Proposition 1.................................................................. 104

Proposition 2 ..................................................................... 105

Proposition 3........................................................................ 106

Proposition 4................................................................... 109

Proposition 5............................................................ 110

Recommendations................................................................ 118

Application of the Conclusions

by Practitioners

Implications for Research

BIBLIOGRAPHY

APPENDICES.

APPENDIX A

APPENDIX C 


\section{LIST OF TABLES}

TABLE

PAGE

I Management Team Survey Responses: Eagle Point School District 9................................................................................. 53

II Management Team Survey Responses: Lincoln County School

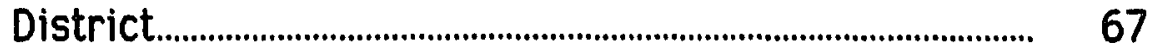

III Management Team Survey Responses: Lake Oswego School

District 7J...................................................................................... 80

IV Management Team Survey Responses: Comparison of Three

School Districts.................................................................................. 92 
AN ABSTRACT OF THE DISSERTATION OF James R. Carnes for the Doctor of Education in Educational Leadership presented May 10, 1988.

Title: A Study of Successful Management Teams in Oregon Public School Systems.

APPROVED BY THE MEMBERS OF THE DISSERTATION COMMITTEE:

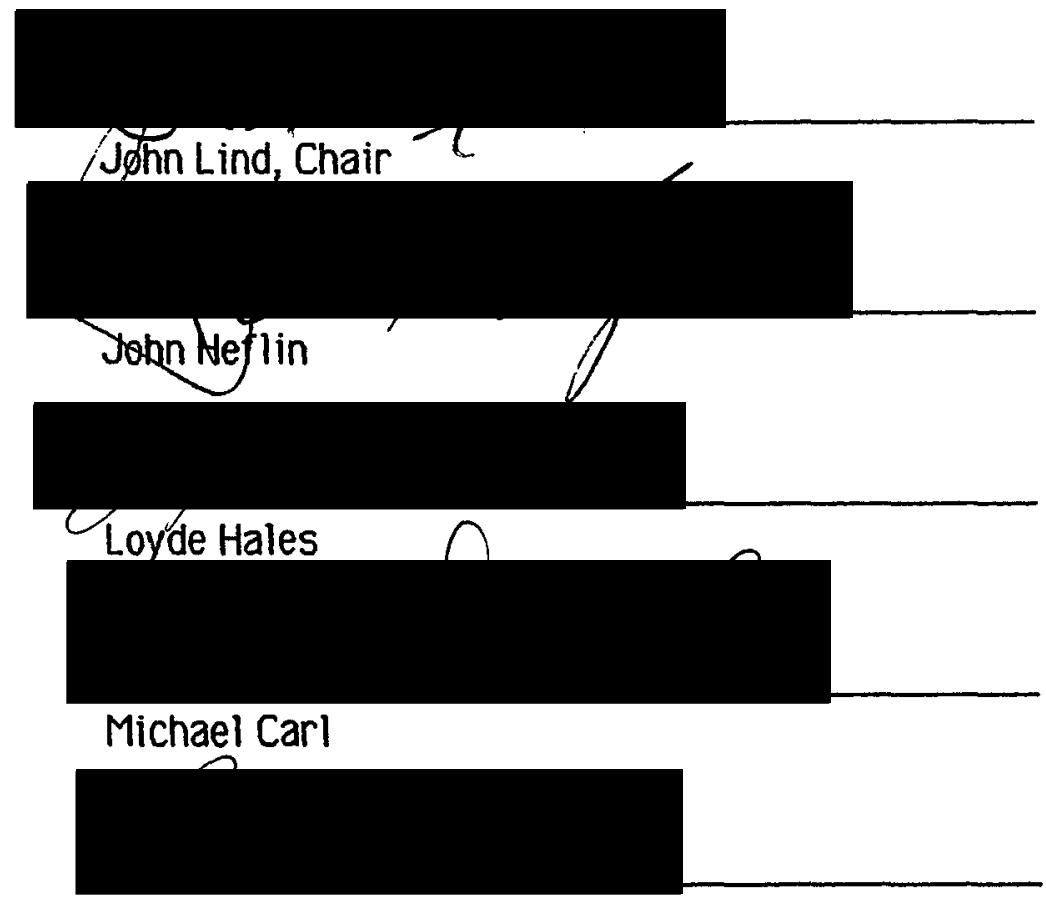

Roderic Diman

The purpose of this study was to identify and describe the current status of successful management teams in Oregon public schools as they exist in 1988, after more than fifteen years of evolution as the preferred management practice. Study questions asked were: (1) Why was the team management concept implemented? (2) How has the management team 
evolved? (3) How is the management team organized? (4) How does the management team operate? (5) How are management team members involved in developing, recommending, implementing, and monitoring school district policies and administrative regulations? (6) What are the most important characteristics or elements found as part of successful management teams which are essential to the school district's management team being "successful"?

A descriptive, multiple-case study design was used to study the activities of successful management teams within the unique context of their actual school system operations. Three "successful" management teams were selected for case studies by a panel of educational experts, using the following criterion. Which Oregon public school systems represent hoth: (a) "a successful management team" as endorsed and promoted by the Confederation of Oregon School Administrators and the Oregon School Boards Association, and (b) "a state of the art" model of team management as it is evolving? Separate case studies were conducted and written for each of the three selected management teams. Multiple sources of evidence were collected, using (1) documentation, (2) archival records, (3) interviews and surveys, and (4) direct observations. A cross-case analysis was conducted, resulting in a written description of the similarities among successful management teams in three Oregon public school systems.

The conclusions of the study supported the five study propositions: (1) successful management teams implemented the team management concept because it was the preferred method of educational leadership which allowed greater participation by administrators, and resulted in improved decision making; (2) successful management teams have evoived 
since their original implementation, until they presently represent the unique management needs and resources of the school system; (3) successful management teams are made up of a group of school district administrators consisting of the superintendent and (or representatives of) central staff, principals, and ancillary personnel having supervisory positions; and are structured to allow the maximum, efficient input and participation by that group; (4) successful management teams involve administrators in developing, recommending, implementing, and monitoring school district policies and adminisírative regulations; and (5) successful management teams have in common certain characteristics or elements which are essential to the management teams being "successfui."

The following synthesis of the conclusions was developed from a multitude of identified characteristics or elements of successful management teams. Successful management teams: (1) establish and support common goals and direction for the school system; (2) involve all team members in shared decision-making; (3) foster teamwork and team spirit; (4) involve all team members in the policy and administrative regulation activities of the school system; and (5) are designed, organized, and operated in response to the unique requirements of the organization.

Recommendations were made to practitioners for the application of the conclusions and identified characteristics or elements of successful management teams. A Management Team Profile instrument was also developed for use in assessing the successfulness of management teams.

Suggestions for additional study were made based upon the findings and experience in conducting this study. Replication of this study in large school districts and districts with unsuccessful management teams could provide further insights into what makes management teams "successful." 


\section{CHAPTER I}

\section{INTRODUCTION TO THE STUDY}

The "management team" has become the preferred method of educational leadership in Oregon today. In June, 1987 the Confederation of Oregon School Administrators (COSA) adopted a resolution reaffirming their support of the management team concept in Oregon school districts. Oregon School Boards Association (OSBA) has also endorsed the management team concept since the advent of collective bargaining in education in the early 1970s. One might expect that, by now, the management team concept would be well established in Oregon school districts. However, management teams appear to exist in varying degrees of maturity among school districts in Oregon.

\section{THE DEVELOPMENT OF THE MANAGEMENT TEAM CONCEPT}

One of the prominent influences on the acceptance of the management team concept was the estabilshment of collective bargaining in educational settings. Lieberman (1970) reported that administrators, who in the past questioned the ethics of teachers who engaged in negotiations, were supporting collective negotlations for themselves in an effort to gain security and avoid isolation. In 1972, the National Education Association (NEA) excluded administrators from its membership. Oregon's collective bargaining law was passed in 1973. Collective bargaining in education had 
become a reality, nationally and in Oregon. School boards began to see management teams as a means of deterring collective bargaining by administrators (Erickson \& Gmelch, 1977).

Additional influences on the acceptance of management teams were acknowledged by Erickson and Gmelch (1977) in their monograph on school management teams as: (1) shifts in power within education, (2) increasing pressures on administrators, and (3) efforts to improve educational administrative organizations. They concluded that superintendents would form management teams in order to gain security and to avoid isolation, and that principals would see team management as a way to increase their involvement and provide a significant role in the decision-making process. Therefore, team management appeared to be a legitimate means of creating a united front in response to growing pressures and demands.

During this same period, the following national educational organizations endorsed the management team concept: National Association of Secondary School Principals (NASSP), National Association of Elementary School Principals (NAESP), American Association of School Personnel Administrators (AASPA), Association of School Business Officials (ASBO), National School Boards Association (NSBA), and American Association of School Administrators (AASA).

The Confederation of Oregon School Administrators (COSA) and the Oregon School Boards Association (OSBA) likewise endorsed the concept of team management during this period.

McNally (1973) warned of impending problems if the management team concept wasn't taken seriously:

Unless superintendents and boards of education make remarkable changes in their relationships with middle management in the 
schools, unless they treat middle managers with more respect, enlist them more widely and meaningfully in decision making on system goals, policies, and procedures, and confer with them far more meaningfully on matters relating to their roles, salaries, and conditions of work, we shall see a rapid increase in the number of administrative bargaining units (or unions, where law permits) throughout the country. (p. 22)

\section{DEFINITION OF MANAGEMENT TEAM}

According to Erickson and Gmelch (1977), "There is no one management team model that meets all organizational needs. This diversity of models makes it difficult to provide one specific def inition of the management team that is appropriate to all situations" (p. 5).

As early as 1971, a case was being developed for administrative teams which would provide greater participation of principals in important decision making. The report by NASSP (1971) concludes that an administrative team, which maintains simultaneously both formal and informal systems of participation in decision making, of fers a professionally satisfying approach to school district administration.

Erickson and Gmelch (1977) state that while management team styles may differ, it is incumbent upon the team to establish clarity of both objectives and each member's role on the management team. Clarification can result from either the team leader's decision or from deliberations of the entire team. Definitions and concepts that will aid the team in arriving at these clarifications include the following:

1. Management activities which are carried out by two or more people engaged together in a mission.

2. A task-oriented group with representatives of important subsystems of an organization who have common goals, who interact through formal role structures, and who have some degree of influence over each other. 
3. Providing input into administrative policy decisions but not the details of management.

4. A number of people - usually a fairly small number - with different backgrounds, skills, and knowledge drawn from various areas of the organization, who work together on a specific and def ined task. There is usually a team leader or a team captain. The team itself can be permanent. Its composition may vary from task to task.

5. Participative management using varlous ways of involving workers in decisions affecting their work.

6. Common synonyms for team management include participatory management, an administrative team, a leadership team, an executive team, a representative team, a constellation, etc. (pp. 5-6)

Contrary to popular conceptions, team management is not always shared decision making. In most cases, Erickson and Gmelch (1977) believe that a more reasonable approach to team management would be to ask representatives of those affected by decisions for suggestions regarding recommendations, policies, and new direction for an organization, but not necessarily to involve them in the day-to-day operational management of the organization.

In most school districts, it is misleading to speak of "the management team." Larger school districts need "management teams" functioning in various units of the district. In these situations the management team concept becomes a more complex structure of interlocked teams within and between various levels of management.

According to Erickson and Gmelch (1977):

A common misunderstanding about the management team is evident in the frequently stated dictum of team decision-making: "All those affected by decisions should be involved in making the decisions." It would be irrational to suggest that the team make all decisions when, in fact, the superintendent alone is responsible to the board. As yet, the authors know of no organizations where a 
board is willing to hold the team responsible for decisions made rather than the superintendent. ( $p .28$ )

Brooks (1978) supports this belief in describing what a management team is not.

It won't take the place of strong leadership from the superintendent. He/she is still the chief executive, not the chief vote taker. That person is still responsible for leadership that accommodates discrepant views. That person must still bring from the group the best it has to offer, sometimes more than they knew they had. That person must still bring it all together into a coherent whole in order to make final recommendations to the board. But it can now be done from a position of strength with facts, ideas, opinions from all quarters.

It won't diminish board authority, but can increase the quality of board decisions. (p. II)

Duncan (1978) describes an administrative team as a collection of school administrators who are interdependent to some significant degree. He adds that, in general, school administrators will become a team when they exhibit:

1. A clearly defined membership.

2. "Team consciousness" or identification with each other.

3. Shared understandings and shared sense of purpose.

4. Interdependence of purpose.

5. Open and accurate communication.

6. The ability to act in concert with unity. (p. 39)

Management team generally refers to the structure resulting when two or more people are engaged, together, in tasks of management. Team management generally means that activities of management are being carried out by two or more people together (Erickson \& Rose, 1973).

Grindle (1982) feels that administrative team management is neither an informal social group, nor an inner circle without status. Rather, it is a group recognized by the board of education and superintendent of schools as 
part of the formal administrative structure of the school system. Management team authority is typically outlined in official school department policy. "In most cases the superintendent of schools continues to assume the responsibility for the management of the system while accountability becomes the function of the team as a whole" (p. 29).

The legal definition of a management employee (Floratos et al., 1978) includes any employee who is in a position which has significant responsibilities for formulating district policies or administering district programs.

They add that the def inition of management employees as part of a management team might read as follows: "A group of individuals identified by the board of trustees to assure the highest quality educational program to the pupils in the school district while maintaining the financial integrity of the school district" (p. 5).

According to McNally (1973):

First, the administrative team is a formally constituted group, recognized by the board of education, the superintendent, and other members of the school system to be a part of the formal administrative structure of the school system...

Second, the team includes both central office and middle management administrative-supervisory personnel. This specifically includes principals and supervisory personnel who work at the school building level. In small school districts it is possible that all such personnel could be included in the team membership. in larger districts some of these groups will participate indirectly through representation. Obviously the team must not be so large that it is unwieldy.

Third, the administrative team has formally recognized responsibility and authority for making important decisions on school system policy interpretation and operational matters This does not imply that the team will make all administrative decisions, of course, but it will be involved appropriately. .

The foregoing characteristics def ine an administrative team as 
something distinct from an administrative "advisory group," a central of fice "administrative cabinet," or an administrative union. The administrative team is a group formally constituted by the board of education and superintendent, comprising both central office and middle echelon administrative-supervisory personnel, with expressly stated responsibility and authority for participation in school system decision making. (p. 22)

The management team concept is also defined as a united effort of the policy team and the administrative team in carrying out the management functions in a school district (Buckeye Association of School Administrators, 1978).

Salmon (1977b) def ines an ef fective administrative team as one which includes the superintendent and certified and uncertified management staff at both district and building levels, and serves as an effective resource to the board of education. He adds:

Initially, the team approach is written into board policy. Team members must be chosen carefully and inciude all administrators in the district (both certified and classified). A team job description should be developed that outlines the relationships between and among team members. It also designates the duties to be accomplished, the cooperative ventures to be undertaken, and the responsibility and authority of team members.

-The team is the of ficially designated leadership unit for developing, recommending, implementing, and monitoring board policy and administrative regulations.

- The team must be recognized by the board as a storehouse of seasoned counsel that operates on the level where the action is; this resource should be tapped regularly and consistently for information and aovice.

-The team serves as a primary source of evaluation for district personnel and programs.

-The team functions through the superintendent.

-The team must be protected and rewarded. The board must recognize that team members need protection from unwarranted attack and having its actions and decisions reversed by higher authorities. (Nevertheless, agreed-to procedures should be open to 
review and reversal at a higher level, but such arrangements must be understood and condoned before an incident occurs that could cause reversal.)

- Team members are compensated through a process that guarantees members fair and just reward for the time they work and the responsibility and skill they must exercise in their tasks. (pp. 24-26)

\section{MANAGEMENT TEAM INVOL VEMENT WITH POLICIES AND REGULATIONS}

Salmon (1977b) suggests the use of educational impact statements to insure broader involvement by administrators on management teams.

Superintendents and school boards. . have sought long and hard for ways to involve principals and other middle members of the administrative team in the development of policies and regulations...

The educational impact statement. . . is a device which reveals to the decisionmaker the probable consequences of the decision under consideration. . .

The Board of Education should require that an impact statement accompany every policy recommendation...

There are a few imperatives which must be followed if the educational impact statement is to achieve its maximum potential.

- The board must require undertaking an educational impact statement when policy is being made.

- Members of the administrative team must have sufficient time to develop a statement. Time constraints must be made known at the time the policy change is proposed.

- Individual team members who feel the impact would be slight or non-existent should make their feelings known. Otherwise, failure to respond might be construed as a consent to the proposal.

- Various classes of administrators - i.e., elementary principals, secondary principals, etc. - must be required to synthesize a statement representing the view of all such members. Additional opinions may be submitted by dissenting individual members.

- Superintendents must recelve, study, and use the impact statement coming from the administrative team to develop their impact statement for the board. (p. 19) 
He believes that the use of the educational impact statements should insure greater input by all levels of management in developing policies and regulations.

In a joint publication of AASA and NSBA entitled Principles of Effective School District Governance and Administration (1984), one important expectation of administrators as a member of a leadership team is "a voice in the development and implementation of all policies" (p. 9). Better policy decisions will be made by a school board if appropriate staff members have an opportunity to suggest and review the possible impact of proposed policies affecting those programs for which they are responsible. They conclude that "involvement not only leads to better decisions, but also encourages good morale and team spirit" (p. 10).

Salmon (1977a) issues the following advice:

To help assure that the team makes sound decisions from the outset, the board of education should let team members have a say before any policies are adopted. This amounts to a debugging device before final action is taken by the board. The procedure requires that each member of the team review proposed policies and file an Educational Impact Statement with the Superintendent. The justification for this process is twofold: First, it assures that each member has both the opportunity and responsibility to analyze proposed policies from his respective point of view; he or she can assess proposals on the basis of his own sphere of operation and of fer observations concerning the administrative consequences if given policies were adopted and implemented. Second, it requires responsible and continuing participation by each member of the team. (p. 26)

Lieberman (1977) adds that the usual opinion of appointees to an administrative team runs thus: "If we're in it together, we must have something to say about how schools are administered" (p. 27). In other 
words, they are convinced that they have a right to participate in the development of school district policy.

In his opinion, employee participation in the policy-making process is a means to an end, with limits and conditions that should be subject to managerial discretion. He believes that whether such discretion is exercised democratically depends as much on its relationship to the community as it does to its acceptability to middle management or other employees.

When decisions are needed, Geisert (1982) suggests that the superintendent convene group meetings rather than individual conferences, thereby drawing on the talents, skills, and knowledge of many individuals. Those affected by the policies then have the opportunity to participate in their development. With a team approach, problems can be identif ied and resolved across major functional or organizational lines, and solutions found that are best for the total organization, rather than for a vested few.

\section{PURPOSE OF THE STUDY}

Differing perceptions among the various members of Oregon management teams appear to exist as to the nature of their involvement in team management. When asked, superintendents usually claim to involve their administrators and supervisors as management team members in developing, recommending, implementing, and monitoring school district policies and administrative regulations (rules, procedures). But, what is the actual involvement of management team members in Oregon public schools in these activities? 
In January 1976, The American School Board Journal put the question directly to principals (Heddinger, 1978):

How is the management team concept working? An onslaught of frustration was evoked. After all those good words about principals on the management team, we learned from the Journal's random survey of principals in the U.S. and Canada that many principals regarded the management team idea as a "myth." Others contended that team management in their situations was "all talk and no action," with the central office still calling the shots and principals taking orders as usual. Specifically, 45 percent of all principals polled by the Journal were distressed that teacher bargaining - in which these principals played no part - had whittled away their prerogative as school managers. Nearly half (48 percent) complained that serious troubles hampered their dealings with school boards and superintendents. Many said their hands were tied when it came to making decisions. (p. 30)

The first purpose of this study was to identify and describe the status of three "successful" management teams in Oregon public school systems in 1988. Successful management teams were those identified in Oregon school systems by a panel of experts, described in Chapter III Methods and Procedures. These successful management teams exemplified the concepts expressed in Chapter I - Introduction to the Study and Chapter II - Review of Related Literature. In order to describe their status, it was essential to understand the culture and activities of these three management teams that were considered to be successful. As a result, the commonalities and differences among the management teams studied were identified. Case studies of three successful management teams in Oregon provided the opportunity to accurately describe the state of the art in team management through observations, interviews, surveys, and written documents and records. 
The second purpose of this study was to add to the body of knowledge and research about management teams. Little formal research, either quantitative or qualitative, exists after more than fifteen years of management team experience. Case studies of successful Oregon management teams were conducted objectively, with a concentration on the in depth exploration of their cultures and activities. The results of this study provided valuable knowledge of modern management teams in education.

The third purpose of this study was to provide useful information to those in school systems who are currently operating management teams, or who are interested in possibly doing so. The common features of successful management teams were identified; they should prove useful in improving or developing management team practices. 


\section{CHAPTER II}

\section{REVIEW OF RELATED LITERATURE}

Much has been written about management teams during the past fifteen years. Most of the existing body of knowledge related to team management is in the form of articles and monographs written for practicing educational administrators. A search through the Educational Resources Information Center (ERIC) revealed a variety of documents adressing topics related to management teams. Descriptors used to locate the literature included: administrative team, management team, administrative leadership team, and participatory management.

in order to narrow the focus of this review of related literature, this researcher chose that information which related to "management teams in school systems," rather than in schools. Similarly, participatory management information was used only whenever it related to the activities of management teams in school systems.

This review of related literature also focused specifically on information which is related to "management team activities and involvement dealing with policies and administrative regulations." While these activities appear in most definitions of management teams, a review of Dissertation Abstracts located no direct research which addresses them. The most current, comprehensive research related to management teams was found in a doctoral dissertation by Brooks (1980) entitled An Analysis of the Administrative Team Process in Public School Districts in Colorado. 
Contemporary works from the private sector which describe current trends in management practices that may apply to management teams in school systems were reviewed but are not included in this review of related literature. While the information may have applicability to the management of educational organizations, it does not specifically relate to management teams in education and,therefore, this researcher chose to use the material only as background knowledge for conducting this study.

The following operational definition of "management team" was developed by the researcher as a result of summarizing the literature on: a) the definition of management team, and b) management team involvement with policies and regulations. A management team is: A group of school district administrators consisting of the superintendent and (or representatives of) central staff, principals, and ancillary personnel having supervisory positions, who, as a group, develop, recommend, implement, and monitor school district policies and administrative regulations; and who participate in the decision-making processes of the district.

\section{THE RATIONALE FOR MANAGEMENT TEAMS}

The prospect of developing management teams which encompass all administrators is attractive to school boards which view such teams as a means of deterring collective bargaining by administrators. Likewise, many principals disillusioned with both boards and superintendents because they lack a significant role in the district's decision-making process, see team management as a means for increasing their involvement. 
Wynn (1973) states that the administrative team concept derives its credibility from several beliefs deep in our culture, but warns that it should be understood prior to implementation.

It assumes that consent derives from those governed; that men are more likely to reach wise choices when the range of perception, information, knowledge, expertise, and debate is broadened; that subordinates are likely to generate greater commitment to the goals and policies of an organization when they help shape them; that this participation in administration provides a unique and essential vehicle for self-development and renewal; and, in sum, that the democratic process is superior to autocratic or oligarchical processes. This does not suggest that the democratic process is easier or simpler or less prone to conflict than other processes; Winston Churchill noted that democracy is the worst form of government - except for all others.

Superintendents or boards of education who lack fundamental trust in the democratic process should probably not attempt to institute an administrative team. These superintendents and boards are more likely to conceive of administration as either a technological system or a system of public responsibility. (pp. 38-39)

In Oregon, a joint communique by the administrator association (COSA) and school boards associations (OSBA) declared that "the essence of the team approach to management is the involvement of team members in the decision-making process" (ErIckson \& Gmelch, 1977, p. 2). However, they ralse questions with regard to the realities of team management:

But precisely what is meant by "involvement"? And what is meant by "decision-making process"? A principal may believe that everyone af fected by decisions should be involved in the making of that decision. A superintendent may consider involvement in the decision-making process as an opportunity for principals to "be heard" prior to his/her making the final decision. A board member may conceive only of a new organizational chart which seeks a broader base of input prior to decision-making by the board. (p. 2) 
Erickson and Rose (1973) explain that interest in team management by principals is created by feelings of "being in the middle" and not being heard. The principal has more opportunity to contribute in team management.

Pressures that superintendents experience from the board, teachers, and today's complex school problems have heightened their interest in the management team. Through team management they may be able to gain back some lost power by involving representatives of all groups, while still serving as the board's executive officer responsible for the schools.

School boards' interest in team management is prompted by collective bargaining processes which do not of ten involve principals as a part of the management negotiating team. School board members are def inite in wanting principals to be their management representatives in the district.

Duncan (1978) states that a genuine and fully functioning administrative team can contribute to effective school management directly and indirectly in the following ways:

1. The administrative team approach provides administrators a chance to specialize to greater extent. Those school leaders with special strengths and interests are given fuller scope to bring to bear upon district problems.

2. A team approach provides administrators ample opportunity to learn new skills as they work intimately with other administrators.

3. A team approach to administration makes administrators more accountable since they plan and work with other administrators. Peer pressure brings about improved performance.

4. A team approach enables the school system to mobilize a much wider range of administrator strengths to bring to bear upon problems in the district as a whole

5. An administrative team approach makes it possible for a number of school leaders to gain and share a perspective of the school system as a whole. This enhances the probability of a more accurate and complete view of the system, leading to better evaluation, goal setting, and direction. (p. 37) 
Boles (1975) adds that the concept [administrative team] infers an involvement of administrators at all levels in planning, implementing and decision-making when those activities directly affect the professional responsibilities of the individuals who comprise the "team."

According to Erickson and Rose (1973), regardless of the organizational structure used in a school district, the concept of team management is more important than the structure of that team. They amplify their conclusion:

The idea of "team" implies shared and concerted effort in solving complex administrative problems. This "shared responsibility" is based on two main assumptions. First, it is based on the assumption that most decisions, especially difficult ones, turn out better if a) the people who will be affected by the decision are somehow included in the decision making; $b$ ) several alternatives are considered; c) possible decisions are challenged for their effectiveness and utility by other staff members. Secondly, the "shared responsibility" of a management team is based on the assumption that most employees need and want to reel an important part of the enterprise for which they work. With employee participation of a significant nature, there results higher employee morale, hence greater motivation to excel and thus better performance -- all fostering success. (p. ii)

Hogan (1982) states that team management encourages consensus decision-making while simultaneously establishing a sense of collaboration. "In its totality, team management is a double-edged sword: high-level performance and accountability are demanded in return for free reign in one's jurisdiction" (p. 27).

The advantages and disadvantages of team management are identified by Erickson and Rose (1973):

Advantages of the management team:

The quality of decisions is usually better when several people share in the decision making. In this way a solution is "sifted," 
and continually improved by the group -- challenged and tested for its strength and utility.

With team management, those affected by certain decisions may be part of the decision making. There is more humaneness in this process than if management simply tells what should be done. Overall, employee morale is high because of their meaningful involvement in the enterprise.

Disadvantages of team management:

The team management process of decision making takes more time than the traditional approach.

If this can be considered a "disadvantage" -- team management requires a sincere effort on the part of the manager not to be the man with all the answers. To be a democratic leader -- necessary for team management -- must be a heart felt attitude rather than a "going through the motions." (pp. $11-12$ )

The concept of management by team, rather than by board-superintendent decree is a reaction to the prospect of unionized middle management, which seems clearly to be on the rise among building principals, created mainly by middle management's perception of itself as impotent in influencing the substance of decisions in school governance.

Geisert (1982) indicates that "team management is effective and efficient in carrying out a mission precisely because it enables the organization to meet the needs of individuals within the system, as well as those it serves" (p. 30). He concludes that they are much more likely to be accountable or successful if they have had input into the development of the decisions or policies they are to administer.

Floratos et al. (1978) conclude that commitment is developed through team management:

A decision which is made by a team of staff members, following a process which allows for the exercise of individual thought and action, means additional time and energies are expended. It means that some members of the management team will be approaching the problem with less background knowledge about and personal 
Interest in its solution than would have been brought to the problem by someone making a unilateral decision. It is this diversity which, while it results in time consumption and ambiguity compared to a unilateral, top-level decision, contributes most to the quality of the problem solution and its support by members of the team. (p. 8)

Team management is not new. According to Swift (1971) it has been used by General Electric for many years. As companies grew very large, it became impossible for the central office to acquire sufficient information to make the most effective decisions about local problems. Firms had to develop ways to maintain control of their various branches without reducing incentive. Swift compares this phenomenon with the rationale for management teams. "The central administration became a policy-setting unit that relied heavily on committees, while production units were permitted to make decisions within the parameters set by the board of directors" (p. 33). He adds:

Teams are more than just committees. They may function like a committee quite frequently, but there is a crucial difference: Teams are composed of professional employees who are granted a social status that enables them to control methodology and output even when working within an organization. Without this status, the worker or middle management employee is powerless to resist the dictates of his employers.

Team management is more than just the infusion of football spirit. It is an organizational pattern in which administrators share power and responsibilities with each other and with subordinates. The hierarchy gains commitment, identification, and flexibility, while subordinates gain power, even autonomy, in their particular domain. As such, team management is part of the current trend toward decentralization. As Basset put it: "The history of human organizations since .. .early time has been one of gradual extension of the prerogatives of the leader further and further into the ranks of his people." (p. 33) 
Any school district that effectively implements the management team approach can expect to derive a number of distinct benefits (Buckeye Association of School Administrators, 1978):

There will be a greater sense of community among all members of the administrative team.

$\square$ There will be greater job satisfaction among the members of the administrative team.

$\square$ Communication will be improved throughout the school district.

$\square$ There will be a higher degree of trust between and among the members of the management team.

$\square$ Administrators will achieve more rapid job growth as a result of their assuming greater managerial responsibilities.

$\square$ Both the quality and the acceptance of decisions should be improved.

口 It is less likely that administrators will desire to form collective bargaining units.

$\square$ The overall productivity of both the policy team and the administrative team should be higher. (p.15)

\section{ORGANIZATIONAL SUITABILITY}

Erickson and Gmelch (1977) state that to determine if an organization is suitable for the implementation of team management, several variables need to be considered:

First, is there sufficient time for team consultation?

A second question is whether the reward structure encourages participation, sharing of ideas, and collaborative behavior.

The third question concerns how secure administrators feel in their current position.

A fourth question relates to the present level of trust within the organization.

Finally, what is the quality of information which will be received by the management team? ( $p .22)$ 
Hogan (1982) questions the long term stability of team management:

... team management is a utopian administrative theory that can be physically constructed and that will result in reactive productivity, but will not be stable enough to endure, at least not in its original form. Team management requires a high degree of democracy, with a smidgeon of dictatorship thrown in. It is built on trust, and individual responsibility - highly subjective and highly unpredictable qualities.

Even though the pure team management falls apart after awhile, it is not entirely a waste. New procedures will have been instituted; perhaps a degree of accountability will have been achieved indirectly. Managerial structure will be defined, at least on paper. ... the utopia will end, to be replaced by a system less dazzling but perhaps more permanent. (p.29)

Geisert (1982) agrees that unless administrators see their futures tied to the success of the superintendent and top management, there will not be commitment or responsiblity for new courses of action by those whose cooperation and commitment are essential to effective team management.

According to Roberts (1978), if one is serious about the management team concept, one's district must be able to respond positively to the following questions:

1. Are administrators represented on the board's negotiating team?

2. Do administrators have an opportunity to react to proposed policy or regulation before adoption?

3. Do administrators have adequate input in employment, promotion and dismissal decisions of school district employees?

4. Is there a regular procedure for determining salaries and fringe benefits for administrators?

5. Do salary and benefits of administrators compare favorably with those of their counterparts in like districts and/or with the state-wide average?

6. Does the district have a formal evaluation procedure for all administrators? If so, did administrators have substantial involvement in the development of the evaluation instrument? 7. Are administrators granted multi-year contracts following a probationary period? 
8. Has the board of education adopted a policy statement regarding the administrative philosophy of the district?

9. Does the board of education (as opposed to individual board members) tend to appreciate and support the efforts of district administrators?

10. Does an effective communications system exist between and among all levels of administrators and the board of education?

11. Do administrators tend to understand and support the efforts of the board of education? (pp. 8-9)

Wynn (1973) states that the administrative team depends for its success on trust in the administrative staff. "When a school board and superintendent estabiish an administrative team .. they are sharing authority and responsibility with the administrative staff, which is a demonstration of faith in people" (p. 39). He explains further:

The administrative team concept requires a staff that is both qualitatively and quantitatively adequate. For example, the principal who assumes a share of responsibility for districtwide decision making must have greater understanding and competence than the principal who presides only over his own school building. Without this broader competence, he cannot function effectively as a member of the administrative team, and the decisions he helps to forge may be less desirable than those the superintendent might render alone. Moreover, the administrative team consumes more time than do conventional modes of management. There is no way around it: Meetings take time. Many school districts must increase the size of their administrative staffs if the administrative team is to be implemented effectively. (p. 39)

\section{Iight-loose Coupling}

Weik (1976) establishes the concept of educational organizations as "loosely coupled" systems. In def ining loose coupling, he states that:

Coupled events are responsive, but that each event also preserves its own identity and some evidence of its physical or logical separateness. . . Loose coupling also carries connotations 
of impermanence, dissolvability, and tacitness all of which are potentially crucial properties of the "glue" that holds organizations together. (p. 3)

In loosely coupled educational systems, either consensus on policies and procedures or compliance detection practices are missing from the following four characteristics essential to tightly coupled organizations. Weik (1982) identifies the four characteristics:

1) There are rules,

2) There is agreement on what those rules are,

3) There is a system of inspection to see if compliance occurs, and

4) There is feedback designed to improve compliance. (p. 674)

He adds that leadership in a loosely coupled educational system is diffuse, not concentrated:

Since there are numerous local initiatives to solve problems, the total amount of leadership in a loosely coupled system is of ten greater than the amount of leadership that is present in a centralized, tightly coupled system, but that leadership is unfocused. Given this lack of focus, the administrator needs to stimulate these initiatives to move in a common direction. This is most likely to happen when the administrator articulates a direction with eloquence, persistence and detail. (p. 675)

An educational system gains tight-loose properties, according to Welk (1982), when the administrator of a loosely coupled system "centralizes the system on key values and decentralizes on everything else" (p. 676), and adds:

Expression of key values is monitored very closely. On those key values the system becomes a tightly coupled system complete with rules, agreement on what those rules are, a system of inspection, and feedback to improve compliance...

Goals exist in loosely coupled systems, but they are tailored to local circumstances. Thus different people have different goals. The important question is, does the accomplishment of these goals impart a consistent direction to the system, and does the individual accomplishment cohere sufficiently so that people have 
the impression that they are part of an identif iable, worthwhile unit? The answer to that question depends on the eloquence of the educational administrator. (p. 676)

\section{Membership of Management Teams}

The actual size of management teams in a school district may vary depending on the issue under consideration or other variables. Several criteria for the size of the management team are suggested by Erickson and Gmelch (1977):

- The management team size must be tailor-made for conditions existing in the local administrative unit.

- The team should be large enough to incorporate informed representatives of all important sub-systems.

- The team should be small enough to allow for face-to-face problem solving discussions.

- In larger school districts the management system may be a complex structure of interlocking management teams. Multiple management teams can be formed and connected. . . by "link-pin" members who serve on teams of two different levels and are responsible for carrying information from one team to another. (p. 38)

Schmuck (1974) explains the importance of the size of management teams:

It must be large enough to incorporate the important subsystems that are administratively subordinate to it and, in this sense, be constituted of informed representatives from each of the organization's functioning units. At the same time, it must be small enough to allow for face-to-face problem-solving discussions and collaborative decision-making. With these specifications, the management team typically will not exceed 15 members.

It will be only in rather small districts where there can be a single management team. In most districts, therefore, it is a misuse of language to speak of the (single) management team. When such a phrase is used, it usually refers to a class of administrative personnel including assistant principals, principals, and district of fice administrators and not to a 
functioning team. In large districts, the management team becomes a complex structure of interlocked management teams. In other words, as the number of administrators in a district goes up, multiple management teams should be formed. They in turn would be connected to one another by what Renesis Likert has termed linkpin roles. Link-pin role-takers participate in the deliberations of at least two of the district's management teams, thereby being in a position to carry information from one team to another. As a typical example, area superintendents take the link-pin role when they participate as members of the superintendent's cabinet, and as they convene a team of field administrators. (pp. 10-11)

In a joint publication of the American Association of School

Administrators and the National School Boards Association (1979) entitiled The Administrative Leadershio Team, four basic categories of management team structures are identified:

- The so-called single model, in which the superintendent meets with one group that includes all administrative team members or their representives.

- The dual model,in which the superintendent meets with two teams: one that includes all the team members or their representatives, and another that includes only the central administrators.

- The multiple model, in which the superintendent meets with the entire team, and also with other groups composed of segments of the team.

- The divisional model, in which the superintendent meets with several groups representing different segments of the team rather than the total team itself.

The composition of management teams is affected by many variables according to Erickson and Gmelch (1977).

The small district may well have a management team including the superintendent, one or two central office assistants, and five principals, so that all the major line administrators constitute the leadership or central management team. In another district with 100 principals and a large central administrative staff, it is 
possible to operate a leadership team only through a representational system which will probably include several subteams. (p. 39)

While some have suggested that the school board should be considered a part of the management team jointly with superintendents, central office staff, and principals, that notion has not typically been implemented. Erickson and Gmelch (1977) conclude that a central leadership team might participate with the superintendent at board meetings, but a single chief executive responsible for the operation of the schools is necessary.

Danley (1979) identifies the preferred composition of an administrative team as including principals along with the superintendent and his/her immediate associates and other building adminstrators. He determines this composition to be appropriate for most school districts, serving less than 3,000 students, and for many larger districts which already have decentralized sub-districts of fairly small size.

\section{Responsibilities of Team Members}

According to Erickson and Gmelch (1977), "the appropriate responsibilities of an effective management team are in the recommendation of policy or broad management areas, not in the administration of operational details" (p. 37).

Duncan (1978) believes that mutual trust and confidence has a serious effect upon all interaction among team members.

Unless and until the superintendent exhibits through his behavior and communication that he has complete trust and confidence in team members, the effectiveness of the team management approach will be limited. Administrative team operation implies genuine involvement of team members - before the fact- in goal setting, decision-making and problem-solving processes. In 
demonstrating trust and confidence, the superintendent can utilize several "levels" of involvement vis-a-vis the team, and will probably make use of all of these levels from time to time.

1. Information dissemination

Typically, the information dissemination level of involvement is used when the content of a decision is not particularly critical to team members. It usually takes the form of the superintendent simply relating to team members what action or decision has occurred. This is the simplest level of involvement.

\section{Consulting}

The superintendent may wish to consult with his team members in order to gather relevant information on which to base a decision. Decisions calling for this level of involvement might include personnel actions or relate to specific information requested by the school board. Consulting as an involvement technique is of ten over-used by superintendents who take the position that since they are the ones held responsible by boards to administer the system, they will make all decisions.

\section{Participation}

With very few exceptions, the fully functioning administrative team should be party to the decision-making processes of the school system. Decisions should be consensual whenever possible. That is, the agreements derived from team participation should be such that all team members can live with them and commit themselves to carrying them out. ( $p .41$ )

Lynch (1978) reinforces these findings in summarizing the following steps necessary for more effective management teams:

First, we must be sure that our management team has a purpose that is thoroughly defined, articulated and understood. We cannot borrow a purpose. We must develop our own. Second, we should make a thorough evaluation of the organizational structure that has been developed for the management team. In the process of this evaluation we should be bold in proposing modifications in that structure that will better meet the needs of our district and that will more accurately reflect the uniqueness and individuality of our particular management team. And finally, we must make every effort to remove feelings of mistrust and suspicion and to create an environment of mutual trust and confidence within which the management team can freely operate. (p. 10) 
Team management allows the role of the administrator to be shaped so that power and responsibility can be shared with other administrators in a nonthreatening way. This strengthens their commitment to the organization, while reinforcing the organizational goals, and enhancing their power in their particular domain (Grindle, 1982).

Wynn (1973) describes the administrative team in operation as disturbing old boundaries of authority, responsibility, and accountability.

As one's authority is broadened but shared, so must one's responsibility and accountability be broadened and shared. The principal on the administrative team can no longer shrug his shoulders at criticism of school district plans and policies that he now helps to shape. The superintendent cannot expect to broaden the accountability of subordinate administrators without a commensurate broadening of their authority over those variables that impinge on the success of their jurisdictions. (pp. 40-41)

In a document entitled A Strategy for Implementing the School Management Team, the Ohio School Boards Association (1982) summarizes the responsibility of management team members:

Many boards and superintendents have been reluctant to explore the management team concept because they feel they would be abrogating their duties. Those arriving at this opinion ignore a vital aspect: despite its reliance on broad-based input, team management is still management. As one writer noted: "The goal of team management need not be 100 percent agreement. The goal is primarily that everyone understands the issue at hand, can paraphrase it, has a chance to air his or her feelings, and is at least willing not to sabotage the majority's decision." (p. 13)

Brooks (1980) conducted a study to describe the involvement of Colorado public school administrators in the administrative team process, and to assess their degree of satisfaction with the process. The study also determined the similarities and differences among the various administrative positions in regard to their perceived and desired 
involvement and the discrepancy between the two in the categories of shared decision-making, effective communications, goal setting, supportive atmosphere, conflict resolution, and professional environment. Included in the analysis of data were the responses of $\mathbf{5 8 7}$ administrators from thirtyone Colorado school districts. Her findings and conclusions were:

1. Administrators had more involvement in communications and in establishing an environment that was supportive than in shared decision-making. This suggested that their present level of involvement in communications was not necessarily bringing about the impact on decision-making that they wanted.

2. Superintendents and assistant superintendents were more satisf ied with their level of involvement than were the other administrators. The implication was drawn that those positions which are closest to the power source, namely the board of education, have opportunities to inf luence decisions more directly which affect working conditions and relationships and this creates satisfaction.

3. Junior high and elementary principals were the most dissatisfied with their level of involvement, suggesting that their position does not provide opportunities necessary to directly influence final decisions.

4. District size was not related to administrator satisfaction/dissatisfaction, suggesting that factors other than the number of students and the complexity of the organizationai structure affect implementation of the administrative team concept.

5. It was concluded that most districts were involved in varying stages of the processes related to the concept but only nineteen school districts were identified, by the writer's definition, as utilizing the concept.

6. When the areas of common characteristics were analyzed, conflict resolution was identified as the category of most dissatisfaction. This suggested that administrators were concerned about their lack of opportunity to examine possible solutions before decisions were made.

7. Contradictory to the literature, opportunities to meet periodically with the superintendent and formal recognition by the board of education were not indicators of utilization of the administrative team concept. 
8. A majority of the superintendents indicated that there was an administrative team recognized by the board of education, but a majority of the administrators did not agree with this perception.

\section{Teamwork}

Cross (1974) found central elements running through all definitions of team which may also be found in the concept of administrative team: individuals are linked together; their actions are concerted; and they are moving in the same direction.

According to McGinley and Rafferty (1973), the executive secretary of AASA, Paul Salmon, has identified four possible ways administrators might function on the administrative team:

1) benevolence of the superintendent;

2) informal (meet and confer) negotiation;

3) management manifesto; and

4) adversary bargaining. (p. 26)

Collective bargaining was immediately ruled out as not compatible with the administrative team concept because it establishes an adversarial relationship between the superintendent and other members of the team.

In discussing teamwork, McGinley and Rafferty (1973) conclude: There had to be recognition in fact as well as in statement that principals and other administrators are keys to improving instruction in the schools and that they could and should have a voice in deciding - as well as implementing - educational policy. There had to be recognition at the local school level that principals are not just middle management: In the eyes of parents, pupils, teachers, and other local school employees, they are top management. The board had to recognize that, in this age of participatory decision making, principals must be able to establish the same one-to-one correspondence for problem solving that is available to all other employee groups in the collective bargaining process. Once administrators are able to sit as equals with their administrative superiors, a great deal of progress can be made. (p. 28) 
Team management is designed to allow cooperative leadership to take place in educational administration. Given that educational organizations are loosely coupled systems as described by Welk (1982), public school systems have both a need for centralized, shared values and decentralized, school-based autonomy. Management teams offer the structure, within this context, for both to occur. Team management may have been created as an alternative to collective bargaining for administrators, but its foundations are based in participatory management. Administrators expect to have input into decisions which affect their realm of responsibility, especially with regard to policies and administrative regulations. Through management teams, administrators can cooperate in establishing the values, goals, directions, policies, and administrative regulations of the school system while maintaining the independence necessary to manage their unique responsibilities.

A comprehensive summary of team management concepts is presented in an ERS Monograph entitled School Management Team: Their Structure. Function, and Operation by Erickson and Gmeich (1977):

- Agreement is still lacking when it comes to a definitive, operational, and a widely accepted def inition of team management. - Alternative terms for team management include: participative management, group management, leadership teams, administrative teams, advocate teams, a team system of governance, coalition administration, shared decision-making, and collegial teams.

- A typical but ambiguous definition, such as "the team concept involves team members in the decision-making process, especially decisions that affect them and must be carried out by them," creates a number of middle-manager expectations that may not be compatible with the thinking of top managers. 
- Administrators will risk misunderstandings and disappointments if they introduce and implement the team concept without it being clearly understood by all involved.

- Team management should be considered primarily as a process with better management decisions as its major goal.

- Additional objectives of team management include: employee identification with goals; increased satisfaction; and understanding of the nature of problems and keener interest in how they may be solved.

- It is important that managers avoid the over-enthusiasm often associated with new, simplistic panaceas. Unfortunately team management is being grasped by some as a panacea for a variety of problelms.

- Many management teams are too large and therefore unwieldy. They are of ten composed of administrators untrained in interpersonal relationships and therefore tend to be less effective than desired.

- If it is accepted that individual differences exist in administrators just as they do in students, it is unwise to assume that every administrator should be able to function effectively within the team concept.

- Adoption of the team concept is not without cost. It requires an investment of additional time, money, and resources.

- Some proponents of team management infer that an administrative team is the only viable alternative to unions for administrators. Such thinking can result in taking the right actions for the wrong reasons.

- In order to develop sound recommendations and/or decisions, a management team needs maximum input from various organizational levels. In larger organizations this can only be achieved by having representatives from each of the administrative groups.

- Team management is not an administrative method whereby everyone's wishes will be accepted and accommodated, but a method of operation requiring respect for differing opinions and consensus in group decision-making.

- The foundation for developing an effective team lies in the development of interpersonal communication skills as well as skills in handling intergroup conflicts.

- Without careful planning of the team management system, a great deal of valuable management time can be wasted. 
- Team management can involve different degrees of participation in decision-making, from consultation to absolute control over final decisions. Top management should clearly specify in advance the guidelines to be followed by all involved.

- No plan of team management, regardless of how elaborate, will be any better than the quality of the team's individual members or its leader.

- If a superintendent does not have a team management plan on paper, school boards should not construe this to mean that their superintendent is ineffective or out of date. The results of the administrator's work are of greater significance than the label of the management style used.

- A question remains as to whether all school board members are willing to accept the higher frustration levels and the longer time required for decision-making if their executive officer were to use the team management mode.

- The implementation of a management team concept will not be embraced with open arms by everyone. Resistance may be expected from some board members or principals.

- A management team requires that the superintendent must be willing to change and relinquish some of his previously held power and influence.

- Many principals justifiably feel that they are being excluded from portions of the decision-making process in which the previously were involved. Hence, they feel they often lack the authority commensurate with their responsibilities. Team management provides greater participation by principais in the decision-making process. Such participation is needed because principals are closest to the point of implementation. (pp. 47-49)

In conclusion, the review of related literature corroborates that an appropriate operational definition of "management team" is: A group of school district administrators consisting of the superintendent and (or representatives of) central staff, principals, and ancillary personnel having supervisory positions, who, as a group, develop, recommend, implement, and monitor school district policies and administrative regulations; and who participate in the decision-making processes of the district. 


\section{CHAPTER III}

\section{METHODS AND PROCEDURES}

\section{A Study of Successful Management Teams in Oregon Public School}

Systems was intended to address the following purposes: 1) to identify and describe the current status of successful management teams in three Oregon public school systems as they exist in 1988, after more than fifteen years of evolution as the preferred management practice; 2) to add to the existing body of knowledge and research about management teams in educational administration; and 3) to provide useful information for practicing administrators of school systems, who are currently operating management teams, or who are interested in possibly doing so.

According to Yin (1984), in Case Study Research: Design and Methods:

In general, case studies are the preferred strategy when "how" or "why" questions are being posed, when the investigator has little control over events, and when the focus is on a contemporary phenomenon within some real-life context. Such "explanatory" case studies also can be complemented by two other types "exploratory" and "descriptive" case studies. (p. 13)

In order to describe the current status of successful management teams in three Oregon public school systems, a case study research methodology was selected. The activities of management teams were best studied within the unique context of their actual school system operations. Experiment research strategies were not appropriate since control over behavioral events was not sought. Instead, a description of what currently 
exists was the focus of the study. Survey research strategies would have yielded opinion based data from the management team members without control over behavioral events, but would not have provided a comprehensive description of the cultural aspects and activities of the management teams. While a history or archival analysis research strategy would have provided a description of the apparent functioning of the management team, a more complete description was established using case study strategies. As Yin (1984) states:

The case study is preferred in examining contemporary events, but when the relevant behaviors cannot be manipulated. Thus, the case study relies on many of the same techniques as a history, but it adds two sources of evidence not usually included in the historian's repertoire: direct observation and systematic interviewing. Again, although case studies and histories can overlap, the case study's unique strength is its ability to deal with a full variety of evidence - documents, artifacts, interviews, and observations. (pp. 19-20)

\section{CASE STUDIES}

This study was designed to closely parallel case study strategies recommended by Yin (1984). He offers the following technical definition:

A case study is an empirical inquiry that:

- investigates a contemporary phenomenon within its real-life context; when

- the boundaries between phenomenon and context are not clearly evident; and in which

- multiple sources of evidence are used.

To accomplish the stated purposes of this research, a descriptive case study strategy was designed, which describes the real-life context in which an intervention [successful team management activities] has occurred. A multiple-case study consisting of multiple embedded cases was 
selected for this purpose. The multiple-case design followed a replication, rather than a sampling, logic. The findings of each case study were not pooled across cases, but were used to describe each individual management team or case. A cross-case analysis was used to identify the commonalities among the successful management teams. This led to a number of findings which were analyzed with respect to the propositions to draw conclusions.

Yin (1984) identifies five components of research design that are especially important for case studies:

(1) a study's questions

(2) its propositions, if any;

(3) its unit(s) of analysis;

(4) the logic linking the data to the propositions; and

(5) the criteria for interpreting the findings. (p. 29)

This researcher addressed each of these components in developing the case study research design used to study successful management teams.

\section{Study Questions}

For each of the selected cases [successful management teams in three Oregon public school systems], the following study questions were used as the basis for collecting descriptive information about its management team. The study questions, derived from the review of related literature and the researcher's experience, defined the broad parameters of the investigation.

1. Why was the team management concept implemented?

2. How has the management team evolved?

3. How is the management team organized?

4. How does the management team operate?

5. How are management team members involved in developing, 
recommending, implementing, and monitoring school district policies and administrative regulations?

6. What are the most important characteristics or elements found as part of successful management teams which are essential to the school district's management team being "successful"?

\section{Propositions}

The general "how" and "why" nature of the study questions suggested that the case study was the appropriate research methodology for this study. They did not allow the researcher to narrow the focus of the investigation to exactly what to study, however. The following propositions were stated to assist in determining where to look for relevant evidence.

1. Successful management teams implemented the team management concept because it was the preferred method of educational leadership which allowed greater participation by administrators, and resulted in improved decision making.

2. Successful management teams have evolved since their original implementation, until they presently represent the unique management needs and resources of the school system.

3. Successful management teams are made up of a group of school district administrators consisting of the superintendent and (or representatives of) central staff, principals, and ancillary personnel having supervisory positions; and are structured to allow the maximum, efficient input and participation by that group.

4. Successful management teams involve administrators in developing, recommending, implementing, and monitoring school district policies and administrative regulations. 
5. Successful management teams have in common certain characteristics or elements which are essential to the management teams being "successful."

\section{Units of Analysis}

A descriptive multiple-case study design was created for this investigation of successful management teams. The essential unit of study was the "management team." Because the management teams were made up of administrators who have varying roles and responsibilities within the school system, however, individual administrators became secondary units of analysis.

\section{Linking Data te Propositions}

Because this study was a descriptive multiple-case study, the data from each individual case was presented in response to the study questions to create a description of each management team. Cross-case analysis then was possible in identifying similarities and differences among the successful management teams, using the propositions as the focus for the comparisons.

\section{Criteria for Interoreting the Findings}

The purpose of this study was to describe the status of management teams in three Oregon public school systems in 1988. When two or more of the selected cases demonstrated the same attributes or findings, a commonality was determined to exist. Those commonalities were described in a cross-case analysis. 


\section{VALIDITY AND RELIABILITY}

Four tests for validity and reliability were applied to the research design. These tests are: construct validity; internal validity; external validity; and reliability.

\section{Construct Validity}

Correct operational measures had to be established for the concepts being studied. This was accompilished by using multiple sources of evidence which essentially provided multiple measures of the same phenomenon. This triangulation process developed converging lines of inquiry in the case study. A chain of evidence was also established in order to provide construct validity.

\section{Internal Validity}

The concern over internal validity for case study research focuses on the problem of making inferences, rather than the appropriateness of conclusions about causal relationships. Because this study was a descriptive case study inferences were minimal.

\section{External Validity}

The problem of knowing whether a study's findings are generalizable beyond the immediate case is a significant concern with case study designs. This study used a multiple-case research design, based upon replication logic. Again, because the case study was descriptive its generalizability is limited. 
Reliability

If this study were replicated, the same findings and conclusions should result. As many steps as possible were made as operational as possible, and procedures were carefully documented. In addition, the researcher created a case study data base consisting of notes, documents, tabular materials,surveys, and narratives.

\section{PROCEDURES}

\section{Selecting the Cases}

Goetz and LeCompte (1984) indicate that ethnographers of ten use criterion-based selection to identify cases for study. A list of attributes or criterla is established in advance and then investigators search for cases that match the specified array of characteristics. This procedure for selection of case studies was used in determining which management teams would be investigated in this study.

The following criterion was established by this researcher. Which Oregon public school systeins represent both: a) "a successful management team" as endorsed and promoted by $\operatorname{COSA}$ and OSBA, and $b$ ) "a state of the art" model of team management as it is evolving? Responses to this question were collected from four reliable sources, who were experienced in working with Oregon public school systems and knowledgeable about the team management concept: the policy specialist for the Oregon School Boards Association; the field services specialist for the Confederation of Oregon School Administrators; the assistant superintendent of school district services for the Oregon Department of Education; and the researcher, a school district superintendent in Oregon. 
To select the cases to be studied, informal data gathering was conducted, using casual, non-threatening conversations to solicit responses to the criterion-based question. The researcher hoped to obtain a high level of truthfulness of response through obtaining internal perceptions from the respondents in an uncontrolled manner. The researcher's own response to the criterion was based upon a variety of casual contacts with professional associates, representing a wide sample of administrators.

From the 305 Oregon school districts, only the following five school systems were identified by all four respondents as meeting the criterion for selection as a case for purposes of this study: Eagle Point School District 9; Gladstone School District 115; Hood River County School District; Lake Oswego School District 7J; and Lincoln County School District. The researcher chose to use Hood River County School District for only pilot study purposes, since it was the school district by which he was employed. Meeting the selection criterion and accessibility were the reasons for this decision. Because Gladstone School District 115 was experiencing labor strife, the researcher chose not to select that school system as a case study. The remaining three school systems, representing various regions of Oregon were selected as cases for study of successful management teams.

\section{Sources of Evidence}

Yin (1984) lists six different sources of evidence on which case studies may be based. They are: documentation, archival records, interviews, direct observation, participant-observer, and physical artifacts. of these six sources, this researcher chose to use four of the sources which were appropriate for the case studies of successful management teams in 
three Oregon public school systems: 1) documentation; 2) archival records;

3) interviews; and 4) direct observation.

Documentary information was obtained by collecting data from a variety of sources. School board policies and administrative regulations provided one source of information about the management team concept, as did the agendas, announcements and minutes of management team meetings. Administrative memoranda and school system documents describing the management team were also collected.

Archival records such as organizational charts and administrative personnel lists were reviewed. School board meeting minutes describing actions taken with regard to team management were also sought.

Interviews and surveys provided an important source of information in this study. Key administrators and supervisors in the school systems were interviewed using a focused interview format. The interviews also remained open-ended, allowing the respondents to include their opinions and insights into the study of team management. Administrators were also surveyed using the Management Team Survey Form presented in Appendix B.

Direct observations of actual management team meetings provided an opportunity to personally witness the interactions of the management team members. These on-site field visits were essential in developing an understanding of the culture that existed in and around each management team, and provided follow-up leads for additional investigation.

\section{Experience and Role of the Investigator}

This researcher was aware of the essential skills required of the investigator for conducting case studies. Yin (1984) lists them: 
- A person should be able to ask good questions - and to interpret the answers.

- A person should be a good "listener" and not be trapped by his or her own ideologies or preconceptions.

- A person should be adaptive and rlexible, so that newly encountered situations can be seen as opportunities, not threats.

- A person must have a firm grasp of the issues being studied, whether this is a theoretical or policy orientation, even if in an exploratory mode. Such a grasp reduces the relevant events and information to be sought to manageable proportions.

- A person should be unbiased by preconceived notions including those derived from theory. Thus, a person should be sensitive and responsive to contradictory evidence. (pp. 56-57)

This researcher has been a practicing educational administrator since 1971 , serving as an elementary principal, director of elementary education, assistant superintendent, and currently as superintendent. Management team training has been received on two separate occasions; once while serving as a principal in Pasco School District in Washington, and once in the Hood River County School District in Oregon. Through participation on these management teams, this researcher has developed a practical knowledge of the concepts and issues related to team management. A review of related literature has broadened that practical understanding to include a theoretical knowlege about team management. The researcher entered this study with no particular position to prove, but with an interest in determining what constitutes a successful management team in 1988. By describing those management teams considered successful, useful information was made available for those who are interested in establishing management teams or who wish to improve existing management teams. Therefore, this researcher entered into this case study with a thorough understanding of the issues involved, willing to listen and discover, without bias. This researcher was the only investigator conducting this descriptive 
multiple-case study, and therefore performed the searches for documentary and archival evidence, the interviews, surveys, and the direct observations at each of the three selected school systems.

\section{Conducting the Study}

As previously discussed, a descriptive, multiple-case study design was selected for conducting this study, and the cases were then selected. Approval to conduct case studies in the selected school districts was then received from those superintendents. Prior to the pilot study, a content analysis of Chapters I and II was conducted, deriving questions raised by the related literature. Potential sources of evidence were then identified by the researcher for use in conducting the case studies. This material is presented as Appendix A. The study was then conducted in four separate phases.

First, a pilot study was conducted in the Hood River County School District. Data collection activities and instruments were designed, field tested and modified during this phase. During the field testing of the data collection instruments, the researcher found them to be unwieldy and extremely time consuming. The Management Team Survey Form, found in Appendix $\mathrm{E}$, was restructured from the content analysis to create a list of characteristics or elements found in management teams. Management Team Interview Forms (Appendix $\mathrm{C}$ ) were developed as guidelines for interviews related to the study questions. Management Team Document and Archival Records Forms (Appendix D) and Management Team Observation Forms (Appendix E) were developed to provide consistent data collection from multiple sources [triangulation] to take place during the second through the fourth phases of the study. 
Second, on-site field visits took place in the three selected school systems. The purpose of these visits was to: 1) search for archival and documentary evidence, 2) interview the superintendent, and 3) directly observe the management team in action.

The third phase of the study involved interviews with key administrators and supervisors in each of the school districts. These were focused interviews, but were open-ended to allow for additional input. A written survey of management team members was also conducted.

The fourth phase was a visit to each school district to follow-up on leads developed during the second and third phases. Where appropriate, additional direct observations were conducted, as well as additional interviews, surveys, and document and archival investigations.

Following the collection of information, a single-case description was written for each selected school system management team. A crosscase analysis was then conducted, resulting in a written description of the similarities among these successful management teams in three Oregon pubilic school systems. 


\section{CHAPTER IV}

\section{PRESENTATION AND ANALYSIS OF FINDINGS}

Intensive, on-site visitations of three successful management teams in Oregon were conducted, as described in Chapter III, during February and March 1988. Multiple sources of evidence were gathered in response to the following study questions:

1. Why was the team management concept implemented?

2. How has the management team evolved?

3. How is the management team organized?

4. How does the management team operate?

5. How are management team members involved in developing, recommending, implementing, and monitoring school district policies and administrative regulations?

6. What are the most important characteristics or elements found as part of successful management teams which are essential to the school district's management team being "successful"?

Using the study questions as the format for presenting case study descriptions, three separate case studies are presented in this chapter. The findings of these case studies describe the uniqueness of each individual management team within the context of its real life existence. Additionally, a cross-case analysis is presented, using replication logic, rather than pooled data, resulting in a description of the commonalities of the three individual case studies. 
CASE STUDY: EAGLE POINT SCHOOL DISTRICT 9

Eagle Point School District 9 is located approximately twelve miles east of Medford in southern Oregon. The district covers 640 square miles between the Cascade Mountains and the Rogue River, including the incorporated cities of Eagle Point and Shady Cove plus the unincorporated area of White City. It is considered to be a rural-suburban school system.

Approximately 3,500 students are served in eight schools: five elementary schools, one middle school, one junior high and one high school. The district has 412 employees, of which nineteen are administrators. All nineteen administrators, including the superintendent, who has served in the district for the last six years, comprise the Eagle Point School District management team.

Why Was the Team Management Concept Implemented?

While the literature suggests that a major reason for the initial establishment of management teams in school systems was to prevent the formation of collective bargaining units by administrators, no evidence corroborating that position was found. Interviews with administrators clearly indicated that the reason for creating an administrative team in the Eagle Point School District was to establish an administrative structure which provided for input from administrators into the decision making process and support for the superintendent. The superintendent stated that a management team was established in the district, "To allow input into the decision making process." The directors of curriculum and instruction incicated that in the 1970s, "The team management structure was in place 
but the teamwork was not." Following a study and reorganization of the management team, the administrative team approach was also reaffirmed by the School Board in a policy adopted in 1984.

\section{How Has the Management Team Evolved?}

Documents, interviews, and archival records all indicate that the administrative team was restructured by the current superintendent in 1984. Until that time, according to those interviewed, the administrative team had not been successful. It had existed in name only, with the previous superintendent running the ship his way. A 1984 memorandum from the current superintendent (RE: Revisiting roles and relationships -administrative team) began the process of redefining roles and relationships among administrative team members. As a result, a document entitled "Team Management Concept" was developed, covering philosophical guidelines, district mission statement, role definition, administrative team meetings and decisions, and the superintendent's office. One administrator described the modifications as, "The difference between night and day." The school board added their support of these modifications by adopting Policy 2210 (Management Team) which states, "The Board supports the concept and application of team management and delegates to the Superintendent the authority to develop and apply the guidelines under which it operates" (p. 38). The superintendent remains open to further changes in the administrative team as do the administrators who would like to broaden the base of their influence, especially in the area of curriculum. The management team appears to have evolved to the point where its members feel comfortable with additional involvement. 
How Is the Management Team Organized?

The multiple model administrative team, as described in Chapter II (p. 25), is practiced in the Eagle Point School District. The superintendent meets regularly with the administrative team, but also meets with numerous sub-units of the team. Documents, such as agendas, and interviews indicate the existence of a variety of administrative team subunits. Actual observation of meetings of these sub-units by the researcher served to validate their existence.

The Extended Team is comprised of all nineteen administrators. They meet monthly for breakfast, where socializing and information sharing takes place on an informal basis. The superintendent also uses this gathering to discuss items of district-wide concern with all administrators present. For example, the researcher observed one of these meetings at which the topic of whether or not to hold a personal renewal day inservice was discussed by the Extended Team.

The Extended Team Meetings are immediately followed by a series of Mini-Team Meetings. Separate meetings are held with the building administrators of each of three different levels: administrators of grades $\mathrm{K}-3$; administrators of grades 4-8; and administrators of grades 9-12. The superintendent, the director of instruction, and the director of curriculum cooperatively lead the Mini-Team Meetings. Topics relevant to each respective level are discussed at these meetings.

The Regular Team consists of the four district office administrators, principals of each school, and the high school vice principal. They meet monthly to participate in administrative professional growth activities and to discuss topics of district-wide significance. This is the decision making 
sub-unit of the administrative team, as evidenced by decisions made on field trip budgets, parent-teacher conferences, and personal renewal day.

The Cabinet, composed of district level administrators and supervisors, meets weekly to coordinate calendars, report on their specific areas of responsibility, and coordinate school board and administrative team activities. The administrative direction of the district is generally planned at this level.

\section{How Does the Management Team Operate?}

While the activities and operations of the administrative team were identified through documents and interviews, the way in which it actually operates is most evident through observation. The researcher was able to observe the following meetings: Extended Team Meeting; three Mini-Team Meetings; and Regular Team Meeting.

The Extended Team Meeting was a breakfast meeting, emphasizing socialization among the administrators. Attendance at these meetings is not required, but everyone usually attends. At this meeting, all administrators were present except for one principal who was absent due to illness. Following breakfast, the superintendent asked for input from team members about whether or not to continue having the district personal renewal day. Seven of the administrators responded. Additional input was encouraged by the director of instruction. The superintendent had to leave the meeting early, but even in his absence, consensus was reached on this issue. The observer's impression of the meeting was that the feeling tone was cordial and friendly, with quiet discussion taking place, leading to team support for the action taken. 
At each of the three, one hour Mini-Team Meetings, the same agenda items were discussed with different administrators representing the various grade levels of the district. The superintendent along with the directors of instruction and curriculum led their respective sections of the agenda. The administrators were also asked if they had any agenda items for the meeting. At the meeting of grades $4-8$, three principals added agenda items; grades K-3, no additions; and grades 9-12, two additions. The vast majority of agenda items at the Mini-Team Meetings allowed the total group to take part in problem solving activities related to their areas of responsibility. Several agenda items required input from either the administrators or their staffs. In addition, a few administrators took the opportunity to share information with the group. The superintendent facilitated the meeting, keeping things moving, adding comments, and injecting humor. These meetings were business-like and professional, allowing for open discussion, even frank expression of frustation and clearing the air. The meetings were generally relaxed, with moments of humor.

The Regular Team Meeting, attended by eleven administrators and the superintendent, consisted of three different segments. During the first segment, a staff development specialist provided inservice on peer coaching as part of the ongoing administrative professional growth program.

The second segment of the meeting consisted of the planned agenda. The superintendent and director of instruction led their respective portions of the agenda. The superintendent's agenda consisted mainly of sharing information, proposing actions, explaining processes, setting expectations, and acknowledging good administrative performance. The director of 
instruction's agenda predominantly asked for input and responses from administrators and their staffs on a variety of issues. Calendar items were also firmed up, and the results of a survey shared.

The third segment (Roundtable) provided the opportunity for any administrator to ask questions, present information, or raise issues not scheduled on the agenda. Six of the administrators took advantage of this opportunity. This administrative team meeting of the Regular Team was conducted by the superintendent in a business-like manner. It was more formal than the previously discussed meetings, but the feeling tone was very positive and supportive.

Administrative team members were surveyed, using the Management Team Survey Form, to identify which characteristics or elements of management teams are found in the Eagle Point School District administrative team, and which characteristics or elements are essential to the team being successful. Fifteen of the nineteen administrative team members completed the survey, establishing a seventy-nine percent response. Of the fifty-two characteristics or elements, management team members identified thirty-six which exist in the Eagle Point School District; and twenty-four which are essential to the successfulness of their management team. Only those characteristics or elements identified by two-thirds or more of the team members responding to the survey are reported by the researcher as existing $(X)$ or essential $(\bullet)$ in Table I. 
TABLE ।

MANAGEMENT TEAM SURVEY RESPONSES:

EAGLE POINT SCHOOL DISTRICT 9

A review of related literature identifies the following characteristics or elements as being found in management teams.
Which of these are found as part of your district's management team?
Which of these are essential to your district's management team being "successful."

$N=15$ respondents

$X=67 \%$ or more of respondents $=$

1.3 There is an organized unit for administrative collective bargaining.

1.4 Management team members

$\times \quad 87$

53

are involved in the collective bargaining with other bargaining groups. (i.e., teachers, classified)

1.6 Team management in $\times \quad 93$

87 the school district provides for participation by administrators in decisions affecting their work.

1.7 Team members describe

60 the quality of decisions made by the management team compared to decisions made by individual administrators as being improved.

1.8 Administrators feel more

$\times \quad 87$

- 80 accountable for decisions made by the management team.

More supportive.

More successful. 
TABLE I (CONTINUED)

\begin{tabular}{|c|c|c|}
\hline $\begin{array}{l}\text { A review of related literature } \\
\text { identifies the following char- } \\
\text { acteristics or elements as being } \\
\text { found in management teams. }\end{array}$ & $\begin{array}{l}\text { Which of these } \\
\text { are found as part } \\
\text { of your district's } \\
\text { management } \\
\text { team? }\end{array}$ & $\begin{array}{l}\text { Which of these are } \\
\text { essential to your } \\
\text { district's manage- } \\
\text { ment team being } \\
\text { "successful." }\end{array}$ \\
\hline
\end{tabular}

$N=15$ respondents

$X=67 \%$ or more of respondents $=\bullet \quad X \quad \% \quad \&$

1.9 The management team

X 93

93

93

approach allows administrators

to gain and share a perspective of

the school system as a whole.

1.10 Involvement as a

$\times \quad 93$

87

management team member

makes the members feel like

a more important part of the

enterprise for which they work.

3.1 The management team has a

$\times \quad 67$

60

clearly understood structure.

3.2 All sub-units are well

60

60

represented on the management team.

3.4 The various management

$\times \quad 87$

- 67

team units are linked together.

3.6 The purpose of the

60

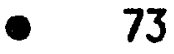

management team is clearly defined.

3.7 The authority of the management team is acknowledged and specified by:

the School Board.

the Superintendent.

$\begin{array}{rll}X & 93 & 80 \\ \times & 93 & 8\end{array}$


TABLE I (CONTINUED)

\begin{tabular}{lll}
\hline A review of related literature & Which of these & Which of these are \\
identifies the following char- & are found as part & essential to your \\
acteristics or elements as being & of your district's district's manage- \\
found in management teams. & management & ment team being \\
& team? & "successful."
\end{tabular}

$N=15$ respondents

$X=67 \%$ or more of respondents $=$

3.8 The management team is stable.

3.9 The roles and responsibilities of management team members are clearly defined.

3.11 The team is protected and

47 40 rewarded regarding its decisions and recommendations.

3.12 The special strengths

60

60

of team members are utilized.

4.3 Suificient tíme for management team activities is provided.

4.4 Definite rules and procedures are followed by the management team.

4.6 Management team members are involved in decision making.

$\times \quad 100 \quad 80$

4.8 Management team members $\times \quad 80$ - 67 are involved in district program evaluation. 
TABLE I (CONTINUED)

\begin{tabular}{lll}
\hline A review of related literature & Which of these & Which of these are \\
identifies the following char- & are found as part & essential to your \\
acteristics or elements as being & of your district's & district's manage- \\
found in management teams. & management & ment team being \\
& team? & "successful."
\end{tabular}

$N=15$ respondents

$X=67 \%$ or more of respondents $=\bullet$

4.10 Management team members have adequate input in employment, promotion, and dismissal decisions of school district employes.

4.11 Team management contributes to better morale.

Motivation.

Collaboration.

4.12 There is a greater sense of community as a result of team management.

4.13 The level of trust and security is improved through team management.

4.14 Management team members feel tied to the success of the

\begin{tabular}{l}
$\mathrm{X} \quad \bullet \quad 80$ \\
\hline
\end{tabular}

$\times \quad 80$

60

X 73

60

$\times \quad 80$

- 73

Superintendent.

vice versa.

$\times \quad 87$

- 80

\section{Vice versa.}

4.15 The School Board supports and appreciates the management team.

Vice versa.

X 87

60

53

40

$\times \quad 93 \quad 80$

$\times \quad$
$-\quad 73$ 
TABLE I (CONTINUED)

\begin{tabular}{|c|c|c|}
\hline $\begin{array}{l}\text { A review of related literature } \\
\text { identifies the following char- } \\
\text { acteristics or elements as being } \\
\text { found in management teams. }\end{array}$ & $\begin{array}{l}\text { Which of these } \\
\text { are found as part } \\
\text { of your district's } \\
\text { management } \\
\text { team? }\end{array}$ & $\begin{array}{l}\text { Which of these are } \\
\text { essential to your } \\
\text { district's manage- } \\
\text { ment team being } \\
\text { "successful." }\end{array}$ \\
\hline
\end{tabular}

$N=15$ respondents

$X=67 \%$ or more of respondents $=\bullet \quad X \quad \% \quad$ \%

4.16 Team management

contributes to shared values, purpose, direction.

Team belonging.

4.17 Team management improves communications.

Quality of information.

4.18 An effective communications system exists between and among all levels of administrators, and the School Board.

4.19 Interpersonal relations

40

27

problems and conflicts are resolved better through team management.

4.20 Open and accurate communications is provided for.

4.22 The management team fosters success. Job satisfaction.

4.23 Team management develops centralized goals and direction for the school district, and decentralized autonomy for team members. $\times \quad 80 \quad 73$

$60 \quad 47$

$33 \quad 47$ $\times \quad 93 \quad \bullet \quad 67$

\section{0}


TABLE I (CONTINUED)

\begin{tabular}{lll}
\hline A review of related literature & Which of these & Which of these are \\
identifies the following char- & are found as part & essential to your \\
acteristics or elements as being & of your district's & district's manage- \\
found in management teams. & management & ment team being \\
& team? & "successful."
\end{tabular}

$N=15$ respondents

$X=67 \%$ or more of respondents $=\bullet \quad X \quad \% \quad \bullet \quad \%$

5.1 The responsibilities of the

33

27

management team include

policy and regulation development.

5.2 Management team members

are involved in:
a) developing
b) recommending
c) implementing
d) monitoring

policies and administrative

regulations.

5.3 The management team affects the quality of policles and regulations.

5.4 Management team members support team developed policies and plans.

5.5 The impact of policy

53

40

recommendations is communicated

by the management team to the

School Board.

The Superintendent.

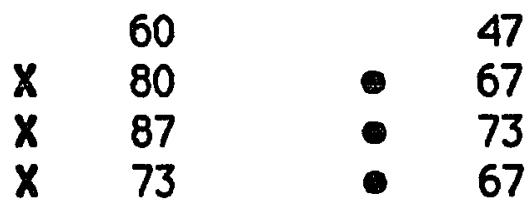

$\times \quad 87$

47

X 73

- 73

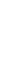


How Are Management Team Members Involved in Developing, Recommending, Imolementing, and Monitoring School District Policies and Administrative Requlations?

Through multiple sources of evidence, it is apparent that the Eagle Point School District management team takes part in the policy and administrative regulation process of the district; and they feel it is important to do so. The Management Team Survey (item 5.2) illustrates that administrators strongly feel that they are involved in the recommending, implementing, and monitoring of policies and regulations. Interviews with administrators confirm that the role of the management team is in these areas, and not necessarily in the developing of the policies, which seems to be a function of the Cabinet and School Board. Limited observations by the researcher identified activities by the management team in the monitoring and implementing areas. The management team is asked for input regarding policy and regulation development, and that input is seriously considered by the superintendent and the Cabinet before presentation to the School Board. During the researcher's observation, the Regular Team was asked for input into a district policy on teacher release time for curriculum activities and also the use of personal leave by teachers.

What Are the Most Important Characteristics or Elements found as Part of Successful Management Teams Which Are Essential to the School District's Management Team Being "Successful"?

The survey of management team members asked the respondents to identify the ten most important characteristics or elements which made their team "successful." The following list represents a synthesis of their responses. The researcher chose to report those items which were listed by 
at least a majority of the responding team members. They are listed in order from those most mentioned to those least mentioned.

1. Shared values and a sense of team belonging

2. Support from and for other team members and the team as a whole

3. Good communications with team members and team units

4. Shared decision-making leading to quality, supported decisions

5. Centralized goals and direction for the district

6. Trust between and among team members

7. Input into problem-solving and policy processes

8. Shared success for the achievements of the management team

Through additional observations, documents and interviews, the researcher identified several other characteristics or elements that appear to be essential to the success of the Eagle Point School District

management team. In discussing team management with the superintendent, it is apparent that he understands the concept, and is strongly motivated to have a successful management team in the district. He is committed to it; his school board recognizes this, and supports the superintendent. The superintendent has developed a written set of philosophical guidelines related to the team management concept which states, "The management team concept must emphasize that all team members support or respect one another and pull together to reach common goals." Evidence of his leadership is found in the documents and records of the district as previously mentioned. The superintendent models the teamwork that he asks of his management team. He asks other administrators for their input and opinions. He participates in the various meetings without controlling them. The superintendent not only coordinates administrative professional growth activities, but he also takes part in them. 
The superintendent has established an organizational structure which allows team management to occur. Evidence of participatory management is found in the agendas and observations of the various units of the administrative team. The structure of the Eagle Point School District management team is designed to take advantage of the strengths of the people within the organization. Every team member has a forum for involvement in the leadership and management of the district in areas which affect his/her responsibilities, as illustrated by the grade level organization of the three Mini-Teams (grades: $K-3 ; 4-8 ; 9-12$ ). The team members understand this and participate fully so that the management team concept will be successful. When asked on the Management Team Survey to indicate if management team members are involved in decision making, $100 \%$ of the respondents answered in the affirmative.

There is an observable effort on the part of the superintendent and the Cabinet to strike a careful balance between centralized goals and direction for the district, and decentralized leadership and management at the school level. This is best illustrated by the way in which a question of future staff inservice was handled at the Regular Team Meeting. The director of instruction asked, "Shall we run the entire district staff through Phase II training of Assertive Discipline [tight-coupling], or shall we let it be selective on the part of buildings or teachers [loose-coupling]"? The participation at all meetings of the sub-units of the administrative team by the superintendent and directors of instruction and curriculum also imparted that while building level administrators have the authority and responsibility to operate their schools, the goals and direction of the district will not be forgotten. 


\section{CASE STUDY: LINCOLN COUNTY SCHOOL DISTRICT}

Lincoln County School District is a county unit district which occupies a fifty-five mile strip of the central Oregon coast from Cascade Head in the north to Cape Perpetua in the south. The county's population of over 38,000 clusters around the five coastal towns of Lincoln City, Depoe Bay, Newport, Waldport and Yahats, and the inland communities of Toledo, Siletz and Eddyville. Newport is the county seat and school district headquarters for this 1,100 square mile county.

Nearly 5,900 students attend seventeen schools located in four areas of the district. The north area includes two elementary schools, one middle school, and one high school in the Lincoln City vicinity. Two elementary schools, one middle school, and one high school are also located in the west area near Newport. The east area, serving Toledo, Siletz, and Eddyville, contains three elementary schools, one middle school, one high school, and one $\mathrm{K}-12$ school. In Waldport, the south area, there are one elementary school, one middle school, and one high school.

Lincoln County School District has 770 empioyees. Thirty-six of these, including the superintendent, who has served in the district for five years, are administrators who constitute the management team.

\section{Why Was the Management Team Concept Impiemented?}

The management team concept was originally promoted in the early 1970 s in an effort to unify the Lincoln County School District. Interviews with administrators revealed that because of the geographic distance between the schools of the district, independent operations had become the standard. Numerous superintendents during the last fifteen years had unsuccessfully attempted to make team management a working reality in 
the district. Leadership styles of the superintendents ranged from operating totally through concensus to autocratic rule. According to the current superintendent, the previous district of fice administration was fraught with "political intrigue" and "power trips." The management team banded together in an effort to insure the "preservation of the building administrators." The previous superintendent was informed by the management team members that he was not welcome in the schools of the county.

The Lincoln County School Board had always maintained the practice of conferring and consulting with the administrators rather than bargaining. That practice was formalized by school board policy in 1979. None of the administrators interviewed associated the formation of the management team in the district with collective bargaining concerns.

\section{How Has the Management Team Evolved?}

With the installation of the current superintendent in 1983, a significant modification of the team management process took place. A new organizational chart was created which flattened the heirarchy of administrators and redistributed the power and influence of the district office downward to the director level. The existing management team was suspended. In its place the superintendent established a system which encourages centralized values and decentralized management. According to the superintendent, additional movement toward school-based management is anticipated for the future. While the school board has not formally recognized the management team through policy, they have granted the superintendent the authority to establish the administrative practices of the district. 
How Is the Management Team Organized?

In Lincoln County School District, the dual model management team as described in Chapter II (p. 25) is utilized. The superintendent meets with the entire management team in a beginning-of-the-year planning retreat and then on several occasions as needed throughout the year. The researcher was able to view a slide presentation of this year's retreat in which the management goals of the district are featured.

The superintendent also holds a Superintendent's Meeting with the directors on a weekly basis. Actual observation of one of these meetings allowed the researcher to validate its existence and identify its function as the goal and direction setting group of the district. At these meetings, the school board agenda is planned and the positions on issues taken by the administration at the school board meetings are developed. The All Administrator Meetings are also planned by this group. In addition to the Superintendent's Meeting, the directors meet informally once each week for lunch. The purpose of this is to communicate with each other and socialize.

Because of the geographic distribution of schools over 1,100 square miles, a weekly telephone conference call is held among the director of elementary and middle education, director of secondary education, and four principals (area coordinators) representing each of the four geographic areas of the district.

Twice each month Elementary and Middle School Administrator Meetings occur as do Secondary School Administrator Meetings. These meetings are led respectively by their directors. These meetings address issues relative to the specific responsibilities of the group members. 
How Does the Management Team Operate?

The structure of the Lincoin County School District management team and its sub-units is designed to be responsive to the unique geographic situation which exists. As a result, the researcher was only able to observe the Weekly Conference Call, the Superintendent's Meeting, which included planning for an All Administrator Meeting, and the Management Team Planning Retreat (through a slide presentation).

The Weekly Conference Call took place at 9:00 a.m. on Monday morning, involving two directors and four area coordinators. The purpose of this activity is to establish regular communications links with all schools of the district. The area coordinators serve as representatives of the administrators of their respective areas. Of the nine agenda items covered, five required input or response from the area coordinators; three involved the sharing of information; and one entailed a discussion of a rumor regarding the sale of an unused school. On one occasion an area coordinator jokingly asked, "Can we take a vote"? Discussion was uninhibited, with everyone participating. A great deal of business was covered in a very short time. The feeling of the meeting was relaxed, but productive.

The Superintendent's Meeting, attended by all directors of the school district (the level of administration immediately below the superintendent and immediately above the principals), transpired in four separate activities. The first activity was a preparation for the upcoming school board meeting and agenda setting for the following school board meeting. Discussion about each school board agenda item was led by the superintendent. Directors were asked for comments and freely gave them. The second activity was an opportunity for individual contributions from each administrator at the meeting. Five of the directors shared information 
or sought input from the group about an issue of district level significance. The third activity was the planning of a forthcoming All Administrator Meeting being held mainly for budgeting purposes. The final activity of the Superintendent's Meeting was a calendar review to coordinate the activities of the directors. The meeting was led by the superintendent in a professional, business-like manner and a sense of shared responsibility existed among the directors. Occasional humor was injected into the conversation, relieving the tension of an otherwise task oriented meeting.

According to informal interviews with administrators, the operational activities of the Lincoln County management team take place at the Elementary and Middle School Administrator Meetings and the Secondary School Administrator Meetings led by the respective directors. The All Administrator Meetings, led by the superintendent, serve as events for refocussing on the central goals and direction of the district. Items of district-wide significance are addressed, giving administrators an opportunity for input into decisions and directions that affect them. One director said, "The superintendent very carefully selects opportunities to convey the mission and values of the district to the administrators. He focuses on the 'what' and 'why' but not the 'how'."

Management team members were surveyed, using the Management Team Survey Form to identify which characteristics or elements of management teams are found in the Lincoin County School District management team, and which characteristics or elements are essential to the team being successful. Twenty-seven of the thirty-six administrative team members completed the survey, establishing a seventy-five percent response. Of the fifty-two characteristics or elements, management team members identified thirty-eight which exist in the Lincoln County School 
District, and forty-nine which are essential to the successfulness of their management team. Only those characteristics or elements identified by two-thirds or more of the team members responding to the survey are reported by the researcher as existing $(X)$ or essential $(\bullet)$ in Table II.

TABLE II

MANAGEMENT TEAM SURVEY RESPONSES: LINCOLN COUNTY SCHOOL DISTRICT

\begin{tabular}{lll}
\hline A review of related literature & Which of these & Which of these are \\
identifies the following char- & are found as part & essential to your \\
acteristics or elements as being & of your district's district's manage- \\
found in management teams. & management & ment team being \\
& team? & "successful."
\end{tabular}

$N=27$ respondents

$X=67 \%$ or more of respondents $=\bullet \quad X \quad \% \quad \bullet \quad \%$

1.3 There is an organized unit for administrative collective bargaining.

1.4 Management team members

are involved in the collective bargaining with other bargaining groups. (i.e., teachers, classified)

1.6 Team management in the school district provides for participation by administrators in decisions affecting their work.
1.7 Team members describe
$\times \quad 74$
- 89 the quality of decisions made by the management team compared to decisions made by individual administrators as being improved. 
TABLE II (CONTINUED)

A review of related literature identifies the following characteristics or elements as being found in management teams.
Which of these are found as part of your district's management team?
Which of these are essential to your district's management team being "successful."

$N=27$ respondents

$X=67 \%$ or more of respondents $=$

1.8 Administrators feel more accountable for decisions made by the management team.

More supportive.

More successful.

1.9 The management team approach allows administrators to gain and share a perspective of the school system as a whole.

1.10 Involvement as a management team member makes the members feel like a more important part of the enterprise for which they work.

3.1 The management team has a clearly understood structure.

3.2 All sub-units are well

$\times \quad 78$

- 100

$x \quad 93$

- 85

$\times \quad 78$

- 93

$\times \quad 89$

represented on the managemeri.

team.

3.4 The various management team units are linked together.

$\times \quad 78$
$\times \quad 67$
$\times \quad 78$

3.6 The purpose of the 59 78 management team is clearly defined. 
TABLE \| (CONTINUED)

\begin{tabular}{lll}
\hline $\begin{array}{l}\text { A review of related literature } \\
\text { identifies the following char- } \\
\text { acteristics or elements as being } \\
\text { found in management teams. }\end{array}$ & $\begin{array}{l}\text { Which of these } \\
\text { are found as part } \\
\text { of your district's } \\
\text { management } \\
\text { team? }\end{array}$ & $\begin{array}{l}\text { Which of these are } \\
\text { essential to your } \\
\text { district's manage- } \\
\text { ment team being } \\
\text { "successful." }\end{array}$ \\
\hline $\begin{array}{l}N=27 \text { respondents } \\
X=67 \% \text { or more of respondents = }\end{array}$ & $X \quad \%$ & $\%$ \\
\hline
\end{tabular}

3.7 The authority of the management team is acknowledged and specified by:

the School Board.

the Superintendent.

3.8 The management team is stable.

3.9 The roles and responsibilities of management team members are clearly def ined.

3.11 The team is protected and rewarded regarding its decisions and recommendations.

3.12 The special strengths of team members are utilized.

\subsection{Sufficient time for} management team activities is provided.

4.4 Definite rules and procedures are followed by the management team.

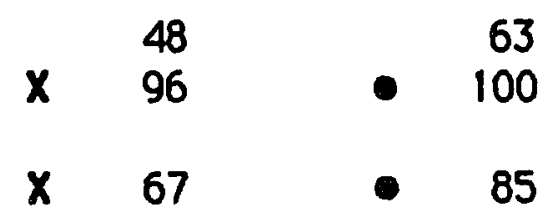


TABLE II (CONTINUED)

A review of related literature identifies the following characteristics or elements as being found in management teams.
Which of these are found as part of your district's management team?
Which of these are essential to your district's management team being "successful."

$N=27$ respondents

$X=67 \%$ or more of respondents $=\bullet$

4.8 Management team members

59

are involved in district

program evaluation.

4.10 Management team members

$\times 81$

- 81

have adequate input in employment, promotion, and dismissal decisions of school district employes.

\subsection{Team management} contributes to better morale.

Motivation.

Collaboration.

4.12 There is a greater sense of community as a result of team management.

4.13 The level of trust and security is improved through team management.

4.14 Management team members feel tied to the success of the Superintendent.

vice versa.

$\begin{array}{cccc}X & 78 & \bullet & 100 \\ X & 81 & \bullet & 89 \\ X & 85 & \bullet & 96\end{array}$

$\times \quad 78$

- 93

$\times \quad 70$

- 74

4.15 The School Board supports

59

- 89 and appreciates the management team.

Vice versa. 
TABLE \| (CONTINUED)

\begin{tabular}{lll}
\hline $\begin{array}{l}\text { A review of related literature } \\
\text { identifies the following char- }\end{array}$ & $\begin{array}{l}\text { Which of these } \\
\text { are found as part }\end{array}$ & $\begin{array}{l}\text { Which of these are } \\
\text { acteristics or elemential to your }\end{array}$ \\
found in management teams. & $\begin{array}{l}\text { of your district's } \\
\text { management }\end{array}$ & $\begin{array}{l}\text { district's manage- } \\
\text { ment team being } \\
\text { team? }\end{array}$ \\
\hline
\end{tabular}

$N=27$ respondents

$X=67 \%$ or more of respondents $=0 \quad X \quad \%$

4.16 Team management

$\times \quad 67 \quad 0 \quad 81$

contributes to shared values, purpose, direction.

Team belonging.

$\times \quad 74 \quad 69$

4.17 Team management improves communications.

Quality of information.

$\times \quad 78 \quad \bullet \quad 78$

48

48

4.18 An effective communi-

cations system exists between and among all levels of administrators, and the School Board.

4.19 interpersonal relations problems and conflicts are resolved better through team management.

4.20 Open and accurate communications is provided for.

$56 \quad 81$

4.22 The management

team fosters success. Job satisfaction.

59

- 70

4.23 Team management develops centralized goals and direction for the school district, and decentralized autonomy for team members. 
TABLE II (CONTINUED)

\begin{tabular}{|c|c|c|}
\hline $\begin{array}{l}\text { A review of related literature } \\
\text { identifies the following char- } \\
\text { acteristics or elements as being } \\
\text { found in management teams. }\end{array}$ & $\begin{array}{l}\text { Which of these } \\
\text { are found as part } \\
\text { of your district's } \\
\text { management } \\
\text { team? }\end{array}$ & $\begin{array}{l}\text { Which of these are } \\
\text { essential to your } \\
\text { district's manage- } \\
\text { ment team being } \\
\text { "successful." }\end{array}$ \\
\hline
\end{tabular}

$N=27$ respondents

$X=67 \%$ or more of respondents $=0 \quad X \quad \% \quad \%$

5.1 The responsibilities of the

$\times \quad 78 \quad \bullet \quad 89$

management team include

policy and regulation develop-

ment.

5.2 Management team members

are involved in:
a) developing
b) recommending
c) implementing
d) monitoring
$\times \quad 89$
$\times \quad 93$
85
$-\quad 93$
$x \quad 93$
X 96
- 89
X 85
- 89

policies and administrative regulations.

5.3 The management team affects the quality of policies and regulations.

5.4 Management team members support team developed policies and plans.

5.5 The impact of policy

recommendations is communicated

$\times \quad 67$

- 74

by the management team to the

School Board.

The Superintendent.

$\times \quad 78$

- 85 
How Are Management Team Members Involved in Develooing. Recommending. Implementing, and Monitoring School District Policies and Administrative Requlations?

The management team members feel strongly, as indicated in the survey, that they are involved in every aspect of the policy and regulation process. School board agendas and observations of the Superintendent's Meeting, however, illustrated that the directors take a much more prominent role in these processes than the other management team members. Seventeen policy revisions were being presented to the school board in future meetings as part of a systematic revision process. The personnel director, for example, was presenting a series of personnel policies for discussion at the next school board meeting. These policies were reviewed by the directors at the meeting observed by the researcher. Generally, management team members are asked for their input and reactions to proposed policies and regulations prior to their finalization.

What Are the Most Important Characteristics or Elements Found as Part of Successful Management Teams Which Are Essential to the School District's Management Team Being "Successful"?

The survey of management team members asked the respondents to identify the ten most important characteristics or elements which made their team "successful." The following list represents a synthesis of their responses. The researcher chose to report those items which were listed by at least a majority of the responding team members. They are listed in order from those most mentioned to those least mentioned.

1. Centralized goals and direction for the district

2. Good communications with team members and team units 
3. Shared decision-making leading to quality, supported decisions

4. Shared values and a sense of team belonging and collaboration

5. Input into problem-solving and policy and regulation processes

6. Shared success for the achievements of the management team

7. Trust between and among team members

8. Support from and for other team members and the team as a whole

Through additional observations, documents and interviews, the researcher identified several other characteristics or elements that appear to be essential to the success of the Lincoln County School District management team. One comment made by the superintendent during an interview illustrates the organizational frame of mind that is allowing team management to function in this unique district. He explained, "What I have done here is to take a 'big city' superintendency model and superimpose it on a rura! school district." The superintendent believes that the district must have tight-loose coupling, and imparts that belief to his directors and building level managers. The management team must accept the centralized goals and direction of the district, and the accountability that comes with that. In return, they are granted decentralized autonomy in the everyday operation of their schools. Responses to the Management Team Survey (item 4.23 ) indicate that $89 \%$ of the respondents believe that tight-loose coupling exists in Lincoln County School District, and that $93 \%$ of the respondents feel that it is essential to the success of their management team.

The superintendent doesn't just let the management team exist, he fosters its existence through team building activities. An example of this is the three day planning retreat at the beginning of the school year. Team building activities and events, such as athletic competition, board games, and rafting, were carried out prior to administrative planning meetings. 
Also the assignment of principals as coordinators to the various areas of the district fosters the collaboration of the administrators within those areas as sub-units of a larger district team.

An organizational structure conducive to team management has been established in Lincoin County School District. The empowerment of the directors to make decisions in consultation with the building administrators has broadened the base of accountability. Administrators know that decisions that affect them can and will be made when necessary. The superintendent is not a necessary ingredient in this process. He very carefully selects those situations in which he provides direction and leadership for the entire management team. For the most part, team management in Lincoln County School District is a process that takes place within the various sub-units; not at a regularly scheduled, formal meeting of the management team.

\section{CASE STUDY: LAKE OSWEGO SCHOOL DISTRICT 7J}

Lake 0 swego School District $7 \mathrm{~J}$ is a suburban school district located on the southeast outskirts of Portland. A population of 28,283 reside in this 13.25 square mile $K-12$ school district.

Approximately 5,600 students attend the district's seven elementary schools, two junior high schools, and two high schools. The district has 580 employees, including the superintendent and 28 administrators who make up the management team. The superintendent, who was promoted from within the organization, is in his first year of service in the district which has a long history of participatory management. 
Why Was the Team Management Concept Implemented?

Lake Oswego has a long-standing tradition of employing participatory management concepts. The personnel director indicated that when he first joined the district in 1959, the administrators of the district were sharing in the decision-making processes of the district. Over the years, continued attempts have been made to involve administrators in the overall operation of the district. The management team concept was directed more at the loss of prerogatives by administrators than any effort to preclude them from collective bargaining processes. Team management in Lake Oswego School District $7 \mathrm{~J}$ addressed the problem of insecurity on the part of building level administrators and the need for support for district level administrators. The school board has always encouraged this approach.

\section{How Has the Management Team Evolved?}

Until 1987, participatory management had taken place whenever it was convenient for that mode of decision-making. Interviews with administrators who had been with the district for many years conf irm that, while team management may have been espoused, in practice, decisions were often handed down. In 1987, the current superintendent began his leadership of the district. He redesigned the job responsibilities, is developing comprehensive administrative performance standards, and emphasized planning and direction. A document describing a three year strategic plan for management and leadership lays out the goals and direction for organizational development. School-based management is encouraged, and increased building level autonomy is anticipated for the future. In 1983, the school board established Policy 2320 which endorses the management team. It states: 
1. The Lake Oswego District subscribes to the concept that the most effective management system is one that provides for particpation in decision making.

2. To allow for participative management, the superintendent shall establish appropriate subgroups of administrators, thus allowing individual members of the management team to participate in the development of policies and the making of decisions that are related to their area of responsibility. (2320)

\section{How is the Management Team Organized?}

The multiple model management team as described in Chapter II (p. 25) exists in the Lake Oswego School District where the superintendent meets regularly with the entire management team as well as with a variety of sub-units. The management team label is not used; meetings of all administrators are called Administrative Council Meetings. These meetings occur monthly and deal with items of a district-wide importance and relevance. The assistant superintendent directs the meeting with administrators leading the discussion of their respective agenda items. They also generally include a presentation or training activity as well.

Cabinet Meetings take piace weekiy, invoiving all district level administrators. Planning for school board agendas takes place at these meetings. Each administrator also reports on his/her area of responsibility.

Weekly Operations Meetings involve the superintendent, assistant superintendent, personnel director, and business manager. These meetings deal with the general operations of the district and planning for other meetings.

Curriculum and Instruction Meetings take place monthly for the purpose of coordinating the instructional and staff development programs of the district. The superintendent, assistant superintendent, director of 
elementary education and the director of secondary education attend these meetings.

Monthly Elementary and Secondary Meetings led by the respective directors are also held. Building level administrators attend these meetings where grade level related topics are discussed.

How Does the Management Team Operate?

The complex structure of sub-units within the management team in the Lake Oswego School District assures a forum for involvement for every administrator. Much of the information regarding these sub-units was gathered by the researcher through interviews; but direct observations occurred at three of these meetings: Operations Meeting; Administrative Council Meeting; and Cabinet Meeting.

The Operations Meeting involved the superintendent, assistant superintendent, and personnel director. This meeting was informal and allowed frank discussion of a number of topics: a review of the school board meeting; negotiations; the need for a staff development schedule; and a personnel matter. The superintendent actively listened. The observer's impression of the meeting was that its function was basically for communications within the inner circle of top level administrators.

The Administrative Council Meeting was directed by the assistant superintendent; but the superintendent took a leading role. In fact, he had the only planned agenda items. When he asked for input, the administrators were willing and eager to provide it. The remainder of the meeting was open for discussion. Nine different administrators contributed to the meeting, mostly sharing information or reporting on specific projects. When questions were raised about a report the superintendent had made, he 
responded, "I should have shared this with you right after the school board retreat." This exemplifies the desire of the superintendent and the administrators to act as a team. The meeting was formal, but good interchange occurred among the administrators.

The Cabinet Meeting was attended by all the district level administrators, except two who were out of town. The meeting consisted of a series of reports from various divisions of the organization, with free dialogue taking place with regard to the reports. It appeared to the observer that this is the direction-setting sub-unit of the organization. The feeling tone was business-like, with the focus on the sharing of information.

Management team members were surveyed, using the Management Team Survey Form to identify which characteristics or elements of management teams are found in the Lake Oswego School District management team, and which characteristics or elements are essential to the team being successful. Twelve of the twenty-nine administrative team members completed the survey, establishing a forty-one percent response. This rate of return was low compared to the returns of seventy-nine percent and seventy-five percent from the other two management teams that were studied. A plausible explanation is that, because this was the new superintendent's first year, administrators might have felt uncomfortable about responding to a survey which described the status of their management team. It is also possible that the obtrusiveness of the researcher within their management team contributed to the low rate of response. Nevertheless, a forty-one percent return was sufficient for purposes of this case study. Of the fifty-two characteristics or elements, management team members identified forty-two which exist in the Lake Oswego School District, and forty-four which are essential to the 
successfulness of their management team. Only those characteristics or elements identified by two-thirds or more of the team members responding to the survey are reported by the researcher as existing $(X)$ or essential ( $\bullet$ ) in Table III.

TABLE III

MANAGEMENT TEAM SURVEY RESPONSES: LAKE OSWEGO SCHOOL DISTRICT 7J

\begin{tabular}{lll}
\hline A review of related literature & Which of these & Which of these are \\
identifies the following char- & are found as part & essential to your \\
acteristics or elements as being & of your district's & district's manage- \\
found in management teams. & management & ment team being \\
& team? & "successful." \\
\hline
\end{tabular}

$N=12$ respondents

$X=67 \%$ or more of respondents $=$

1.3 There is an organized unit for administrative collective

\begin{tabular}{lll}
$X$ & $\%$ & $\%$ \\
\hline$\times$ & 92 & 17
\end{tabular}
bargaining.

1.4 Management team members

$\times \quad 67$

50 are involved in the collective bargaining with other bargaining groups. (i.e., teachers, classified)

1.6 Team management in

$\times \quad 100$

- 100 the school district provides for participation by administrators in decisions affecting their work.

1.7 Team members describe $\times \quad 67$ 50 the quality of decisions made by the management team compared to decisions made by individual administrators as being improved. 
TABLE III (CONTINUED)

\begin{tabular}{lll}
\hline A review of related literature & Which of these & Which of these are \\
identifies the following char- & are found as part & essential to your \\
acteristics or elements as being & of your district's & district's manage- \\
found in management teams. & management & ment team being \\
& team? & "successful." \\
\hline
\end{tabular}

$N=12$ respondents

$X=67 \%$ or more of respondents $=\bullet \quad \times \quad \% \quad \bullet$

1.8 Administrators feel more

X $75 \quad 067$

accountable for decisions made by

the management team.

More supportive.

More successful.

1.9 The management team

approach allows administrators

to gain and share a perspective of

the school system as a whole.

1.10 Involvement as a

management team member

makes the members feel like

a more important part of the

enterprise for which they work.

3.1 The management team has a clearly understood structure.

3.2 All sub-units are well

represented on the management team.

3.4 The various management team units are linked together.

X 75

- 75

X 75

- 67

$\times \quad 75$

- 75

$\times \quad 83$ 
TABLE III (CONTINUED)

A review of related literature identifies the following characteristics or elements as being found in management teams.
Which of these are found as part of your district's management team?

Which of these are essential to your district's management team being "successful."

$N=12$ respondents

$X=67 \%$ or more of respondents $=$

$x \quad$

$\%$

3.7 The authority of the management team is acknowledged and specified by: the School Board. the Superintendent.

$\begin{array}{r}42 \\ \times \quad 92 \quad 82 \\ \hline\end{array}$

3.8 The management team is $\times \quad 67$

- 67 stable.

3.9 The roles and responsibilities of management team members are clearly defined.

3.11 The team is protected and rewarded regarding its decisions and recommendations.

3.12 The special strengths

58

- 83

of team members are utilized.

4.3 Sufficient time for

17

- 67

management team activities

is provided.

4.4 Definite rules and procedures

50

- 67 are followed by the management team.

4.6 Management team members

$\times \quad 92$

- 100 are involved in decision making. 
TABLE III (CONTINUED)

\begin{tabular}{lll}
\hline A review of related literature & Which of these & Which of these are \\
identifies the following char- & are found as part & essential to your \\
acteristics or elements as being & of your district's district's manage- \\
found in management teams. & management & ment team being \\
& team? & "successful." \\
\hline
\end{tabular}

$\mathrm{N}=12$ respondents

$X=67 \%$ or more of respondents $=$

4.8 Management team members are involved in district

program evaluation.

4.10 Management team members have adequate input in employment, promotion, and dismissal decisions of school district employes.

\subsection{Team management} contributes to better morale.

Motivation.

Collaboration.

4.12 There is a greater sense of community as a result of team management.

4.13 The level of trust and security

$\times \quad 83$

- 92 is improved through team management.

4.14 Management team members

X 92

- 92

$\mathrm{x}$
$\mathrm{x}$

$x \quad 92$

- 100

- 100

x 83

- 92

feel tied to the success of the

Superintendent.

vice versa.

$\times \quad 83$

- 75

$\times \quad 67$

- 67

4.15 The School Board supports

42 and appreciates the management team.

Vice versa.

42

58 
TABLE III (CONTINUED)

\begin{tabular}{lll}
\hline A review of related literature & Which of these & Which of these are \\
identifies the following char- & are found as part & essential to your \\
acteristics or elements as being & of your district's district's manage- \\
found in management teams. & management & ment team being \\
& team? & "successful."
\end{tabular}

$N=12$ respondents

$X=67 \%$ or more of respondents $=$

4.16 Team management

contributes to shared values, purpose, direction.

Team belonging.

$\times \quad 75$

- 83

4.17 Team management improves communications.

Quality of information.

$\times \quad 100$

- 100

X 75

- 67

4.18 An effective communications system exists between and among all levels of administrators, and the School Board.

4.19 Interpersonal relations

42

58

problems and conflicts are resolved better through team management.

4.20 Open and accurate communications is provided for.

$\times \quad 92 \quad \bullet \quad 92$

4.22 The management

$\times \quad 92 \quad 83$

team fosters success. Job satisfaction.

\begin{tabular}{l}
$\times \quad 83 \quad 92$ \\
\hline$\quad 9$
\end{tabular}

4.23 Team management develops centralized goals and direction for the school district, and decentralized autonomy for team members.

$\times 100 \quad 100$ 
TABLE III (CONTINUED)

\begin{tabular}{|c|c|c|}
\hline $\begin{array}{l}\text { A review of related literature } \\
\text { identifies the following char- } \\
\text { acteristics or elements as being } \\
\text { found in management teams. }\end{array}$ & $\begin{array}{l}\text { Which of these } \\
\text { are found as part } \\
\text { of your district's } \\
\text { management } \\
\text { team? }\end{array}$ & $\begin{array}{l}\text { Which of these are } \\
\text { essential to your } \\
\text { district's manage- } \\
\text { ment team being } \\
\text { "successful." }\end{array}$ \\
\hline
\end{tabular}

$N=12$ respondents

$X=67 \%$ or more of respondents $=0 \quad X \quad \% \quad \%$

5.1 The responsibilities of the management team include

policy and regulation development.

5.2 Management team members are involved in:
a) developing
b) recommending
c) implementing
d) monitoring

$\begin{array}{rrrr}\mathbf{X} & 92 & \bullet & 75 \\ \mathbf{X} & 100 & \bullet & 83 \\ \mathbf{X} & 100 & \bullet & 83 \\ \mathbf{X} & 100 & \bullet & 75\end{array}$

policies and administrative regulations.

5.3 The management team affects the quality of policies and

$\times \quad 92$

- 75 regulations.

5.4 Management team members support team developed policies and plans.

5.5 The impact of policy recommendations is communicated

42

by the management team to the School Board.

The Superintendent.

\begin{tabular}{l}
$\times \quad 75 \quad 75$ \\
\hline
\end{tabular}


How Are Management Team Members Involved in Developing, Recommending. Implementing, and Monitoring School District Policies and Administrative Requlations?

From the Management Team Survey, it is obvious that the responding members of the management team feel that they are fully involved in the policy and regulation processes. One hundred percent of the respondents indicated on item 5.2 that they were involved. School Board Policy 2320 mandates their involvement. The personnel director is responsible for the development of board policies. Interviews indicated that any administrator could recommend new or revised policies. Input is gathered from the standing sub-units of the management team and submitted to the superintendent for processing. The administrators are then responsible for the implementation and monitoring of the policies.

What Are the Most Imoortant Characteristics or Elements Found as Part of Successful Management Teams Which Are Essential to the School District's Management Team Being "Successful"?

The survey of management team members asked the respondents to identify the ten most important characteristics or elements which made their team "successful." The following list represents a synthesis of their responses. The researcher chose to report those items which were listed by at least a majority of the responding team members. They are listed in order: from those most mentioned; to those least mentioned.

1. Shared decision-making leading to quality, supported decisions

2. Centralized goals and direction for the district

3. Good communications with team members and team units

4. Trust between and among team members 
5. Support from and for other team members and the team as a whole

6. Input into problem-solving and policy and regulation processes

Through additional observations, documents and interviews, the researcher identified several other characteristics or elements that appear to be essential to the success of the Lake Oswego School District management team. The superintendent does not leave the organizational direction of the district to chance. He has established a three year plan which clearly outlines the strategic plan for organizational development. The plan includes the development of a shared vision, establishing district prioritles, participatory processes, and developing building autonomy. He summarized his efforts by stating, "The first two years are foundation years. An effective management base is essential to empowering people throughout the organization to be leaders."

The superintendent is committed to modeling the beliefs about leadership that he espouses. Documents, interviews, and observations all disclose his understanding of the need for shared, centralized goals and direction for the district, and decentralized autonomy at the building level. The superintendent developed a three year organizational development plan which focuses on management in the first year; management and resources in the second year; and leadership in the third year. While he encourages school-based management, his presence and involvement is obvious at all meetings of the sub-units of the management team which affect the accomplishment of the district goals. His commitment and intensity in this regard permeate the district. 
CROSS-CASE ANALYSIS

Descriptions of three successful management teams have been presented, representing three unique public school systems in Oregon. While the geographic, demographic, and organizational contrasts of these districts were obvious, the management teams of these districts shared many commonalities. This cross-case analysis is presented to describe the similarities among the three case studies. The data were not pooled as in sampling methods; rather, replication logic was used. Multiple sources of evidence led to responses to each of the study questions in each of the three distinct case studies. The same six study questions were used as the format for presenting the findings in this cross-case analysis.

\section{Why Was the Management Team Concept Imolemented?}

The earliest literature on team management in educational administration indicates that one significant reason for school boards encouraging the establishment of management teams was in reaction to concerns about collective bargaining by administrators. In all three case studies, however, administrators denied any relationship between the original formation of management teams in their districts and collective bargaining concerns. Two prominent reasons for the establishment of management teams did surface in the case studies:

- The need and desire to allow administrators to have input into the decision-making process.

- The need and desire for support from administrators for the superintendent and other district administrators. 
How Has the Management Team Evolved?

Three commonalities are apparent with regard to the evolution of the management teams. As a preface to identifying the commonalities, the researcher notes that each current superintendent joined his district within the last six years. Team management had existed in the districts prior to their appointment, with varying degrees of success. Each superintendent came to the district committed to team management or participatory management concepts.

The following actions were taken by each of the three superintendents in an effort to improve the management team of the district:

- The organizational structure of the district was modified to better utilize existing administrative personnel and to provide systematic opportunities for input and involvement by the administrators.

- Roles and relationships among management team members were modified and clarified.

- School-based management was encouraged and supported.

How Is the Management Team Organized?

The three management teams were organized to address the unique situations of the school districts they serve. Their dissimilarities did not obscure their similarities, however. The management teams had the following structural traits:

- A single management team unit did not exist; the management team was made up of a variety of sub-units, representing all segments of administration. 
- The superintendent met with the entire management team (all administrators), as well as with various sub-units of the management team.

- The various sub-units were linked together for communications purposes by link-pin administrators.

\section{How Does the Management Team Operate?}

The ways in which the three management teams operated were much more similar than the organizational configurations which def ined the management teams. At times the researcher wondered in which district he was observing. The following characteristics were apparent at management team and sub-unit meetings in each district:

- The opportunity for socialization among administrators occurred at each meeting.

- Input and responses were sought from administrators by the superintendent and district level administrators.

- Genuinely open discussion among all administrators was encouraged, and, in fact, took place. Administrators were not reluctant to voice their opinions, even if it disagreed with that of the superintendent.

- Professional growth sessions for administrators were a planned part of the management team activities.

- Sharing of information among administrators took place both formally and informally.

- Agenda items were contributed at meetings by administrators from all segments of the organization.

- Efforts were made to reach agreement through consensus whenever possible. 
Management team members in each district were surveyed, using the Management Team Survey Form to identify which characteristics or elements of management teams existed $(X)$, and which characteristics or elements are essential ( $\bullet$ ) to the team being successful. The results of all three surveys are presented in Appendix F - Management Team Survey: Number and Percent of Responses by School District. The data were used by the researcher to develop Tables I - III in the case study descriptions.

A comparison of the survey results of the three management teams derived from Tables I - III is presented in Table IV - Management Team Survey Responses: Comparison of Three School Districts. For each management team surveyed, only those characteristics or elements identif ied by two-thirds or more of the team members responding to the survey are reported by the researcher.

A comparison of the results indicates that thirty of the characteristics or elements exist in all three management teams; twentytwo are felt to be essential for success in all three management teams. Nine additional characteristics or elements exist in two of the management teams; an additional twenty-two are identified as being essential for success in two of the management teams.

A total of forty-four characteristics or elements found in management teams were identified in at least two of the three case studies as being essential to the success of the management team in that school system. These forty-four items can serve as guideposts for identifying successful management teams and team management practices. 
TABLE IV

MANAGEMENT TEAM SURVEY RESPONSES:

COMPARISON OF THREE SCHOOL DISTRICTS

\begin{tabular}{lll}
\hline A review of related literature & Which of these & Which of these are \\
identif ies the following char- & are found as part & essential to your \\
acteristics or elements as being & of your district's & district's manage- \\
found in management teams. & management & ment team being \\
& team? & "successful." \\
\hline
\end{tabular}

$X=67 \%$ or more of respondents $=$

$E P=$ Eagle Point School District 9

$x$

$\mathrm{LC}=$ Lincoln County School District

LO= Lake Oswego School District 7J EP LC LO EP LC LO

1.3 There is an organized unit for administrative collective bargaining.

1.4 Management team members are involved in the collective bargaining with other bargaining groups. (i.e., teachers, classified)

1.6 Team management in the school district provides for participation by administrators in decisions affecting their work.

\subsection{Team members describe} the quality of decisions made by the management team compared to decisions made by individual administrators as being improved.

\subsection{Administrators feel more} accountable for decisions made by the management team.

More supportive.

More successful.

$x \quad x$

x $x$

X


TABLE IV (CONTINUED)

\begin{tabular}{|c|c|c|}
\hline $\begin{array}{l}\text { A review of related literature } \\
\text { identifies the following char- } \\
\text { acteristics or elements as being } \\
\text { found in management teams. }\end{array}$ & $\begin{array}{l}\text { Which of these } \\
\text { are found as part } \\
\text { of your district's } \\
\text { management } \\
\text { team? }\end{array}$ & $\begin{array}{l}\text { Which of these are } \\
\text { essential to your } \\
\text { district's manage- } \\
\text { ment team being } \\
\text { "successful." }\end{array}$ \\
\hline
\end{tabular}

$X=67 \%$ or more of respondents $=$

$E P=$ Eagle Point School Dist. 9

$L C=$ Lincoln County School Dist.

LO $=$ Lake Oswego School Dist. 7J EP LC LO EP LC LO

1.9 The management team

approach allows administrators

to gain and share a perspective of

the school system as a whole.

1.10 Involvement as a

management team member

makes the members feel like

a more important part of the enterprise for which they work.

3.1 The management team has a clearly understood structure.

3.2 All sub-units are well represented on the management team.

3.4 The various management team units are linked together.

\section{$x \quad x$}

$\mathrm{x} \times \mathrm{x}$

(n)


TABLE IV (CONTINUED)

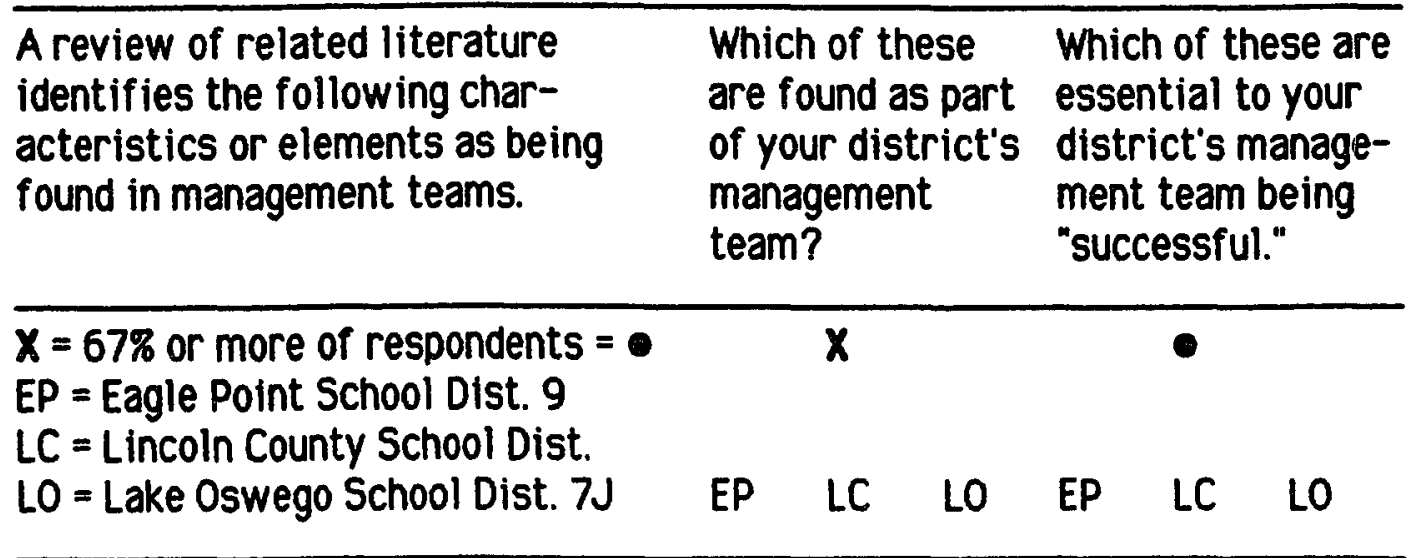

3.7 The authority of the management team is acknowledged and specified by: the School Board. the Superintendent.

3.8 The management team is stable.

3.9 The roles and responsibilities of management team members are clearly defined.

3.11 The team is protected and rewarded regarding its decisions and recommendations.

3.12 The special strengths of team members are utilized.

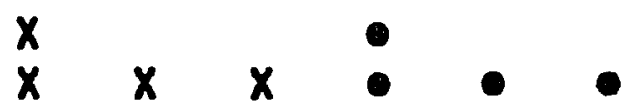

$x \quad x \quad x$

$x$

4.3 sufficient time for management team activities is provided.

4.4 Definite rules and procedures are followed by the management team.

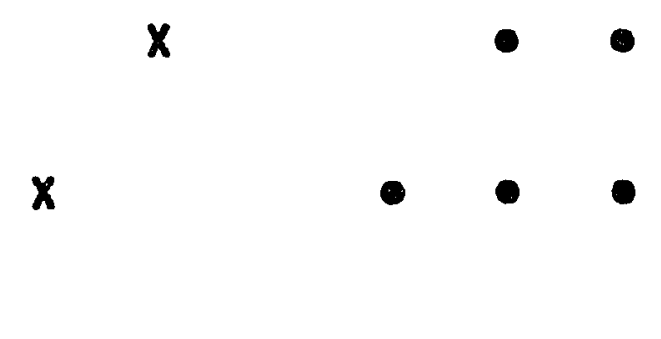


TABLE IV (CONTINUED)

\begin{tabular}{lll}
\hline A review of related literature & Which of these & Which of these are \\
identifies the following char- & are found as part & essential to your \\
acteristics or elements as being & of your district's & district's manage- \\
found in management teams. & management & ment team being \\
& team? & "successful."
\end{tabular}

$X=67 \%$ or more of respondents $=$

$E P=$ Eagle Point School Dist. 9

$L C=$ Lincoln County School Dist.

LO $=$ Lake Oswego School Dist. 7J EP LC LU EP LC LO

4.6 Management team members

$x \quad x \quad \bullet \quad \bullet$

are involved in decision making.

4.8 Management team members

$x \quad x \quad x$

are involved in district

program evaluation.

4.10 Management team members $x \quad x \quad x$

have adequate input in employment, promotion, and dismissal decisions of school district employes.

4.11 Team management

contributes to better morale.

Motivation.

Collaboration.

4.12 There is a greater sense of community as a result of team management.

4.13 The level of trust and security is improved through team management.

4.14 Management team members feel tied to the success of the Superintendent. $x \quad x$

$\begin{array}{lll}x & x & x \\ x & x & x\end{array}$

$\mathrm{x} \times$

$\mathrm{x} \times \mathrm{x}$

$x \times x$

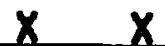


TABLE IV (CONTINUED)

\begin{tabular}{|c|c|c|c|c|c|c|}
\hline $\begin{array}{l}\text { A review of related literature } \\
\text { identif ies the following char- } \\
\text { acteristics or elements as being } \\
\text { found in management teams. }\end{array}$ & $\begin{array}{l}\text { Whi } \\
\text { are } \\
\text { of y } \\
\text { mar } \\
\text { teal }\end{array}$ & $\begin{array}{l}\text { of } t \\
\text { ound } \\
\text { ur di } \\
\text { geme }\end{array}$ & $\begin{array}{l}\text { pare } \\
\text { pict's }\end{array}$ & & $\begin{array}{l}\text { iof t } \\
\text { itial } \\
\text { ict's } \\
\text { tean }\end{array}$ & $\begin{array}{l}\text { ese are } \\
\text { your } \\
\text { anage- } \\
\text { eing } \\
\text { " }\end{array}$ \\
\hline $\begin{array}{l}X=67 \% \text { or more of respondents }= \\
E P=\text { Eagle Point School Dist. } 9 \\
L C=\text { Lincoln County School Dist. } \\
L O=\text { Lake Oswego School Dist. } 7 \mathrm{~J}\end{array}$ & EP & LC & LO & EP & LC & LO \\
\hline $\begin{array}{l}\text { 4.15 The School Board supports } \\
\text { and appreciates the management } \\
\text { team. } \\
\text { Vice versa. }\end{array}$ & $x$ & & & - & $\bullet$ & $\bullet$ \\
\hline $\begin{array}{l}\text { 4.16 Team management } \\
\text { contributes to shared values, } \\
\text { purpose, direction. } \\
\text { Team belonging. }\end{array}$ & $x$ & $x$ & $x$ & - & - & $\bullet$ \\
\hline $\begin{array}{l}4.17 \text { Team management } \\
\text { improves communications. } \\
\text { Quality of information. }\end{array}$ & $x$ & $x$ & $\begin{array}{l}x \\
x\end{array}$ & • & - & - \\
\hline $\begin{array}{l}4.18 \text { An effective communi- } \\
\text { cations system exists between } \\
\text { and among all levels of } \\
\text { administrators, and the School } \\
\text { Board. }\end{array}$ & & & & & $\bullet$ & • \\
\hline $\begin{array}{l}4.19 \text { Interpersonal relations } \\
\text { problems and conflicts are } \\
\text { resolved better through team } \\
\text { management. }\end{array}$ & & & & & - & \\
\hline $\begin{array}{l}4.20 \text { Open and accurate } \\
\text { communications is provided for. }\end{array}$ & & $x$ & $x$ & & - & - \\
\hline
\end{tabular}


TABLE IV (CONTINUED)

\begin{tabular}{|c|c|c|c|c|c|c|}
\hline \multirow{2}{*}{$\begin{array}{l}\text { A review of related literature } \\
\text { identif ies the following char- } \\
\text { acteristics or elements as being } \\
\text { found in management teams. } \\
X=67 \% \text { or more of respondents = } \\
E P=\text { Eagle Point School Dist. } 9 \\
L C=L i n c o l n \text { County School Dist. } \\
L O=\text { Lake Oswego School Dist. } 7 \mathrm{~J}\end{array}$} & \multicolumn{3}{|c|}{$\begin{array}{l}\text { Which of these } \\
\text { are found as part } \\
\text { of your district's } \\
\text { management } \\
\text { team? }\end{array}$} & \multicolumn{3}{|c|}{$\begin{array}{l}\text { Which of these are } \\
\text { essential to your } \\
\text { district's manage- } \\
\text { ment team being } \\
\text { "successful." }\end{array}$} \\
\hline & EP & LC & LO & EP & LC & LO \\
\hline $\begin{array}{l}4.22 \text { The management } \\
\text { team fosters success. } \\
\text { Job satisfaction. }\end{array}$ & $x$ & $x$ & $x$ & $\bullet$ & - & - \\
\hline $\begin{array}{l}4.23 \text { Team management } \\
\text { develops centralized goals and } \\
\text { direction for the school district, } \\
\text { and decentralized autonomy for } \\
\text { team members. }\end{array}$ & $x$ & $x$ & $x$ & - & $\bullet$ & - \\
\hline $\begin{array}{l}5.1 \text { The responsibilities of the } \\
\text { management team include } \\
\text { policy and regulation develop- } \\
\text { ment. }\end{array}$ & & $x$ & $x$ & & • & - \\
\hline
\end{tabular}

5.2 Management team members are involved in:
a) developing
b) recommending
c) implementing
d) monitoring

policies and administrative regulations.

\subsection{The management team} af fects the quality of policies and regulations.

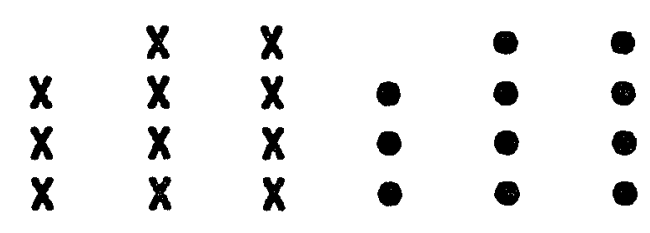


TABLE IV (CONTINUED)

\begin{tabular}{|c|c|c|c|c|c|c|}
\hline $\begin{array}{l}\text { A review of related literature } \\
\text { identifies the following char- } \\
\text { acteristics or elements as being } \\
\text { found in management teams. }\end{array}$ & $\begin{array}{l}\text { Whi } \\
\text { are } \\
\text { of } y \\
\text { mar } \\
\text { teal }\end{array}$ & $\begin{array}{l}\text { of } \\
\text { ond } \\
\text { ur di } \\
\text { geme } \\
\text { ? }\end{array}$ & $\begin{array}{l}\text { se } \\
\text { part } \\
\text { rict's }\end{array}$ & $\begin{array}{l}\text { Whi } \\
\text { esse } \\
\text { dist } \\
\text { men } \\
\text { "suc }\end{array}$ & of & $\begin{array}{l}\text { se are } \\
\text { your } \\
\text { anage- } \\
\text { eing } \\
\text { " }\end{array}$ \\
\hline $\begin{array}{l}X=67 \% \text { or more of respondents }= \\
E P=\text { Eagle Point School Dist. } 9 \\
L C=\text { Lincoln County School Dist. } \\
L O=\text { Lake Oswego School Dist. } 7 \mathrm{~J}\end{array}$ & EP & LC & LO & EP & LC & LO \\
\hline $\begin{array}{l}5.4 \text { Management team members } \\
\text { support team developed policies } \\
\text { and plans. }\end{array}$ & $x$ & $x$ & $x$ & $\bullet$ & - & - \\
\hline $\begin{array}{l}5.5 \text { The impact of policy } \\
\text { recommendations is communicated } \\
\text { by the management team to the } \\
\text { School Board. } \\
\text { The Superintendent. }\end{array}$ & $x$ & $x$ & $x$ & & - & 0 \\
\hline Totals & 36 & 38 & 42 & 24 & 49 & 44 \\
\hline
\end{tabular}

How Are Management Team Members Involved in Developing. Recommending. Implementing, and Monitoring School District Policies and Administrative Regulations?

Management team members in all three school districts feel positively about their involvement in the policy and regulation processes. The following statements represent a summary of the evidence about management team involvement in activities related to policy and regulation processes: 
- Management team members make policy and regulation recommendations.

- The management team is asked for input or reaction to policies and regulations prior to being presented to the school board.

- The quality of the policies and regulations is improved through management team input.

- The superintendent is receptive to input from the management team concerning the impact of policies and regulations on the operation of the schools.

- Management team members do not develop policies and regulations; this is done at the district of fice level.

- Management team members support policies and regulations which they helped to establish.

- Management team members implement policies and regulations.

- Management team members monitor policies and regulations.

What Are the Most Important Characteristics or Elements Found as Part of Successful Management Teams Which Are Essential to the School District's Management Team Being "Successful"?

The Management Team Survey asked the respondents to identify the ten most important characteristics or elements which made their team "successful." The researcher chose to report those items which were listed by at least a majority of the responding team members. The following list represents an unranked summary of those common characteristics or elements found to be most important by all three of the management teams: 
- Centralized goals and direction for the district

- Shared decision-making leading to quality, supported decisions

- Input into problem-solving and policy and regulation processes

- Good communications with team members and team units

- Trust between and among team members

- Support from and for other team members and the team as a whole In addition, the following list represents an unranked summary of those common characteristics or elements found to be most important by two out of three of the management teams:

- Shared values and a sense of team belonging and collaboration

- Shared success for the achievements of the management team Through additional observations, documents and interviews, the researcher identified several other characteristics or elements that appear to be essential to the success of these management teams. The superintendent is instrumental in whether or not management teams are successful. The following characteristics or elements appear to the researcher to be in place, to a substantial degree, in all three of the school districts studied:

- The superintendent understood the team management concept.

- The superintendent was committed to team management and clearly communicated that to the management team and school board; regularly.

- The superintendent established an organizational framework which encouraged and supported team management, given the unique needs and resources of the school district.

- The superintendent modeled the team management behaviors that he espoused. 
-The superintendent led the district using tight-loose principles: a careful balance between shared, centralized values, goals, and direction for the district; and decentralized; autonomous leadership and management at the school level.

-The superintendent had effectively implemented school-based management concepts, and intended to continue to move in that direction. 


\section{CHAPTER V}

\section{CONCLUSIONS AND RECOMMENDATIONS}

\section{A Study of Successful Management Teams in Oregon Public School}

Systems was conducted to accomplish three purposes. The first purpose was to identify and describe the current status of successful management teams in three Oregon public school systems. Intensive, on-site visitations of three successful management teams in Oregon were conducted, as described in Chapter III, during February and March 1988. Multiple sources of evidence were gathered in response to the following study questions:

1. Why was the team management concept implemented?

2. How has the management team evolved?

3. How is the management team organized?

4. How does the management team operate?

5. How are management team members involved in developing, recommending, implementing, and monitoring school district policies and administrative regulations?

6. What are the most important characteristics or elements found as part of successful management teams which are essential to the school district's management team being "successful"?

The study questions were used as the format for describing the status of successful management teams in Eagle Point School District 9, Lincoln County School District, and Lake Oswego School District 7J. Comprehensive 
case study descriptions were presented in Chapter IV. Additionally, a cross-case analysis was presented, summarizing the commonalities discovered among the three successful management teams. The case study descriptions and cross-case analysis, therefore, accomplished the first purpose of this study.

The second purpose was to add to the existing body of knowledge and research about management teams in educational administration; and the third purpose was to provide useful information for practicing administrators of school systems, who are currently operating management teams, or who are interested in doing so. The conclusions and recommendations presented in this chapter address these two stated purposes.

\section{CONCLUSIONS}

Propositions were derived from the review of related literature in order to develop the research expectations of this study. The conclusions of the study are presented using those propositions as the framework for discussion:

Proposition 1. Successful management teams implemented the team management concept because it was the preferred method of educational leadership which allowed greater participation by administrators, and resulted in improved decision making.

Proposition 2. Successful management teams have evolved since their original implementation, until they presently represent the unique management needs and resources of the school system. 
Proposition 3. Successful management teams are made up of a group of school district administrators consisting of the superintendent and (or representatives of) central staff, principals, and ancillary personnel having supervisory positions; and are structured to allow the maximum, efficient input and participation by that group.

Proposition 4. Successful management teams involve administrators in developing, recommending, implementing, and monitoring school district policies and administrative regulations.

Proposition 5. Successful management teams have in common certain characteristics or elements which are essential to the management teams being "successful."

Additionally, recommendations are provided for the application of these conclusions by practicing administrators. Suggestions for further research are also presented for consideration.

\section{Proposition 1. Successful Management Teams Implemented the Team} Management Concept Because it Was the Preferred Method of Educational Leadership Which Allowed Greater Participation by Administrators, and Resulted in Improved Decision Making

During the formative years for team management in education, it was commonly understood by superintendents and school boards that establishing management teams would have the practical effect of lessening the need for administrators to form collective bargaining units. The literature of the time validates this notion. After fifteen years of team management history, however, management team members no longer associate the two. There were other, more direct, reasons for the 
establishment of management teams in educational administration. Two prominent reasons for their establishment surfaced in this study:

- The need and desire to allow administrators to have input into the decision-making process.

- The need and desire for support from administrators for the superintendent and other district administrators.

Team management practices continue to be the preferred methods of educational leadership. Superintendents are reshaping their organizational structures to allow for decentralization of operations, and greater participation in school district decision-making by their administrators.

\section{Proposition 2. Successful Management Teams Have Evolved Since Their} Original Implementation. Until They Presently Represent the Unique Management Needs and Resources of the School System

Successful management teams evaluate their performance, and strive for improvement. This study identified the following actions taken by each of the three superintendents in an effort to improve his management team:

- The organizational structure of the district was modified to better utilize existing administrative personnel, and to provide systematic opportunities for input and involvement by the administrators.

- Roles and relationships among management team members were modified and clarified.

- School-based management was encouraged and supported.

These activities reflect the process of evolution taking place in organizations today. Because of the unique needs and resources of each individual school system, management teams must be designed to be responsive to that uniqueness. Many management team models exist. The 
case study descriptions presented in Chapter IV illustrate three distinct, successful approaches to team management. The approach that is right for a given school district is the one that best achieves the purposes of that particular management team. Essential to the continuing success of a management team is the willingness and ability of its team members to adjust to change.

Proposition 3. Successful Management Teams Are Made Up of a Group of School District Administrators Consisting of the Superintendent and (or Representatives of) Central Staff. Principals, and Ancillary Personnel Having Supervisory Positions, and Are Structured to Allow the Maximum. Efficient Input and Participation by That Group

From the review of related literature, the researcher established the following definition of "management team" for purposes of this study: A group of school district administrators consisting of the superintendent and (or representatives uf) central staff, principals, and ancillary personnel having supervisory positions, who as a group, develop, recommend, implement, and monitor school district policies and administrative regulations, and who participate in the decision-making processes of the district. The membership of the three management teams studied matched this definition. The configuration of each sub-unit was described in the case studies. All three management teams had the following structural traits in common:

- A single management team unit did not exist; the management team was made up of a variety of sub-units, representing all segments of administration. 
The successful management teams analyzed the organizational and geographic considerations of their districts and established a management team which addressed the uniqueness of the districts. For example, the Mini-Teams in Eagle Point School District are responsive to the variety of grade level configurations that exist in that district. The weekly telephone conference call, involving the directors of elementary and secondary education and geographic area coordinators (principals) in Lincoln County School District, is responsive to the geographic distribution of schools over 1,100 square miles.

- The superintendent met with the entire management team (all administrators), as well as with various sub-units of the management team. In both Eagle Point and Lake Oswego School Districts, the superintendents chose to meet with the entire management team and also with a variety of sub-units. This is multiple model management team described in Chapter II. The superintendent of Eagle Point School District was able to meet with all sub-units of the management team because of the manageable size of the district. In Lake Oswego School District, the superintendent participated in all sub-unit meetings except the Elementary and Secondary Meetings.

The superintendent of Lincoln County School District chose to meet only with the directors at the Superintendent's Meeting in addition to the All Administrator Meeting. He used the dual model management team.

In small school districts it would be possible to meet solely with the entire management team, utilizing the single model When the number of management team members becomes too great, as in large urban school districts, the divisional model management team may be utilized. The 
superintendent may only meet with representative sub-units, never actually participating with the management team as a whole.

- The various sub-units were linked together for communications purposes by link-pin administrators.

Regardless of the model used, certain administrators were responsible to insure that representation of other administrators and communication with all administrators was guaranteed. In Lincoln County School District, the directors provided this function between the superintendent and the principals. The area coordinator principals were also responsible to represent the other principals in their areas and to communicate with them. The same was true for the link-pin relationship of the directors of elementary and secondary education in Lake Oswego School District. in the Eagle Point School District, the superintendent served as the link-pin between all the sub-units and the management team.

The following characteristics, which have been illustrated in the case studies, were apparent at management team and sub-unit meetings in each district and provide an insight into the way successful management teams operate:

- The opportunity for socialization among administrators occurred at each meeting.

- Input and responses were sought from administrators by the superintendent and district level administrators.

- Uninhibited discussion among all administrators was encouraged, and, in fact, took place.

- Professional growth sessions for administrators were a planned part of the management team activities. 
- Sharing of information among administrators took place both formally and informally.

- Agenda items were contributed at meetings by administrators from all segments of the organization.

- Efforts were made to reach agreement through consensus whenever possible.

These observations alerted the researcher to the need to clarify the terms "management team" and "team management." A management team is not just one group of administrators who meet regularly to conduct the business of the school system. Rather, a variety of groups of administrators engage, on an on-going basis, in the process of team management of the school system. Management teams in districts with only a few administrators may meet as a single unit, but it is still the process of input and participation described above which makes a group a "management team." Observations of this process lead the researcher to favor the term "cooperative leadership" to describe the process taking place in school systems with successful management teams. Administrators are actively involved in more than participatory management; successful management teams are immersed in the process of "cooperative leadership."

Proposition 4. Successful Management Teams Involve Administrators in Developing, Recommending, Implementing, and Monitoring School District Policies and Administrative Requlations

The role of management team members in various aspects of the policy and regulation processes is considered to be an important element of team management. The evidence from the study of the three successful management teams clearly indicates that administrators take an active role 
in these processes, and feel it is essential for them to do so. Based upon the Management Team Survey results and interviews, the researcher concludes:

- Management team members make policy and regulation recommendations.

- The management team is asked for input or reaction to policies and regulations prior to being presented to the school board.

- The quality of the policies and regulations is improved through management team input.

- The superintendent is receptive to input from the management team concerning the impact of policies and regulations on the operation of the schools.

- Management team members do not necessarily develop policies and regulations; this is usually done at the district of fice level.

- Management team members support policies and regulations which they helped to establish.

- Management team members implement policies and regulations.

- Management team members monitor policies and regulations.

\section{Proposition 5. Successful Management Teams Have in Common Certain} Characteristics or Elements Which Are Essential to the Management Teams Being "Successful"

There are many characteristics or elements which contribute to the success of management teams. Some of them are essential to the successfulness of the management teams, however. In the cross-case analysis in Chapter IV, the results of the Management Team Surveys from the three successful management teams were compared. Forty-four 
characteristics or elements were identified as being essential to the success of management teams. This researcher sorted the forty-four items into five categories (concepts) which represent a synthesis of the content of those items. The presence of these five concepts in management teams appears to be essential to their successfulness. The degree to which they need to be present remains undetermined, but administrators from the three successful management teams concur, overwhelmingly, that the elements, from which the five concepts are derived, are essential to their management teams being successful.

- Successful management teams establish and support common goals and direction for the school system.

The respondents lo the Management Team Survey indicated that development of centralized goals and direction for the school district, and decentralized autonomy for team members is an important function of the management team. Doing so allows the management team members to gain and share a perspective of the school system as a whole and makes them feel like a more important part of the enterprise for which they work. By contributing to the shared values, purpose, and direction of the school district through team management, a greater sense of community is created. When this is accomplished, the superintendent feels tied to the success of the management team, and the management team members feel tied to the success of the superintendent.

- Successful management teams involve all team members in shared decision-making. 
Surveyed team members indicated that when administrators participate as part of a management team in decisions that affect their work, they feel more supportive and accountable for the decisions that are made. Management team members should be involved in decision-making and problem-solving in program evaluations, employee matters, the policy and administrative regulation processes, and any other activities that affect their realms of responsibility.

- Successful management teams foster teamwork and team spirit.

Results of the Management Team Survey affirm that through collaboration with other administrators on the management team, a sense of team belonging is developed. Team management fosters success and job satisfaction. The special strengths of team members should be utilized for the benefit of the whole team, contributing to better morale and motivation. When these things occur, the level of trust and security is improved among all the members of the management team.

- Successful management teams involve all team members in the policy and administrative regulation activities of the school system.

According to the survey results, team members should be allowed input into the development of district policies and administrative regulations, especially in communicating their impact to the superintendent, and they should be strongly involved in recommending, implementing and monitoring them. The actual development of policies and regulations may occur at the district of fice level, however. Participation in these processes can affect the quality of the policies and regulations by taking into account the knowledge and experience of those who must apply 
them. When team members are involved in the policy and regulation processes, they tend to be more supportive of the outcomes.

- Successful management teams are designed, organized, and operated in response to the unique requirements of the organization.

Management team members responding to the survey said that the purpose of any successful management team should be clearly defined. The team's authority should be acknowledged and specified by the superintendent and the roles and responsibilities of management team members should be clearly identified. Definite rules and procedures need to be followed by the management team. It is important for the management team to have a ciearly understood, stable organizational structure, with all sub-units well represented and linked together. Doing so will improve communications, if openess and accuracy are sought, and an effective system of communications exists between and among all levels of administrators and the school board. In order to accomplish these objectives, sufficient time must be allowed for management team activities.

The degree and extent to which these essential concepts exist whithin a management team will determine how successful team management is in a school system. By synthesizing the responses of the three management teams to item 6.0 on the Management Team Survey, the researcher identified those characteristics or elements which are most important to the success of management teams. These characteristics or elements must exist for management teams to be successful. 
- The management team must participate in the establishment of centralized goals and direction for the district, and must support efforts to accomplish them.

A prime example of this kind of activity was found in the Lake Oswego School District where the superintendent had developed a three year organizational development plan which involved the management team in making the transition from management to leadership. The mutually established goal for the schools was to develop and employ participatory processes and a school based change model as approaches to improving school-wide performance.

- Management team members must participate in shared decisionmaking leading to quality, supported decisions.

The Eagle Point School District Management Team members particpated in shared decision-making which illustrates this conclusion. At a meeting of the Extended Team, which includes all administrators, the superintendent asked for input about whether or not to cont inue to hold Personal Renewal Day. The issue was vigorously discussed, with seven of the fourteen attending members participating. Consensus was reached even without the superintendent who had to leave the meeting early. At the Regular Team Meeting, when Personal Renewal Day was an agenda item, the decision was easily made. The management team members had discussed it, asked for input from their staffs, and decided not to continue the Personal Renewal Day.

- Management team members must have input into problem-solving and policy and regulation processes. 
In Lincoln County School District, the school board was in the process of a systematic review of policies. At a Superintendent's Meeting, several personnel policies were presented by the Personnel Director for review by the other directors. Although this was a sub-unit of the management team, the full management team was given an opportunity for input by the directors in one of the All Administrator Meetings prior to adoption by the school board.

- Management team processes must provide good communications among team members and team units.

In all three successful management teams, link-pin administrators assured that communications occured between units. Additionally, each individual administrator was asked if he or she had anything to discuss at meetings of the whole team and at sub-unit meetings. A free flow of dialogue among the team members was always encouraged by the meeting leaders.

- Management team members must develop and demonstrate a high level of trust between and among team members.

"Trust" between and among team members was a response that appeared on the list of most important characteristics or elements from all three management teams. Efforts to increase school-based autonomy and asking for input into problem-solving situations are examples of the demonstration of trust among team members.

- Management team members must be supportive of each other and the team as a whole. 
At the Regular Team Meeting of the Eagle Point School District, a professional growth activity for administrators was presented on "peer coaching." All team members, including the superintendent, participated in the training. Later in the meeting principals gave unsolicited testimonials about their experiences with peer coaching since the last training session. While this might appear trivial, it demonstrated how comfortable and supportive the administrators felt among other management team members.

- Management team members must foster a sense of shared values, team belonging, and collaboration.

The Lincoln County School District retreat for all administrators is illustrative of the kind of opportunities that encourage team members to develop shared values and team belonging. Challenging situations, requiring collaboration, were presented in a conscious effort by the superintendent to provide team building activities.

- Management team members must experience shared success for the achievements of the management team.

The superintendent of Lincoln County School District shared a journal article with his directors at a Superintendent's Meeting. The article was about the new method of administrative evaluation that was being used in their school district. The evaluation procedures and processes had been developed by the management team, with the role of the directors being very important. The superintendent pointed out that he had received over 160 requests for their administrative evaluation document from all across the country. The directors were visibly pleased by the sharing of this success. 
The superintendent is also instrumental in whether or not management teams are successful. The following characteristics or elements appear to the researcher to be very important in providing an atmosphere conducive to successful team management practices.

- The superintendent must understand the team management concept.

- The superintendent must be committed to team management practices and clearly communicate that to the management team and school board; regularly.

- The superintendent must establish an organizational framework which encourages and supports team management, given the unique needs and resources of the school district.

- The superintendent must model the team management behaviors that he/she espouses.

Two additiional conditions were identif ied by the researcher that appear to be directly related to the success of the management teams in each of the three school districts studied. These same two conditions appear to be only indirectly related to the traditional concepts of team management. Both conditions are more representative of current trends in organizational restructuring which originated in the private sector, and are now being applied in public school systems. While these two conditions may not be critical to the success of management teams, their impact on the success of the three management teams studied is too important to disregard.

-The superintendent led the district using tight-loose principles: a careful balance between shared, centralized values, goals, and direction for 
the district; and decentralized, autonomous leadership and management at the school level.

-The superintendent had effectively implemented school-based management concepts, and intended to continue to move in that direction.

\section{Recommendations}

\section{Adolication of the Conclusions by Practitioners}

Practicing administrators must be careful not to over-generalize the conclusions presented in this study. Case studies, such as the three successful management teams, are not based upon a sampling of all similar populations. Instead, an in-depth investigation of an existing phenomenon, such as successful management teams, is conducted within the natural context of its occurence. The results are descriptive; sometimes explanatory, answering "how" and "why" questions. In this study, the researcher attempted to strike a careful balance between evidence and Insight in developing the conclusions. The usefulness of this study to the practicing administrator is in the establishment of a set of descriptive guidelines for successful management teams, against which team management processes and practices can be compared.

Team management is a process; not a product or event. It requires cooperative leadership on the part of all the management team members. It begins with the superintendent, whose leadership determines what kind of environment exists for team management to take place. The conclusions of this study cannot just be installed in a school system to create a successful management team. Superintendents wishing to improve existing management teams, or to establish them, should consider the following 
recommendations for developing successful management teams. The superintendent should:

- Understand what team management is, and is not; and how successful management teams function.

- Assess the school board's and administrators' level of understanding about team management; and their level of interest in applying team management practices.

- Evaluate his/her own commitment to improving or establishing cooperative leadership processes and practices in the school district.

Team management cannot be imposed on administrators. They must understaild the concept and desire to participate. Likewise, the superintendent must be committed to having a successful management team. The school board should also accept the management team concept as a policy of the school district. If these commitments are not present, it is questionable whether team management can be carried out successfully.

- Communicate to the school board and administrators his/her decision to develop a successful management team in the school district.

- Provide information and training for the school board and all management team members to increase the level of understanding about team management, as well as their level of commitment to having a successful management team.

Both an informed understanding and a commitment on the part of the school board and management team members need to be present prior to actually taking steps to improve or establish the management team. A common basis of knowledge and interest is important if cooperative 
leadership is going to take place in the establishment of processes and practices that are conducive to successful team management.

- Clarify and modify roles and relationships among management team members, taking into consideration their input and recommendations.

- Modify the organizational structure of the district to better utilize existing administrative personnel, if necessary and possible.

- Develop, in cooperation with the management team, linked subunits, representing all segments of administration, which allow for systematic input and participation by all administrators.

- Communicate to the management team what his/her leadership role will be as part of the management team; with which sub-units he/she will meet in addition to the entire management team.

Each management team reflects the uniqueness of the school system it serves. The organizational structure of the management team will allow successful team management to occur if it is developed taking into consideration the special organizational needs and resources of the district.

- Establish a management team meeting format and atmosphere which encourages the kind of participation described under Proposition 3.

- Model the cooperative leadership behaviors that he/she feels are essential to successful team management.

Team management begins with the commitment and efforts of the superintendent, but only becomes successful when cooperative leadership on the part of all management team members occurs. Once the philosophical and organizational considerations have been resolved through the leadership of the superintendent, then the process considerations must be addressed by the entire management team. Management team members wishing to 
improve existing management teams, or establish successful management teams should consider the following recommendations. The management team should:

- Develop a management team purpose statement which clearly delineates the roles and responsibilities of its members, and the team as a whole.

- Develop management team tenets or rules and procedures to be followed by the management team.

- Assess the management team's current status in comparison with the eight characteristics or elements, listed under Proposition 5 (p. 113-115), that must exist for management teams to be successful.

- Develop and implement processes, procedures, and activities which improve the management team's performance in these eight areas.

- Assess the management team's improved status in comparison with the complete list of characteristics or elements, using the Management Team Profile found in Appendix $G$.

- Develop and implement processes, procedures, and activities which improve the management team's performance with regard to the forty-four items of the Management Team Profile.

These recommendations rely heavily on the ef forts of management team members to develop successful management teams, just as the cooperative leadership process itself requires a high degree of commitment and effort on the part of management team members if it is to be successful. Those management teams which carry out these recommendations should experience improved team management and the eventual development of a "successful" management team. 
Implications for Research

This study's contribution to the existing body of knowledge about management teams was the identification of characteristics, elements, and conditions that are essential to management teams being successful. Recommendations for the application of the study's conciusions by practicing administrators were suggesed by the researcher. Additional studies to determine if the application of the recommendations actually develops successful management teams would enhance the body of knowledge regarding team management.

During the process of identifying successful management teams for purposes of this study, Oregon's four largest school systems received little recognition. The researcher is aware of attempts in those districts to employ team management techniques. Research describing the current status of management teams in those districts might disclose interesting similarities or differences, especially when compared with the results of this study. The researcher speculates that because of the size of those districts, administrators do not have a sense of team belonging found in smaller school districts.

Replication of this study with districts whose management teams have not been successful would provide an interesting comparison of the characteristics, elements, or conditions that exist. Case study research would also of fer an understanding of the culture of the organization that allows insights into the reasons for it being successful or unsuccessful.

As a spin-off of this study, it was discovered that those school systems identified as having successful management teams also shared two organizational commonaities. All three school districts were 
123

implementing tight-loose coupling strategies, and were moving into more school-based management practices. Study of these organizational trends in public schools might produce interesting, and useful, findings. 


\section{BIBLIOGRAPHY}

American Association of School Administrators (1979). The administrative leadershio team. Virginia: AASA.

Boles, H. W. (1976). An administrative team? Journal of Educational Administration, 13(2), 73-80.

Brooks, M. (1978). Management team builds trust between board, superintendent. Thrust for Educational Leadership, 8(2), 10-11.

Brooks, V. M. (1980). An analysis of the administrative team process in public school districts in Colorado (Doctoral dissertation, University of Northern Colorado, 1980). University Microfilms International, 8028318

Buckeye Association of School Administrators (1978). The management team: A recommended approach for operating Ohio's public schools. Ohio: Author.

Cross, R. (1974). The administrative team or decentralization? National Elelmentary Principal, 54(2), 80-82.

Danley, W. E. (1979). Requirements for an effective administrative team. National Association of Secondary School Principals Bulletin. 63(427), 29-32.

Duncan, R. C. (1978). New wines in new bottles: The administrative team revisited. Planning and Changing $\mathbf{Z}(2), 35-44$.

Erickson, K. E., \& Rose, R. L. (1973). Management teams in educational administration: Ideal? Practical? Both? Oregon School Study Council Bulletin 17(4).

Erickson, K. A., \& Gmelch, W. H. (1977). School Management Teams: Their Structure, Function, and Operation. Virginia: Educational Research Services. 
Floratos, N., Murchison, W. R., Baumgartner, J., Long, J., Guest, B., \& Walker, D. (1978). The management team and survival. Ihrust for Educational Leadership, $\underline{8}(2), 5-8$.

Geisert, G. (1982, September). A response to Hogan: Merlin Misunderstood! Educational Leadershid pp. 26-29.

Goetz, J. P., \& LeCompte, M. D. (1984). Ethnography and qualitative design in educational research. Florida: Academic Press.

Grindle, B.W. (1982, September). Administrative team management: Four essential components. The Clearing House, 56, 29-32.

Heddinger, F. M. (1978). Do your school principals have enough decisionmaking power? In Pennsylvania, they do. American School Board Journal, 165(2), 30-32.

Hogan, K. M. (1982, September). Camelot for educational administration. Educational Leadership, pp. 26-29.

Lynch, E. (1978). Trust and conf idence - essentials to the management team. Thrust for Educational Leadership $\underline{8}(2), 9-10$.

McNally, H. J. (1973). A matter of trust: The administrative team. National Elementary Principal, 53(1), 20-25.

McGinley, D. J., \& Rafferty, B. F. (1973). Its working in Philadelphia: The administrative team. National Elementary Principal, $\underline{53}(1), 25-28$.

National Association of Secondary School Principals (1971). Management crisis: A solution. Washington: NASSP.

Ohio School Boards Association (1982, April). Astrategy for implementing the school management team. Ohio: OSBA.

Roberts, L. E. (1978, April). The principal as a key member of the management team. Paper presented at the annual meeting of the National School Boards Association.

Salmon, P. B. (1977, June). The administrative team: It's a step forward for schools. The American School Board Journal pp. 24-27. 
Salmon, P. B. (1977, June). The educational impact statement: Glue for the administrative team. The School Administrator, 34, 19

Schmuck, R. A. (1974). Development of management teamwork. Oregon School Study Council Bulletin, 18(2).

Swift, J. E. (1971). The origins of team management. National Elementary Principal, 50(4), 26-35.

Weick, K. E. (1982, June). Administering education in loosely coupled schools. Phi Delta Kappan, pp. 673-676.

Weick, K. E. (1976, March). Educational organizations as loosely coupled systems. Administrative Science Quarterly, pp. 1-19.

Wynn, R. (1973). Theory and practice of the administrative team. Washington: National Association of Elementary School Principals.

Yin, R. K. (1984). Case study research: Design and methods. California: Sage. 
APPENDIX A

CONTENT ANALYSIS OF CHAPTERS I \& II

POTENTIAL SOURCES OF EVIDENCE

IN CASE STUDIES 


\section{APPENDIX A}

CONTENT ANALYSIS OF CHAPTERS I \& II: POTENTIAL SOURCES OF EVIDENCE

IN CASE STUDIES

\section{STUDY QUESTION 1: WHY WAS THE TEAM \\ MANAGEMENT CONCEPT IMPLEMENTED?}

Proposition 1: Successful management teams implemented the team management concept because it was the preferred method of educational leadership which allowed greater participation by administrators, and resulted in improved decision making.

$D=$ Documents

I=Interviews

$A=$ Archival records

$0=$ Direct observation

QUESTIONS

SOURCE

D A

p. 2

$x \quad x \quad x$

1.1 Why was a management team

established in the school district?

1.2 Was the management team established in the school district to prevent collective bargaining by pp. 2-3, $x \quad x \quad X$ administrators?

$14,20,28$,

29

1.3 Is there an organized unit for

p. 1

$x \quad x \quad x$
administrative collective bargaining?

1.4 How are management team members involved in the collective pp. $16,21 \times \times \times$ bargaining with other bargaining groups?

1.5 What was middle management's

p. 18 $x \quad x \quad x$ role in establishing the management team?

The Superintendent's?

The School Board's? 
QUESTIONS

1.6 How does team management in the school district provide for participation by administrators in decisions affecting their work?
SOURCE

pp. $4,14, \quad X$

$15,28,29$,

31

p. 17

$x \quad x$ the quality of decisions made by the management team compared to decisions made by individual administrators?

1.8 Do administrators feel more accountable for decisions made by

pp. 18,20

$x \quad x$ the management team?

More supportive?

More successful?

1.9 How does the management team approach allow administrators to gain and share a perspective of the school system as a whole?

1.10 How does involvement as a management team member make the members feel like a more important part of the enterprise for which they work?

p. $17 x \quad x \quad x$ 
STUDY QUESTION 2: HOW HAS THE "SUCCESSFUL" MANAGEMENT TEAMEVOLVED?

Proposition 2: Successful management teams have evolved since their original implementation, until they presently represent the unique management needs and resources of the school system.

D=Documents

I=Interviews

$A=$ Archival records

$0=$ Direct observation

QUESTIONS

SOURCE

$\begin{array}{llll}D & A & 1 & 0\end{array}$

2.1 How long has a management

p. 1

$x \quad x \quad x$

team existed in the school district?

2.2 How successful has the manage-

p. 10

$x \quad x$

ment team been?

2.3 When was the management team

last modified?

2.4 How was it modified?

p. 1

p. 1

$x \quad x \quad x$

2.5 Was there resistance to the

p. 31

$x \quad x \quad x$ modifications?

2.6 How is the management team working now?

2.7 Is there currently resistance to the modifications?

p. 10

$x \quad x$

2.8 What future modifications or evolution is forseen?

p. 31

$x \quad x$

p. 11

$x$ 
STUDY QUESTION 3: HOW IS THE "SUCCESSFUL" MANAGEMENT TEAM ORGANIZED?

Proposition 3: Successful management teams are made up of a group of school district administrators consisting of the superintendent and (or representatives of) central staff, principals, and ancillary personnel having supervisory positions; and are structured to allow the maximum, efficient input and participation by that group.

$D=$ Documents

$A=$ Archival records
I=Interviews

$0=$ Direct observation

QUESTIONS

SOURCE

pp. $3,23, \quad x$

$24,25,27$

structured?

3.2 How are the various sub-units represented on the management team?

pp. 4, 23, X $x \quad x$

24,25 ,

27,30

3.3 What are the names of the management team components?

pp. $3,4,23, x$

$24,25,27$

3.4 How are the various management team units linked together?

pp. $3,4,23, x$

$24,25,27$

3.5 Who is on the management team? Who is not?

pp. $5,6,21, x$

$23,25,27$

3.6 How is the purpose of the management team def ined?

pp. 5, 6, 7, $x \quad x \quad x$ $14,15,30$, 32

3.7 How is the authority of the management team acknowledged and specified by: the School Board? the Superintendent?

pp. 5, 6, 7, 21,31

$$
\begin{array}{lll}
x & x & x \\
x & x & x
\end{array}
$$


QUESTIONS

3.8 How stable is the management team?

3.9 How are the roles and responsibilities of management team members defined?

3.10 What is the purpose of the management team?

Is it clearly def ined?

3.11 How is the team protected and rewarded regarding its decisions and recommendations?

3.12 How are the special strengths of team members utilized?

$\begin{array}{lllll}\text { SOURCE } & D & A & 1 & 0\end{array}$

pp. 20, 21, 30

pp. $3,30 \times x \quad x$

pp. 5, 27, $\times \quad \times \quad \times$ 30

pp. 7, 18, X $\times \quad \times$

19

p. 16

$x$

$x \quad x$ 


\section{STUDY QUESTION 4: HOW DOES THE "SUCCESSFUL" MANAGEMENT TEAMOPERATE?}

Proposition 3: Successful management teams are made up of a group of school district administrators consisting of the superintendent and (or representatives of ) central staff, principals, and ancillary personnel having supervisory positions; and are structured to allow the maximum, efficient input and participation by that group.

\begin{tabular}{ll}
\hline$D=$ Documents & $1=$ Interviews \\
$A=A$ Cchival records & $0=$ Direct observation
\end{tabular}

\begin{tabular}{llllll}
\hline QUESTIONS & SOURCE & D & A & 1 & 0
\end{tabular}

4.1 How is the management team led?

4.2 When do management team activities take place?

4.3 How is sufficient time for management team activities provided?

4.4 What rules, procedures does the management team follow?

4.5 What activities and issues are handled by the management team?

4.6 How are management team members involved in decision making?

4.7 For what is the management team held accountable?

pp. $3,5,7, X \quad X \quad X$

$18,28,31$

pp. $3,20, \quad X$

$x \quad x$

21,31

pp. $3,18, \quad X$

$x \quad x$

$20,21,30$

pp. $3,22 \quad x$

$x \quad x$

pp. 3, 7,

10,17

pp. 3, 4, $X \quad X \quad X$

$10,14,15$,

$16,17,26$,

$27,29,30$,

31

pp. 6, $16 \times x \times$ 
QUESTIONS

4.8 How are management team members involved in district program evaluation?

4.9 What is the Superintendent's role on the management team?

4.10 Do management team members have adequate input in employment, promotion, and dismissal decisions of school district employes?

4.11 How does team management contribute to morale? Motivation? Collaboration?

4.12 is there a greater sense of community as a result of team management?

How?

Why?

4.13 How is the level of trust and security improved through team management?

4.14 How tied to the success of the Superintendent do management team members feel? Vice versa?

4.15 Does the School Board support and appreciate the management team? Vice versa?

4.16 How does team management contribute to shared values, purpose, 31

direction? Team belonging? $\begin{array}{lllll}\text { SOURCE } & \text { A } & \text { A } & 0\end{array}$

pp. $7,10 \times x \times x$

pp. $16,26 x$

$x \quad x$

p. 21

$x \quad x \quad x$

pp.7, 17

$x \quad x$

p. 19

$x \quad x$

pp. 20, 22,

$x \quad x$

27

p. 21

$x \quad x$

p. 21

$x \quad x$

pp. 23,28 ,

$x \quad x$ 


\begin{tabular}{llllll}
\hline QUESTIONS & SOURCE & D & A & 1 & 0
\end{tabular}

4.17 How does team management improve communications? Quality of information?

pp. 16,20

$x \quad x$

4.18 Does an effective communications system exist between and

p. 21

$x$

$x \quad x$ among all levels of administrators, and the School Board?

4.19 How are interpersonal relations problems and conflicts resolved?

4.20 How are open and accurate communications provided for?

4.21 How formal/informal is the culture of the management team?

4.22 How does the management team foster success? Job satisfaction?

4.23 How does team management develop centralized goals and direction for the school district?

p. 31

$x \quad x$

Decentralized autonomy for team

p. 5

$x$

$x \quad x$

p. 11

$x \quad x$

members?

pp. 22,23 , $27,28,29$, 30 
STUDY QUESTION 5: HOW ARE TEAM MEMBERS OF "SUCCESSFUL" MANAGEMENT TEAMS INVOLVED IN DEVELOPING, RECOMMENDING, IMPLEMENTING, AND MONITORING SCHOOL DISTRICT POLICIES AND ADMINISTRATIVE REGULATIONS?

Proposition 4: Successful management teams involve administrators in developing, recommending, implementing, and monitoring school district policies and administrative regulations.

\begin{tabular}{ll}
\hline$D=$ Documents & I=Interviews \\
$A=$ Archival records & $0=$ Direct observation
\end{tabular}

\begin{tabular}{lllllll}
\hline QUESTIONS & SOURCE & D & A & I & 0 \\
\hline 5.1 Do the responsibilities of the & pp. 6,9, & $\times$ & $\times$ & $\times$ & $\times$ \\
management team include & 10,13, & & & & \\
policy and regulation develop- & 19,26 & & & & \\
ment? & & & & &
\end{tabular}

5.2 How are management team

pp. 7, 10, members involved in:
a) developing
b) recommending
c) Implementing
d) monitoring

policies and administrative

regulations

5.3 How does the management team af fect the quality of policies and $19,22,26$ regulations?

5.4 Do management team members support team developed policies and plans?

pp. 20,26

$x \quad x$

$\begin{array}{llll}x & & x & x \\ x & x & x & x \\ x & & x & \\ x & & x & x\end{array}$




\begin{tabular}{|c|c|c|c|c|c|}
\hline QUESTIONS & SOURCE & $D$ & A & 1 & 0 \\
\hline $\begin{array}{l}5.5 \text { How is the impact of policy } \\
\text { recommendations communicated } \\
\text { by the management team to the } \\
\text { school board? }\end{array}$ & $\begin{array}{l}\text { pp. } 8,9 \text {, } \\
21\end{array}$ & $x$ & $x$ & $x$ & $x$ \\
\hline $\begin{array}{l}5.6 \text { How are impact statements } \\
\text { used by the Superintendent? }\end{array}$ & pp. 8,9 & $x$ & $x$ & $x$ & $x$ \\
\hline
\end{tabular}


STUDY QUESTION 6: WHAT ARE THE MOST IMPORTANT CHARACTERISTICS OR ELEMENTS FOUND AS PART OF MANAGEMENT TEAMS WHICH ARE ESSENTIAL TO THE MANAGEMENT TEAMS BEING "SUCCESSFUL"?

Propositions 1, 2, 3, 4\& 5: Common characteristics or elements exist among "successful" management teams which are essential to their being successful.

\begin{tabular}{|c|c|c|c|c|c|}
\hline $\begin{array}{l}D=\text { Documents } \\
A=A r c h i v a l ~ r e c o r d s\end{array}$ & & & a & er & \\
\hline QUESTIONS & SOURCE & D & A & 1 & 0 \\
\hline $\begin{array}{l}\text { 6.0 What are the most important } \\
\text { characteristics or elements found } \\
\text { as part of management teams } \\
\text { which are essential to the } \\
\text { management teams being } \\
\text { "successful"? }\end{array}$ & $\begin{array}{l}\text { pp. } 33 \\
35,42\end{array}$ & $x$ & $x$ & $x$ & $x$ \\
\hline
\end{tabular}


APPENDIX B

MANAGEMENT TEAM SURVEY FORM 
APPENDIX B

MANAGEMENT TEAM SURVEY FORM

\begin{tabular}{lll}
\hline A review of related literature & Which of these & Which of these are \\
identifies the following char- & are found as part & essential to your \\
acteristics or elements as being & of your district's & district's manage- \\
found in management teams. & management & ment team being \\
& team? & "successful." \\
\hline
\end{tabular}

1.3 There is an organized unit for administrative collective bargaining.

1.4 Management team members are involved in the collective bargaining with other bargaining groups. (i.e., teachers, classified)

1.6 Team management in the school district provides for participation by administrators in decisions affecting their work.

1.7 Team members describe the quality of decisions made by the management team compared to decisions made by individual administrators as being improved.

1.8 Administrators feel more accountable for decisions made by the management team.

More supportive.

More successful.

1.9 The management team approach allows administrators to gain and share a perspective of the school system as a whole. 


\begin{tabular}{lll}
\hline A review of related literature & Which of these & Which of these are \\
identifies the following char- & are found as part & essential to your \\
acteristics or elements as being & of your district's & district's manage- \\
found in management teams. & management & ment team being \\
& team? & "successful." \\
\hline
\end{tabular}

1.10 Involvement as a management team member makes the members feel like a more important part of the enterprise for which they work.

3.1 The management team has a clearly understood structure.

3.2 All sub-units are well represented on the management team.

3.4 The various management team units are linked together.

3.6 The purpose of the management team is clearly defined.

3.7 The authority of the management team is acknowledged and specified by: the School Board. the Superintendent.

3.8 The management team is stable.

3.9 The roles and responsibilities of management team members are clearly defined.

3.11 The team is protected and rewarded regarding its decisions and recommendations. 


\begin{tabular}{lll}
\hline A review of related literature & Which of these & Which of these are \\
identifies the following char- & are found as part & essential to your \\
acteristics or elements as being & of your district's district's manage- \\
found in management teams. & management & ment team being \\
& team? & "successful."
\end{tabular}

3.12 The special strengths of team members are utilized.

4.3 Sufficient time for management team activities is provided.

4.4 Def inite rules and procedures are followed by the management team.

4.6 Management team members are involved in decision making.

4.8 Management team members are involved in district program evaluation.

4.10 Management team members have adequate input in employment, promotion, and dismissal decisions of school district employes.

4.11 Team management contributes to better morale.

Motivation.

Collaboration.

4.12 There is a greater sense of community as a result of team management.

4.13 The level of trust and security is improved through team management. 
A review of related literature identif ies the following characteristics or elements as being found in management teams.
Which of these are found as part of your district's management team?
Which of these are essential to your district's management team being "successful."

4.14 Management team members

feel tied to the success of the

Superintendent.

vice versa.

4.15 The School Board supports and appreciates the management team.

vice versa.

4.16 Team management contributes to shared values, purpose, direction.

Team belonging.

4.17 Team management improves communications.

Quality of information.

4.18 An effective communications system exists between and among all levels of administrators, and the School Board.

4.19 Interpersonal relations problems and conflicts are resolved better through team management.

4.20 Open and accurate communications is provided for.

4.22 The management team fosters success. Job satisfaction. 


\begin{tabular}{lll}
\hline A review of related literature & Which of these & Which of these are \\
identifies the following char- & are found as part & essential to your \\
acteristics or elements as being & of your district's & district's manage- \\
found in management teams. & management & ment team being \\
& team? & "successful." \\
\hline
\end{tabular}

4.23 Team management develops centralized goals and direction for the school district, and decentralized autonomy for team members.

5.1 The responsibilities of the management team include policy and regulation development.

5.2 Management team members are involved in:
a) developing
b) recommending
c) implementing
d) monitoring

policles and administrative regulations.

5.3 The management team affects the quality of policies and regulations.

5.4 Management team members support team developed policies and plans.

5.5 The impact of policy recommendations is communicated by the management team to the School Board. The Superintendent. 
A review of related literature identifies the following characteristics or elements as being found in management teams.
Which of these are found as part of your district's management team?
Which of these are essential to your district's manage- ment team being "successful."

6.0 List the ten most important characteristics or elements found as part of your management team which are essential to your district's management team being "successful."

\section{1.}

2.

3.

4.

5.

6.

7.

8.

9.

10.

Comments:

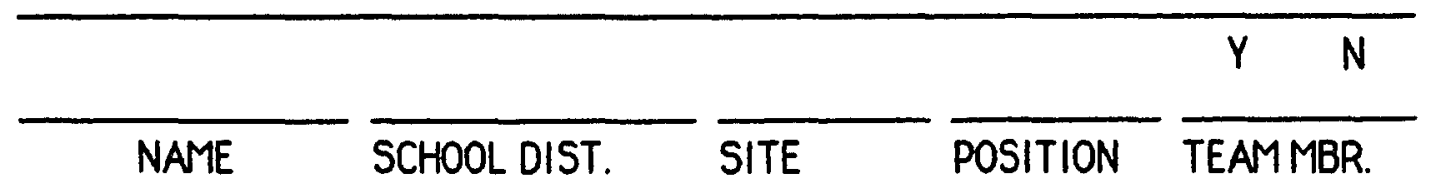




\section{APPENDIX C}

MANAGEMENT TEAM INTERVIEW FORM 
APPENDIX C

MANAGEMENT TEAM INTERVIEW FORM

Study Question 1: Why was the management team concept implemented in your school district?

1.1 Why was a management team established in the school district?

1.2 Was the management team established in the school district to prevent collective bargaining by administrators?

1.5 What was middle management's

role in establishing the manage-

ment team?

The Superintendent's?

The School Board's?

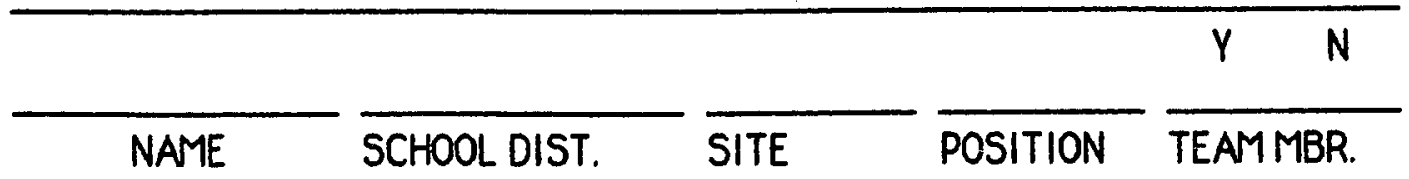


Study Question 2: How has your "successful" management team evolved?

2.1 How long has a management team existed in the school district?

2.2 How successful has the management team been?

2.3 When was the management team last modified?

2.4 How was it modified?

2.5 Was there resistance to the modifications?

2.6 How is the management team working now?

2.7 Is there currently resistance

to the modifications?

2.8 What future modifications or

evolution is forseen?

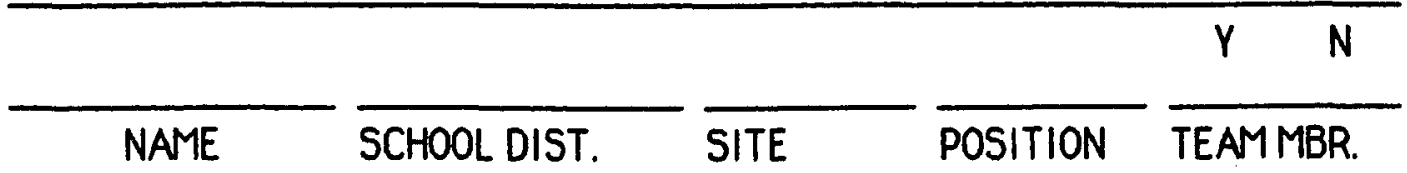


Study Question 3: How is your "successful" management team organized?

3.1 How is the management team structured?

3.5 Who is on the management team? Who is not?

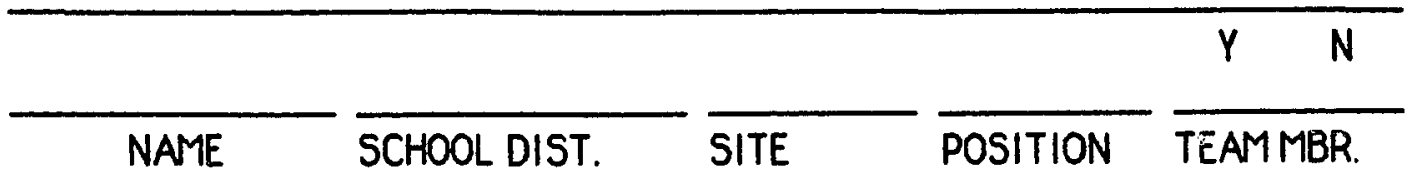


Study Question 4: How does your "successful" management team operate?

4.1 How is the management team led?

4.2 When do management team activities take place?

4.5 What activities and issues are handled by the management team?

4.7 For what is the management team held accountable?

4.9 What is the Superintendent's role on the management team?

4.21 How formal/informal is the culture of the management team?

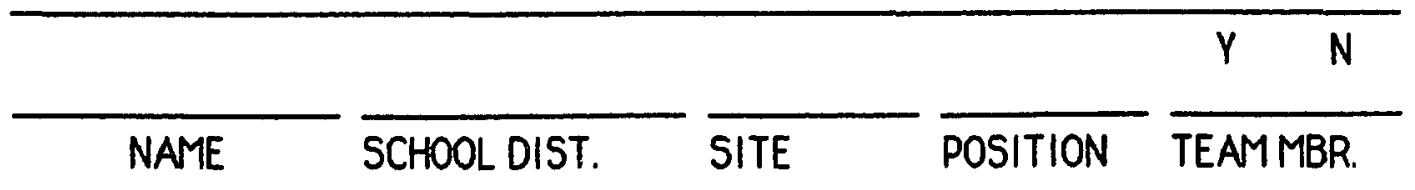


Study Question 5: How are team members of your "successful" management team involved in developing, recommending, implementing, and monitoring school district policies and administrative regulations?

\section{2 a) Developing?}

5.2 b) Recommending?

$5.2 \mathrm{c}$ ) Implementing?

5.2 d) Monitoring?

5.6 How are impact statements used by the Superintendent?

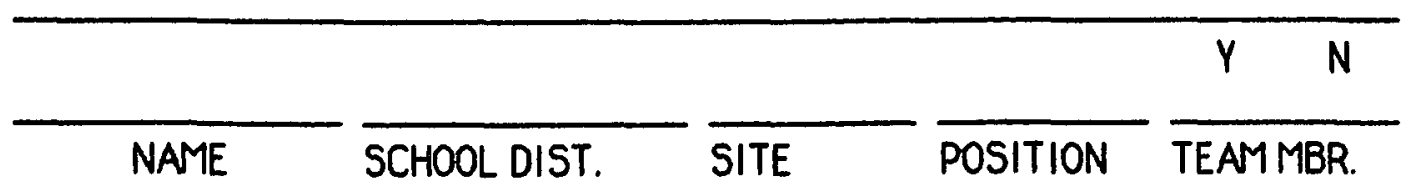


APPENDIX D

MANAGEMENT TEAM DOCUMENT AND ARCHIVAL FORM 
APPENDIX D

MANAGEMENT TEAMDOCUMENT AND ARCHIVAL RECORDS FORM

Notes from, and references to, documents (D) and archival records (A) related to the "successful" management team are collected on this form. The information should be clearly identified and summarized; or attached. 
APPENDIXE

MANAGEMENT TEAM OBSERVATION FORM 
APPENDIXE

MANAGEMENT TEAM OBSERVATION FORM

Notes from observations of the activities of the "successful" management team are collected on this form. Time, place, setting, and participants should be indicated along with a record of the events taking place. 


\section{APPENDIX F}

MANAGEMENT TEAM SURVEY:

NUMBER AND PERCENT OF RESPONSES

BY SCHOOL DISTRICT 
APPENDIX F

MANAGEMENT TEAM SURVEY:

NUMBER AND PERCENT OF RESPONSES

BY SCHOOL. DISTRICT

\section{A review of related literature} identifies the following char-

acteristics or elements as being

found in management teams.
Which of these

are found as part

of your district's

management

team?
Which of these are

essential to your

district's manage-

ment team being

"successful."

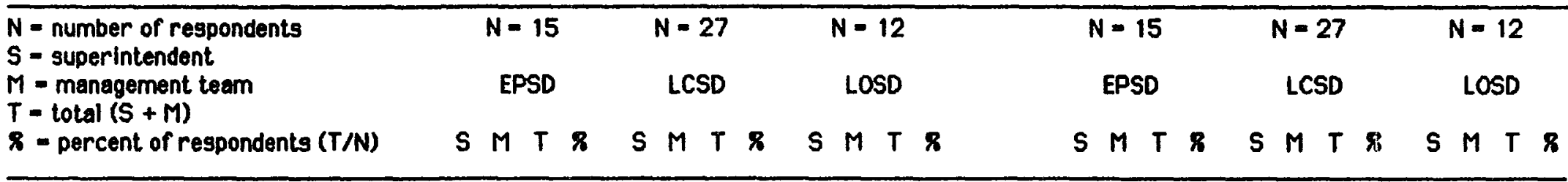

1.3 There is an organized unit for

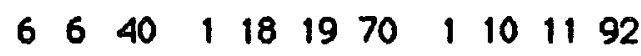

$\begin{array}{lll}4 & 4 & 27\end{array}$

191970

2217

administrative collective

bargaining.

1.4 Management team members

$\begin{array}{llllllllll}1 & 12 & 13 & 87 & 1 & 6 & 726 & 8 & 8 & 67\end{array}$

8853

9933

6650

are involved in the collective

bargaining with other bargaining

groups. (i.e., teachers, classified)

\subsection{Team management in}

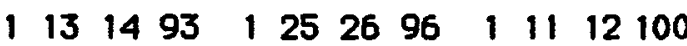

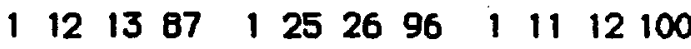

participation by administratorg

in decisions affecting their work. 


\section{APPENDIX $F$ (CONTINUED)}

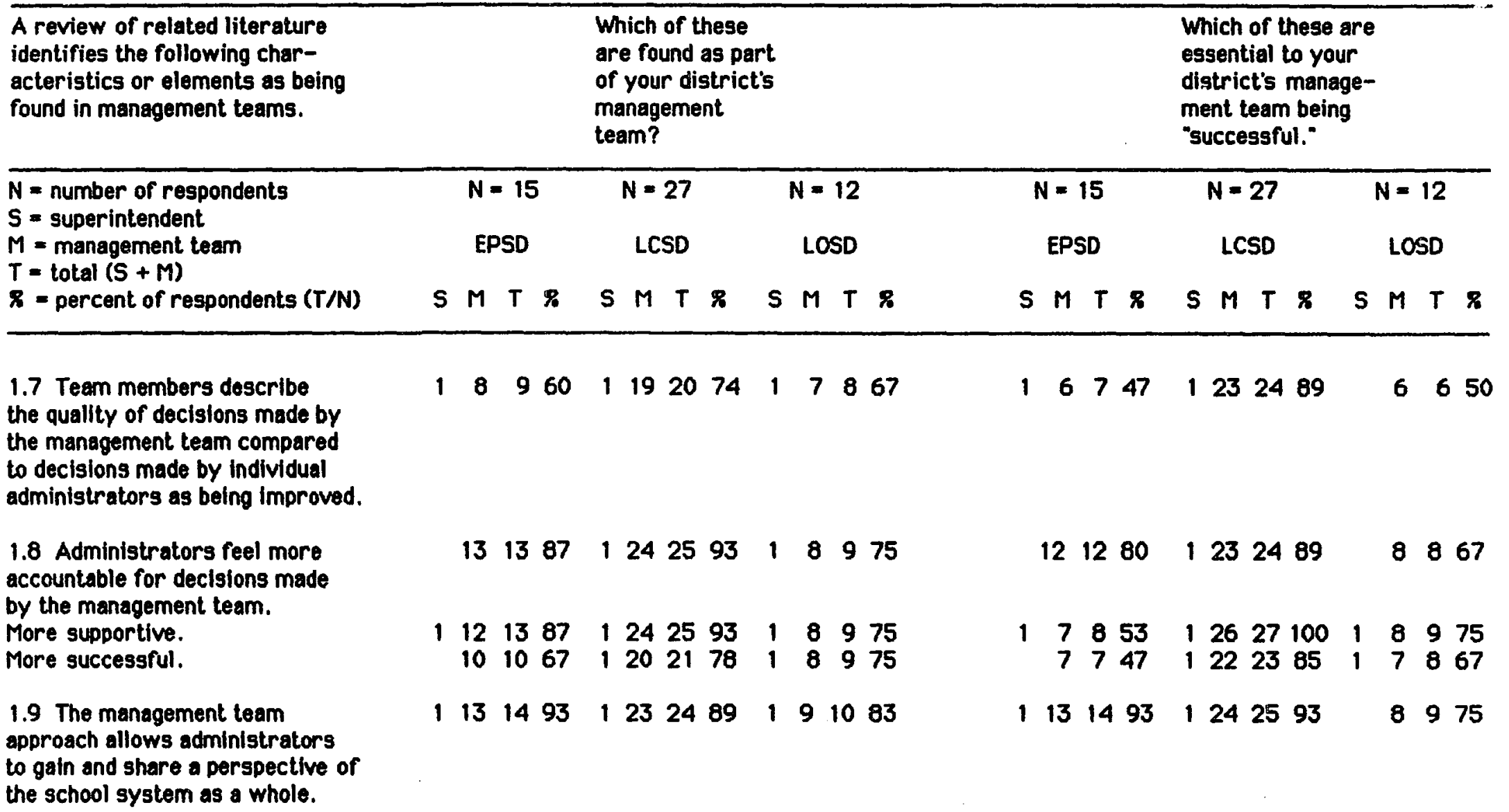


APPENDIX F (CONTINLIED)

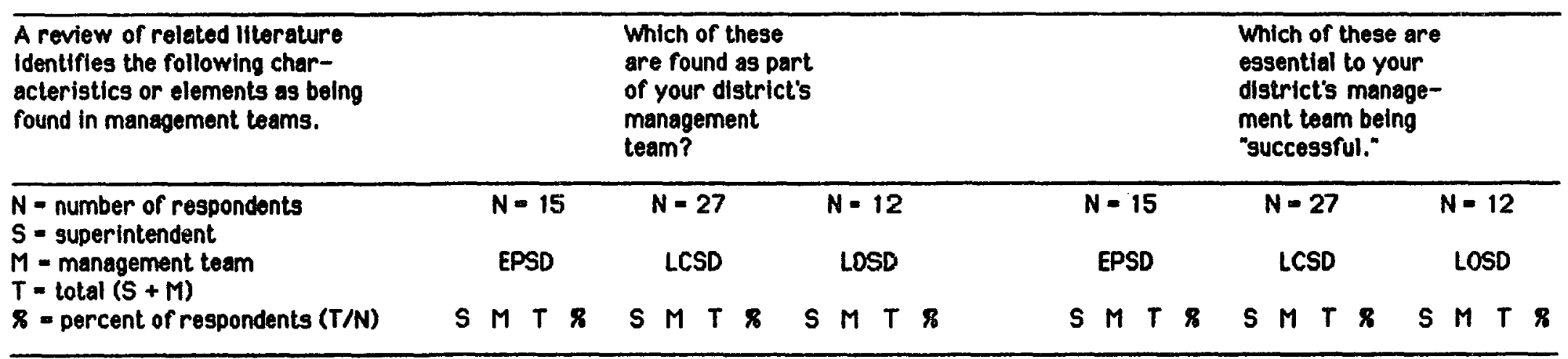

\subsection{Involvement as a}

$\begin{array}{lllllllllll}1 & 13 & 1493 & 1 & 20 & 21 & 78 & 1 & 8 & 9 & 75\end{array}$

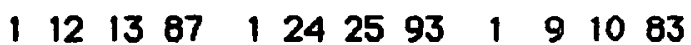
management team member makes the members feel like

a more important part of the

enterprise for which they work.

3.1 The management team has a clearly understood structure.

3.2 All sub-units are well represented on the management

team.

3.4 The various management team units are linked together. defined. 


\section{APPENDIX F (CONTINUED)}

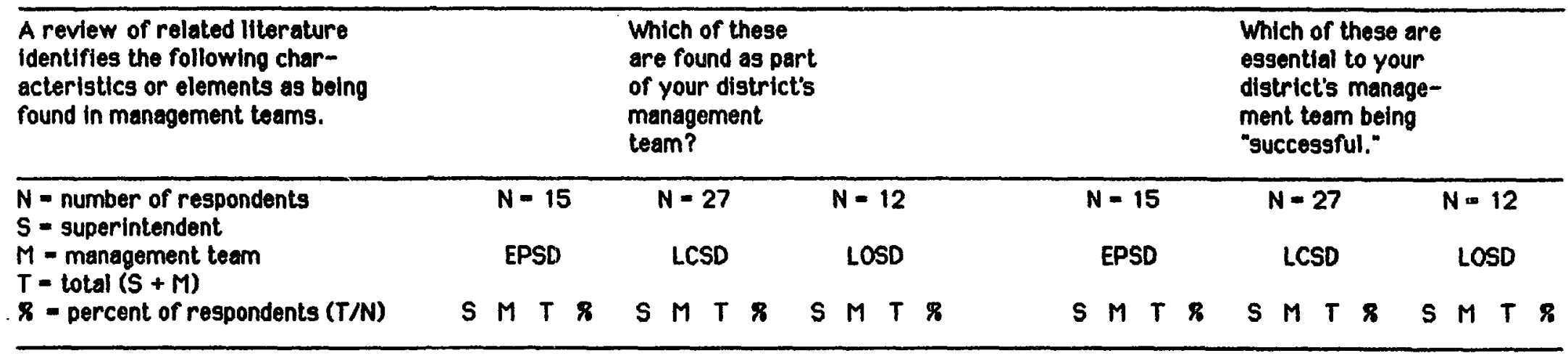

3.7 The authority of the management toam is acknowledged and specified by: the School Board. the Superintendent.

$\begin{array}{lllllllllll}1 & 13 & 1493 & 1 & 12 & 13 & 48 & 1 & 4 & 5 & 42\end{array}$

$\begin{array}{lllllllll}1 & 13 & 1493 & 1252696 & 1 & 10 & 1192\end{array}$

3.8 The management team is stable.

3.9 The roles and responsibillties of management team members are clearly defined.

3.11 The team is protected and rewarded regarding its decisions and recommendations.

3.12 The special strengths of team members are utilized. $\begin{array}{llllllllllll}1 & 11 & 12 & 80 & 1 & 17 & 18 & 67 & 1 & 7 & 8 & 67\end{array}$

$\begin{array}{llllllllllll}1 & 8 & 9 & 60 & 1 & 13 & 14 & 52 & 1 & 7 & 8 & 67\end{array}$

$\begin{array}{lllllllllll}1 & 6 & 7 & 47 & 1 & 16 & 17 & 63 & 5 & 5 & 42\end{array}$

$9960 \quad 1202178 \quad 1 \quad 6 \quad 758$ $\begin{array}{llllllllllll}1 & 11 & 12 & 80 & 1 & 16 & 17 & 63 & 1 & 4 & 5 & 42\end{array}$

$\begin{array}{llllllllll}1 & 11 & 1280 & 12627100 & 1 & 9 & 1083\end{array}$

$\begin{array}{lllllllllll}1 & 7 & 853 & 1 & 22 & 23 & 85 & 1 & 7 & 8 & 67\end{array}$

$\begin{array}{llllllllll}6 & 640 \quad 1212281 & 1 & 8 & 9 & 75\end{array}$

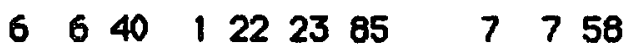

$9960 \quad 1242593 \quad 191083$ 
APPENDIX F (CONTINUED)

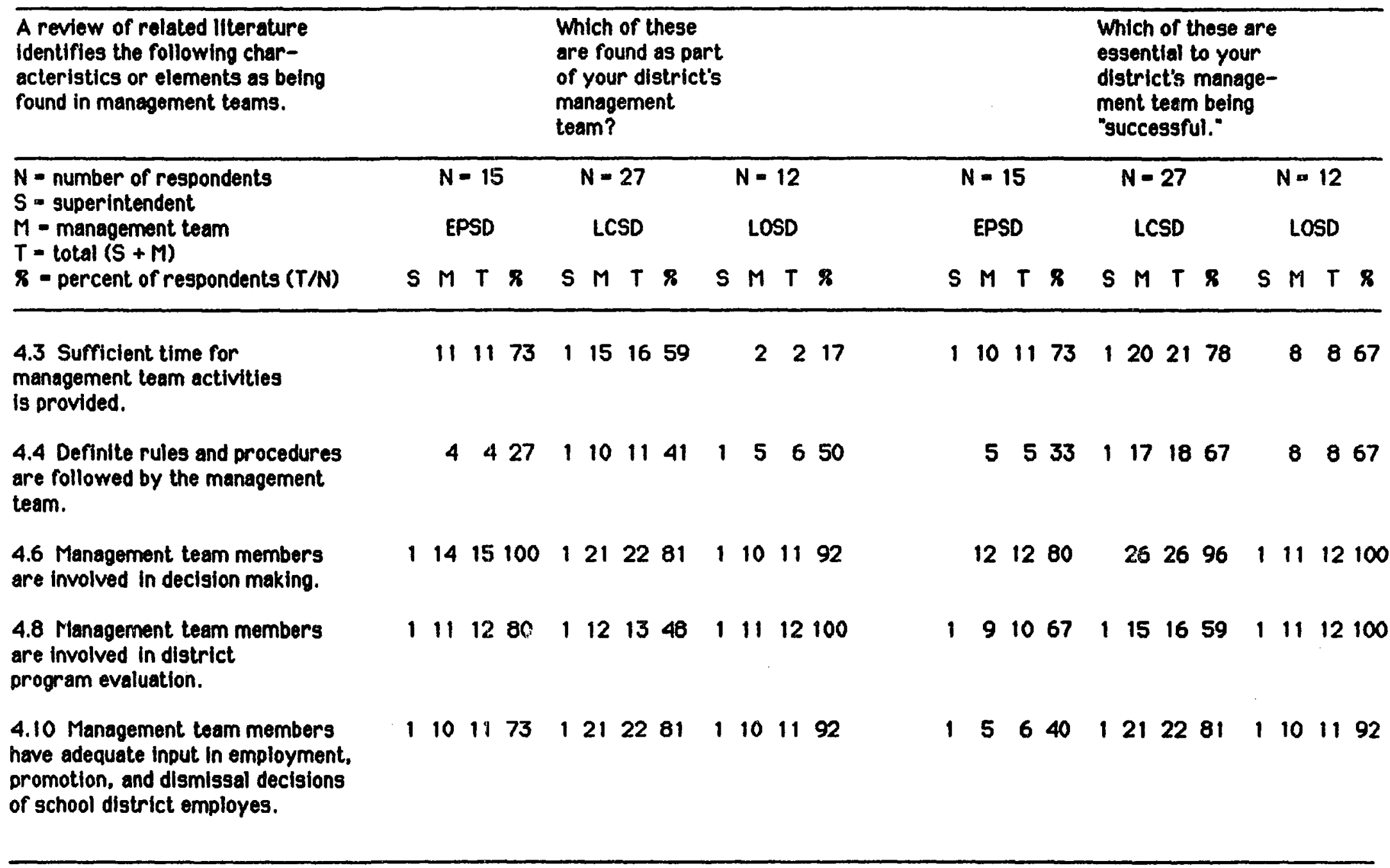


.APPENDIX F (CONTINUED)

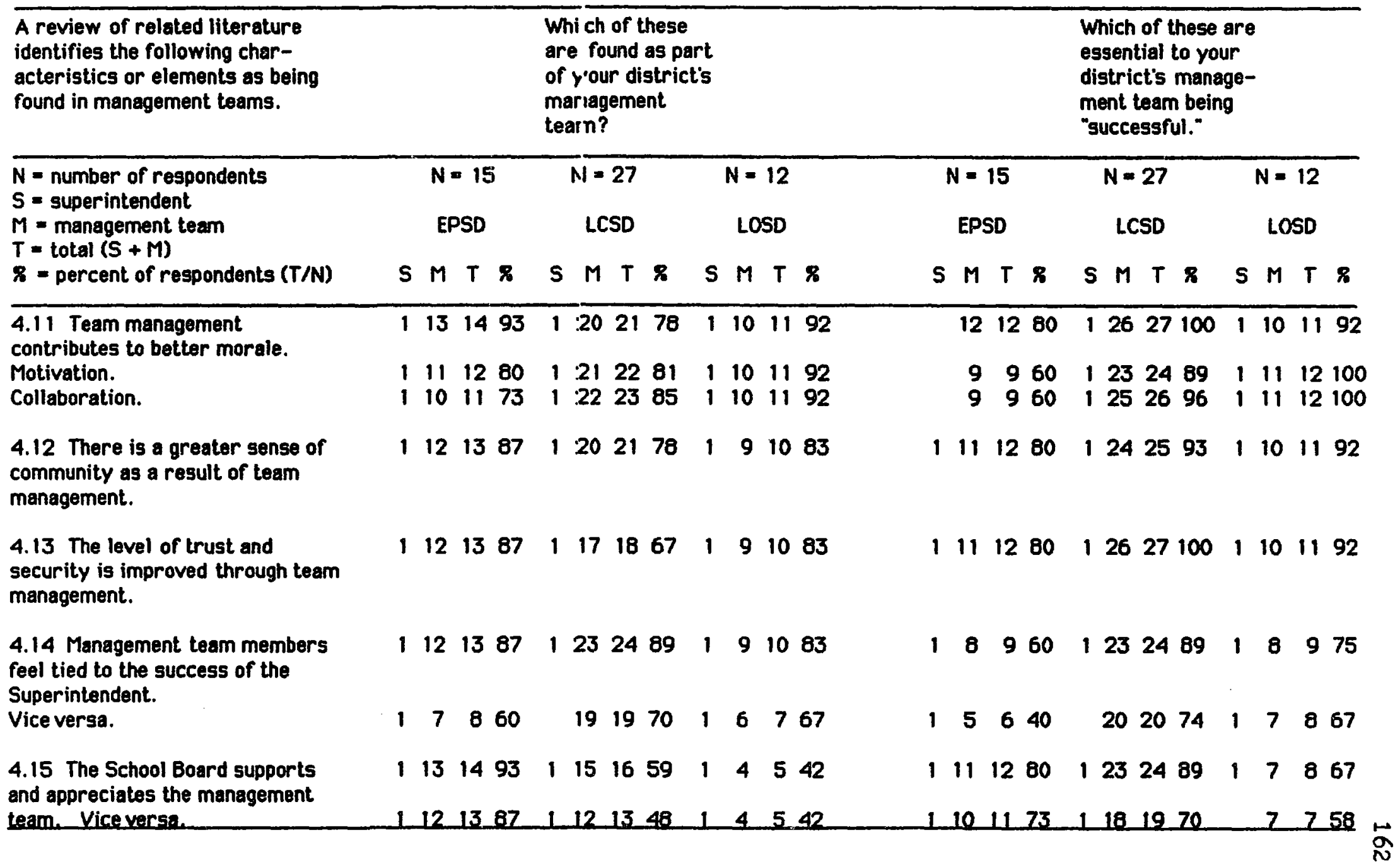


APPENDIX F (CONTINUED)

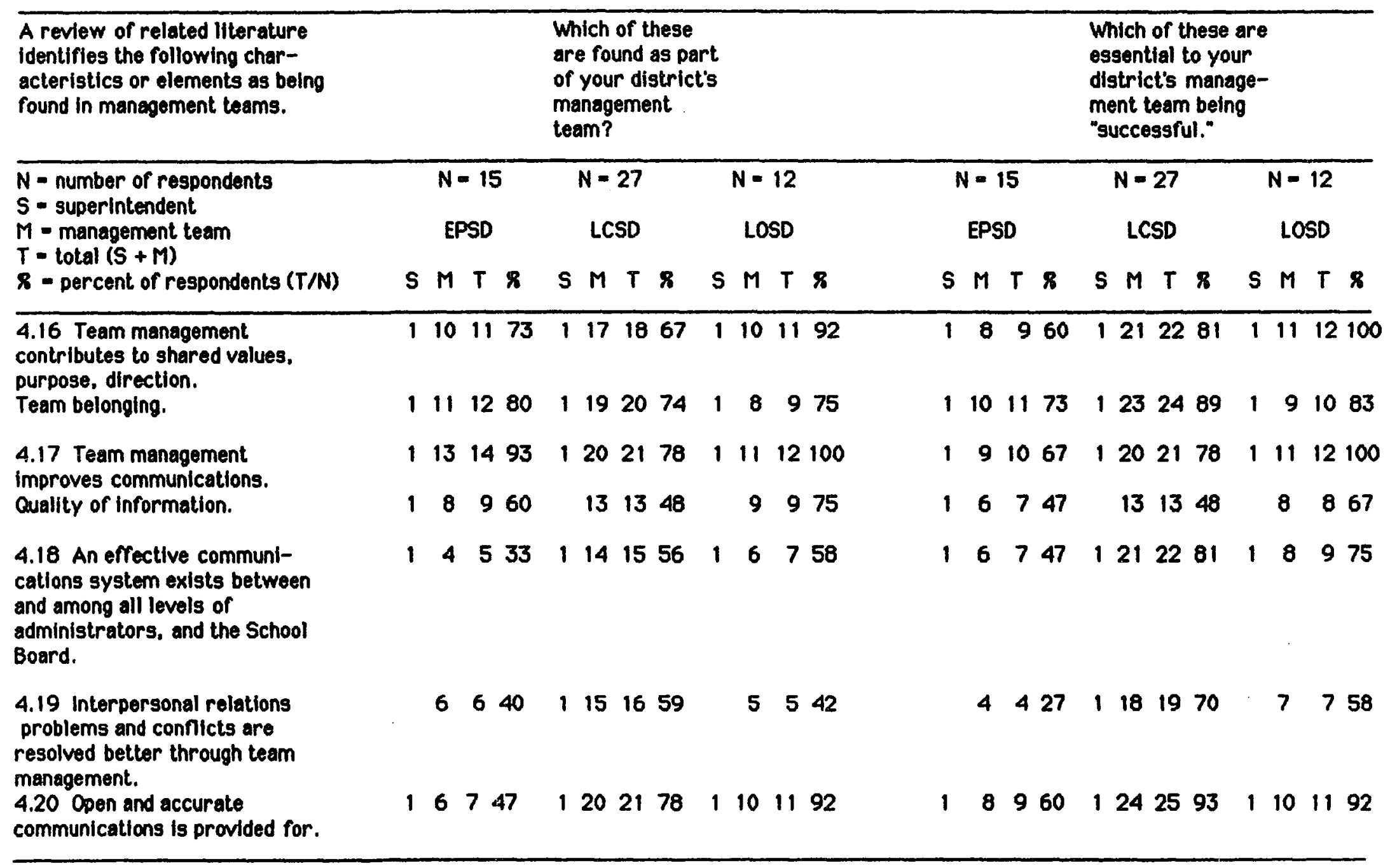


APPENDIX F (CONTINUED)

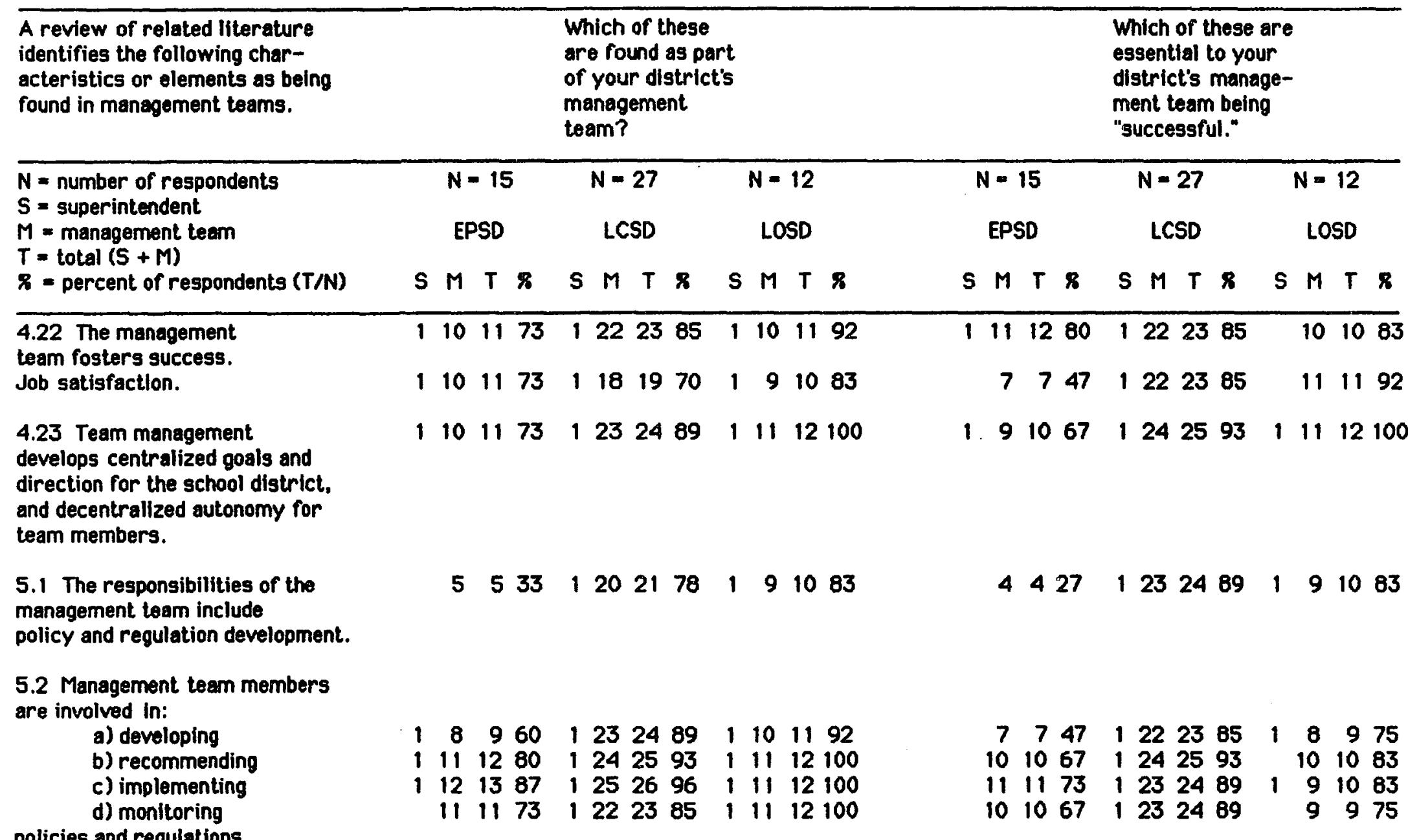

policies and requlations 
APPENDIX F (CONTINUED)

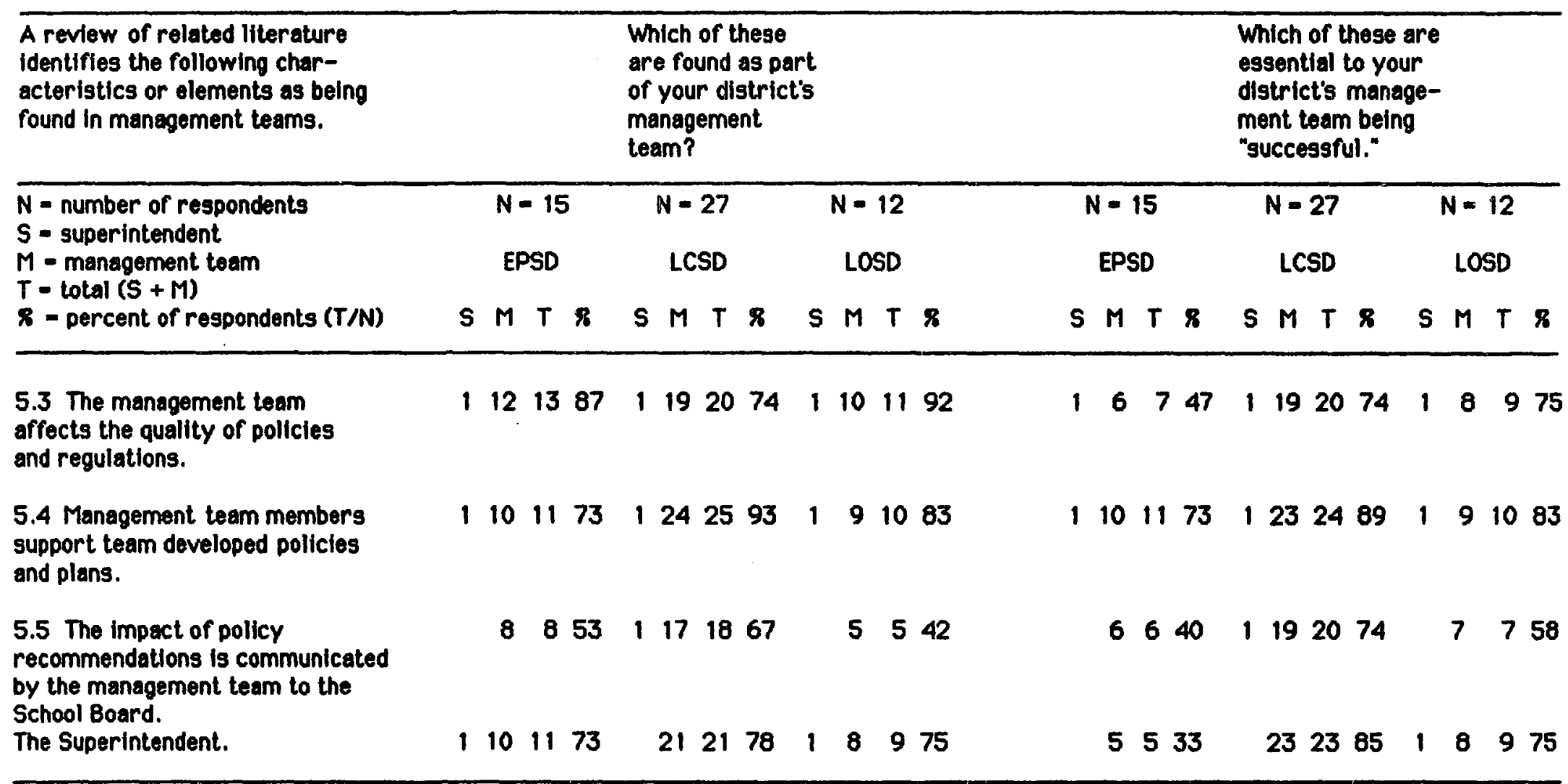




\section{APPENDIX G}

MANAGEMENT TEAM PROFILE 


\section{APPENDIX G \\ MANAGEMENT TEAM PROFILE}

A review of related literature identifies the following characteristics or elements as being found in management teams.
Indicate the extent to which these may be found as part of your district's management team.

\begin{tabular}{|c|c|c|c|c|}
\hline$A=A L W A Y S$ & $U=$ USUALLY & $S=$ SOMETIMES & $R=$ RARELY & $N=$ NEVER \\
\hline & & & U $\quad S$ & $\mathbf{R}$ \\
\hline
\end{tabular}

1. Team management in the school district provides for participation by administrators in decisions affecting their work.

2. Administrators feel more accountable for decisions made by the management team.

3. More supportive.

4. More successful.

5. The management team approach allows administrators to gain and share a perspective of the school system as a whole.

6. Involvement as a management team member makes the members feel like a more important part of the enterprise for which they work.

7. The management team has a clearly understood structure.

8. All sub-units are well represented on the management team. 
A review of related literature identifies the following characteristics or elements as being found in management teams.
Indicate the extent to which these may be found as part of your district's management team.

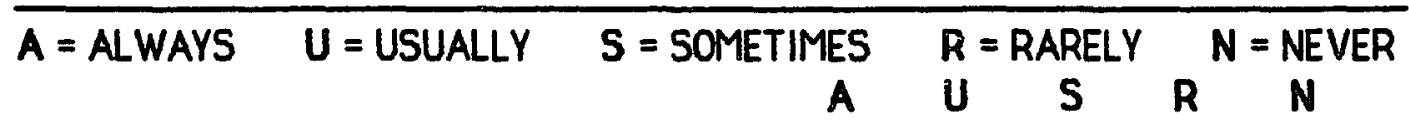

9. The various management team units are linked together.

10. The purpose of the management team is clearly def ined.

11. The authority of the management team is acknowledged and specified by the Superintendent.

12. The management team is stable.

13. The roles and responsibilities of management team members are clearly defined.

14. The special strengths of team members are utilized.

15. Sufficient time for management team activities is provided.

16. Def inite rules and procedures are followed by the management team.

17. Management team members are involved in decision making.

$\square \square \square \square$

$\square$


A review of related literature identifies the following characteristics or elements as being found in management teams.
Indicate the extent to which these may be found as part of your district's management team.

\begin{tabular}{|c|c|c|c|c|}
\hline$A=$ ALWAYS & $U=$ USUALLY & S = SOMETIMES & $R=$ RARELY & $\mathbf{N}=$ NEVER \\
\hline & & A & $\mathbf{U} \quad \mathbf{S}$ & $\mathbf{R}$ \\
\hline
\end{tabular}

18. Management team members are involved in district program evaluation.

19. Management team members have adequate input in employment, promotion, and dismissal decisions of school district employes.

20. Team management contributes to better morale.

21. Motivation.

22. Collaboration.

23. There is a greater sense of community as a result of team management.

24. The level of trust and security is improved through team management.

25. Management team members feel tied to the success of the Superintendent.

26. Vice versa.

27. The School Board supports and appreciates the management team.

28. vice versa. 
A review of related literature identifies the following characteristics or elements as being found in management teams.
Indicate the extent to which

these may be found as part

of your district's management team.

\begin{tabular}{|c|c|c|c|c|}
\hline $\bar{A}=A L W A Y S$ & $U=$ USUALLY & S = SOMETIMES & $R=$ RARELY & $\mathbf{N}=$ NEVER \\
\hline & & & U S & $\mathbf{R}$ \\
\hline
\end{tabular}

29. Team management contributes to shared values, purpose, direction.

30. Team belonging.

31. Team management improves communications.

32. An effective communications system exists between and among all levels of administrators, and the School Board.

33. Open and accurate communications is provided for.

34. The management team fosters success. 35. Job satisfaction.

36. Team management develops centralized goals and direction for the school district, and decentralized autonomy for team members.

37. The responsibilities of the management team include policy and regulation development. 


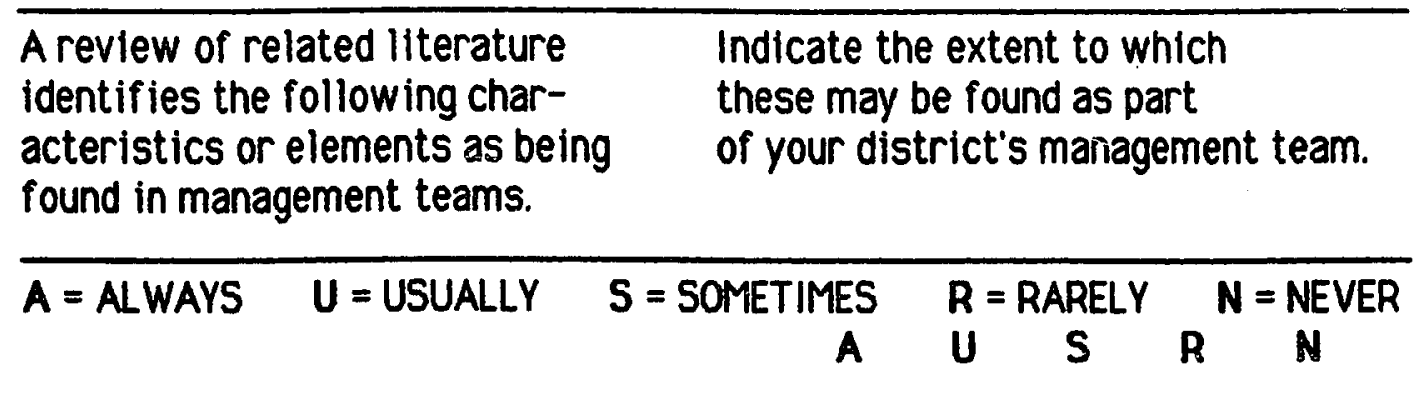

Management team members are involved in:

38. developing

39. recommending

40. implementing

41. monitoring

policies and administrative

regulations.

42. The management team af fects the quality of policies and regulations.

43. Management team members support team developed policies and plans.

44. The impact of policy recommendations is communicated by the management team to the Superintendent.

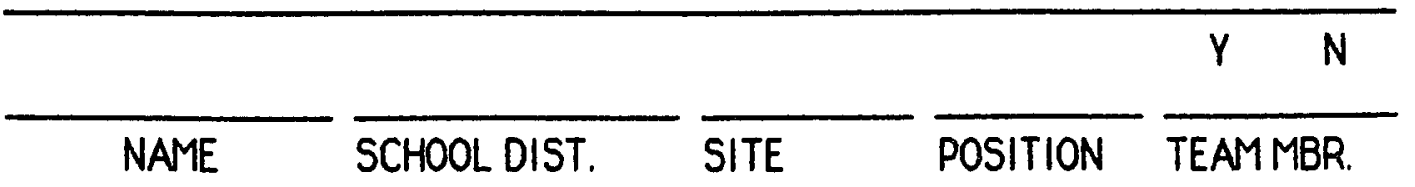

